\title{
Heurísticas Baseadas em Relaxação Lagrangiana para o Dimensionamento de Lotes com Restrições de Capacidade em Sistemas Multiestágios*
}

\author{
Lilian Kátia de Oliveira
}

Orientadora: Profa. Dra. Regina Esther Berretta

Dissertação apresentada ao Instituto de Ciências Matemáticas e de Computação - ICMC-USP, como parte dos requisitos para obtenção do título de Mestre em Ciências - Área: Ciências de Computação e Matemática Computacional. 
A Deus,

aos meus pais e aos meus irmäos. 


\section{Agradecimentos}

- A Deus, primeiramente, por ter me guiado e dado forças em mais uma etapa de minha vida;

- A Profa. Dra. Regina E. Berretta pela orientação e amizade durante o desenvolvimento desta pesquisa;

- Aos meus pais, João e Olivia, e meus irmãos, César e Marco, pelo amor, incentivo e presença em todos os anos de minha vida;

- A toda minha família pelo incentivo e carinho durante esses anos;

- Ao Josemar pelo carinho, paciência, ajuda e momentos felizes juntos;

- À Maristela pela amizade e grande ajuda durante o desenvolvimento desta pesquisa;

- Aos amigos Fábio, Maju, Selma, Silvio, Luciana, Luciane, Ricardo, Araxá, Luiz Fernando, Sandra, Josenildo, Rúbia, Juliana, Ornella, Cláudia, Fernando, Gisele, Thiago, Wellington pela amizade, discussões sobre trabalhos e principalmente pelos momentos de descontração e conversas nada a ver com o trabalho;

- As minhas amigas Osvaldocruzenses, Eliana, Edlene, Soninha, Lene, Gislaine pelas longas conversas, amizade, conselhos e compreensão durante esses anos;

- Aos amigos que fizeram e fazem parte de minha vida, mesmo os mais distantes;

- Aos professores e funcionários do ICMC pelo apoio;

- À FAPESP pelo apoio financeiro;

- E finalmente a todos que colaboraram indiretamente na realização deste trabalho. 


\section{Sumário}

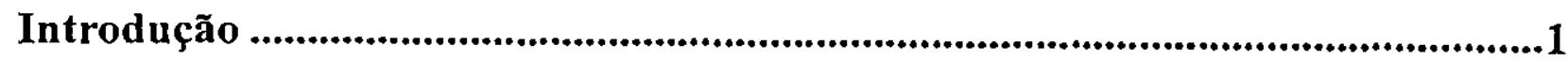

Capítulo 1 - Formulação Matemática do Problema .............................................4

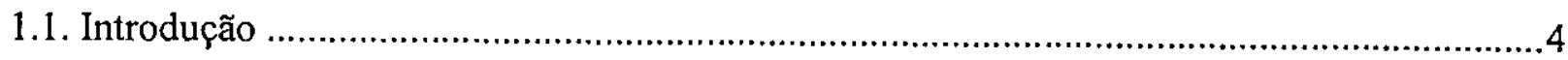

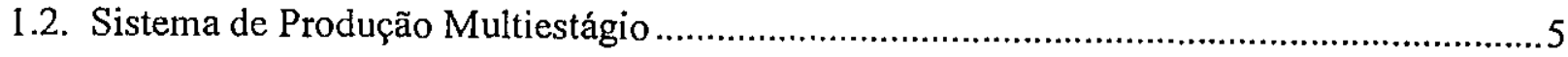

1.2.1. Formulação em Estoque Convencional ....................................................................

1.2.2. Formulação em Estoque de Escalão ………………...............................................

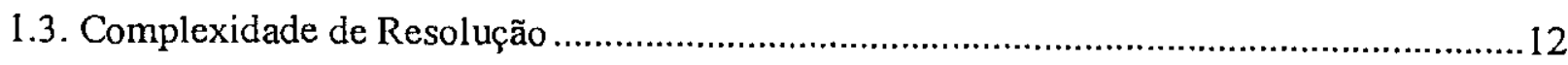

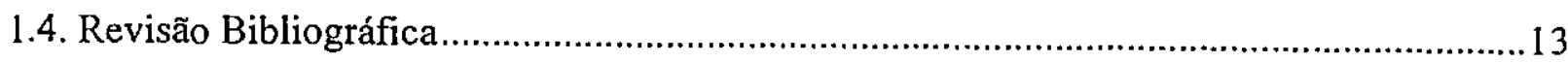

\section{Capítulo 2 - Aplicação de Relaxação Lagrangiana para a Obtenção do} Limitante Inferior

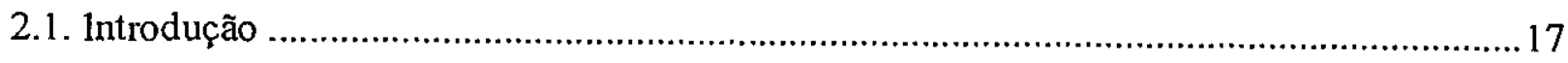

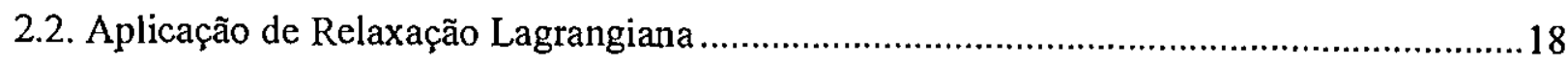

Capítulo 3 - Heurística para a Resolução do Problema....................................22

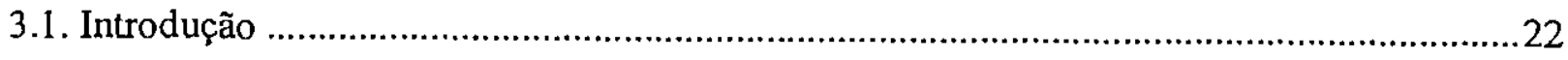

3.2. Obtenção da Solução Inicial - Procedimento P1 ………................................................23

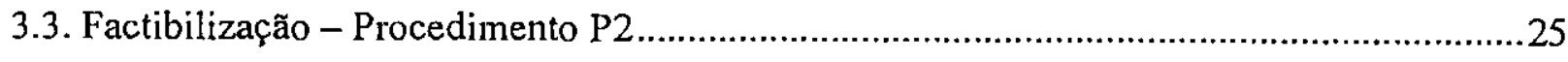

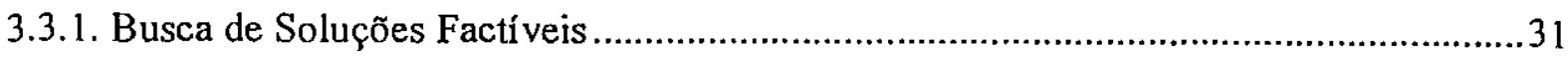

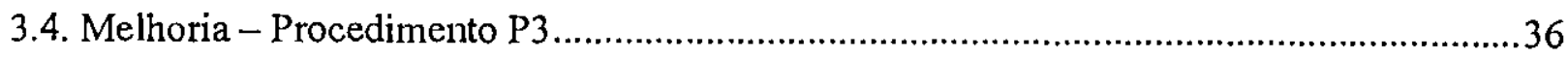




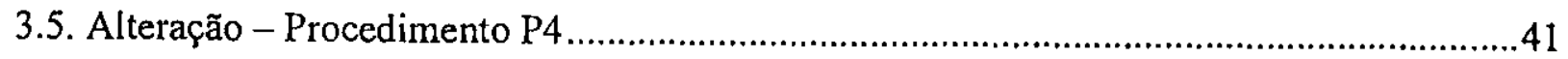

3.6. Atualização dos Multiplicadores de Lagrange - Procedimento P5 ..................................44

3.7. Algoritmos das Heurísticas .................................................................................... 47

Capítulo 4 - Resultados Computacionais.........................................................51

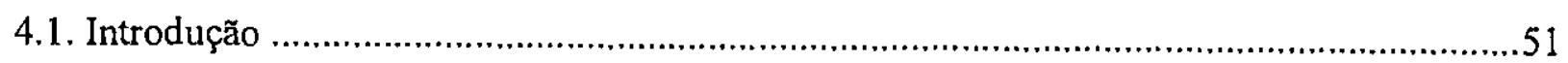

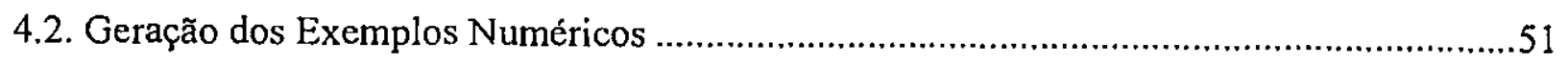

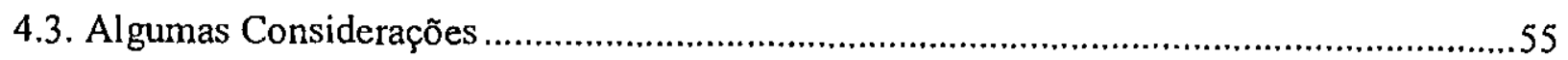

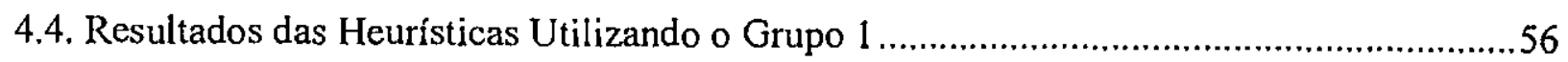

4.4.1. Obtenção de Soluções Factíveis .........................................................................5 57

4.4.2. Qualidade das Soluções ..................................................................................61

4.4.3. Análise de Alguns Resultados Utilizando a Heurística HR2 .....................................65

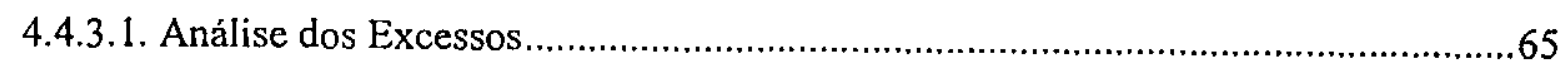

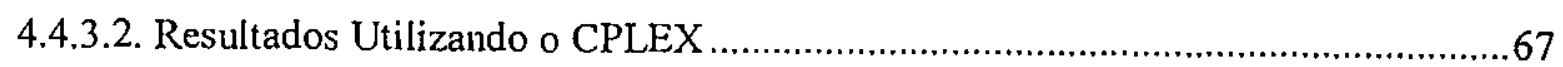

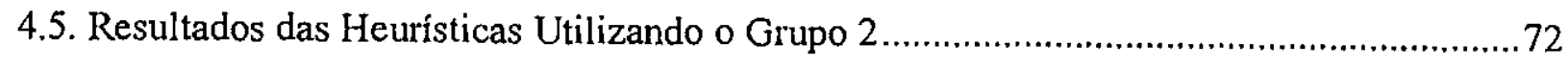

4.5.1. Obtenção de Soluções Factíveis ..........................................................................72

4.5.2. Qualidade das Soluções Obtidas..........................................................................76

4.5.3. Análise de Alguns Resultados Utilizando a Heurística HR2 .....................................82

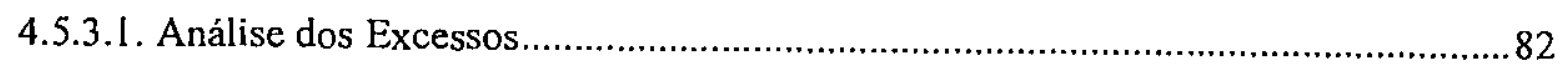

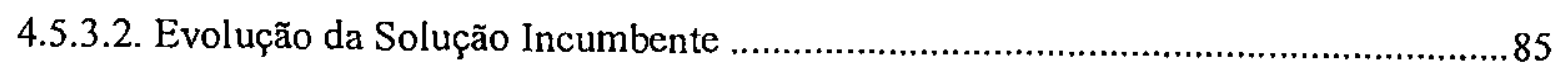

4.5.3.3. Análise do Ganho Obtido nos Valores dos Custos das Heurísticas H0 e HR2 ......87

Capítulo 5 - Conclusões e Propostas Futuras.......................................................89

Referências Bibliográficas.........................................................................92 


\section{Resumo}

O problema de dimensionamento de lotes em sistemas de produção multiestágios, no qual os produtos dependem da produção e/ou compra de outros componentes, consiste na determinação das quantidades de itens a serem produzidas em diferentes períodos, de tal modo que a demanda seja atendida. O problema é formulado como um problema de programação matemática inteiro-misto e utiliza o conceito de estoque de escalão. O objetivo é de minimizar os custos de produção, estoque e de preparação (setup) sujeito a um conjunto de restrições, no caso, limitações de capacidade e de balanço de estoque. Para a resolução desse problema, foram desenvolvidos métodos heurísticos utilizando a técnica de relaxação Lagrangiana com o objetivo de obter planos factíveis e buscar soluções de qualidade. Os resultados dos testes computacionais são comparados com a solução ótima em um conjunto de exemplos de pequeno porte e, para exemplos maiores, os resultados são comparados com um limitante inferior obtido por relaxação Lagrangiana. 


\section{Abstract}

The lotsizing problem in multistage production systems, for which the products depend from either the production or the aquisition of components, consists basically of determining the quantities to be produced in different periods, in such a way that demand is attained. The problem is formulated as mixed-integer problem of mathematical programming and it uses the concept of echelon stock. The objective is to minimize the production, inventory and setup costs subject to a constraints, such as, capacity limitations and inventory balance. Heuristic methods were developed using Lagrangean Relaxation with the objective of obtaining feasible plans and to search for quality solutions. The results from the computational tests are compared with the optimal solution in examples of small size and for medium sized problems the results are compared with a lower bound, which was obtained by Lagrangean Relaxation. 


\section{Introdução}

A indústria de manufatura tem sido estimulada a tornar seus processos mais eficientes devido a maior competitividade imposta pelas transformações que têm afetado a economia mundial. Dessa forma, as indústrias têm sofrido profundas mudanças no seu setor produtivo no que abrange a modernização de seus processos de produção, melhoria de qualidade de seus produtos e racionalização administrativa.

Técnicas de otimização têm encontrado amplo emprego nas mais diferentes áreas envolvendo o controle e planejamento de sistemas produtivos. Desde um nível mais agregado, compreendendo processos de tomada de decisões de longo prazo, até um nível operacional, onde ocorrem as decisões de curto prazo, há um esforço de pesquisa por técnicas e sistemas baseados em modelagem matemática que facilitem e otimizem as ações de gerentes e planejadores.

A área de Planejamento e Controle da Produção (PCP) cada vez mais pede o uso de sistemas computacionais que englobem vários aspectos do processo de produção, com o propósito de escolher as melhores alternativas com respeito aos custos envolvidos e às restrições inerentes ao processo produtivo.

Dentre tais sistemas, um dos mais utilizados é o MRP (Material Requeriments Planning). Um sistema MRP é uma coleção de procedimentos lógicos que tem sido amplamente utilizado para o gerenciamento em nível detalhado do planejamento da produção e estoque em estruturas de manufatura. Seu objetivo é converter o Plano Mestre de Produção (MPS) num plano de fabricação de produtos finais e na produção (ou compra) de seus possíveis itens componentes, ou seja, determinar o tamanho dos lotes de produção e/ou compra. 
Um sistema MRP é baseado em previsões de demanda de cada produto final ao longo de um horizonte de planejamento (MPS), nos niveis iniciais de estoque, na lista de materiais (bill of material) que é definido pela estrutura do produto e no lead time de cada item. Lead time é o teınpo gasto a partir da ordem de produção até que o item esteja pronto. A partir desses dados, o MRP fornece um planejamento sincronizado da produção dos produtos finais e de seus itens componentes, informando a quantidade específica no período adequado a ser produzida (ou comprada), de forma a poder atender a demanda prevista em cada período, ou seja, realizar o dimensionamento dos lotes de produção e/ou compra.

Entretanto, em sua forma básica, o MRP considera que não há restrição de capacidade, isto é, qualquer quantidade de produção é possível. Se os recursos disponíveis para produção são excedidos, deve ser feito um remanejamento de parte da produção ou a adição de capacidade (overtime), na tentativa de ajustar o plano. Mas, este remanejamento pode causar planos impraticáveis ou mesmo gerar planos onde a alocação de recursos não foi feita de maneira ótima ou eficiente. Além disso, o plano gerado pela aplicação do MRP, a princípio, não fornece um plano de produção no sentido do seu custo ser o menor possível, ou seja, não são considerados os custos envolvidos.

Estas limitações de um sistema MRP compõem a essência do problema de dimensionamento de lotes com restrições de capacidade. Este problema tem como objetivo realizar o dimensionamento dos tamanhos dos lotes de produção, de maneira que os custos envolvidos sejam minimizados, considerando recursos para produção limitados. Determinando a quantidade e o período para produzir cada item em um dado horizonte de tempo de tal forma que a demanda seja atendida. Em sistemas multiestágios, o planejamento de cada item depende do planejamento de outros itens situados em niveis hierárquicos inferiores.

Os custos considerados no problema de dimensionamento de lotes podem ser de produção, estoque e preparação (setup $\cos t$ ), sendo este último um custo fixo ao se decidir produzir um determinado lote de um item em um determinado período. Para considerar a utilização dos recursos, pode-se considerar o gasto por quantidade produzida e também o gasto para preparar a produção de um lote de u1n determinado item (setup time).

Considerar a preparação das máquinas para ordenar a fabricação de um lote faz com que o modelo seja formulado como um problema de programação matemática inteiro-misto de difícil resolução. Considerar custos de preparação com os recursos para produção limitados, mesmo com tempos de preparação nulos, torna o problema de obter a solução ótima um problema de classe NP-hard (Garey e Johnson, 1978). Assumir tempos de 
preparação faz com que o problema de factibilidade seja NP-Completo (Maes et al., 1991), o que torna muito improvável a existência de um algoritmo eficiente que garanta a obtenção de uma solução factível. Esta é uma das razões pela qual poucos trabalhos existem incluindo tempos de preparação.

O objetivo deste trabalho é estudar heurísticas baseadas em relaxação Lagrangiana com o propósito de fornecer um plano de produção, isto é, determinar quanto, quando e o que produzir de maneira a minimizar o custo do problema de dimensionamento de lotes com capacidade limitada de produção. Os custos considerados são os de produção, estoque e preparação. Considera-se também, que o tempo de produção de cada produto e componente seja zero.

A organização do trabalho está descrita a seguir. No Capítulo 1 serão dadas formulações para o problema de dimensionamento de lotes multiestágio com capacidade limitada de produção, além disso, serão apresentados alguns trabalhos desenvolvidos na área de dimensionamento de lotes em sistemas multiestágios de produção, sendo apresentados somente os trabalhos que consideram as características das formulações apresentadas neste capítulo. Apresenta-se ainda, a complexidade de resolução de tais problemas.

No Capítulo 2, apresenta-se a técnica de relaxação Lagrangiana para a obtenção do limitante inferior para o problema abordado. O desenvolvimento da heurística para a resolução do problema será apresentado no Capítulo 3.

No Capítulo 4 serão apresentados os resultados computacionais realizados e, finalmente, no Capítulo 5 serão apresentadas as conclusões e algumas sugestões para pesquisas futuras. 


\section{Capítulo 1}

\section{Formulação Matemática do Problema}

\subsection{Introdução}

Esse capítulo apresenta modelos matemáticos para o problema de dimensionamento de lotes com restrições de capacidade.

Considere um horizonte de tempo com T periodos onde se deseja planejar a produção de $\mathrm{N}$ itens. A demanda de cada item $\mathrm{i}$, no período t, é conhecida.

O problema de dimensionamento de lotes consiste em determinar em quais períodos produzir e a quantidade a ser produzida de cada item (tamanho do lote), de modo a atender uma certa demanda com um custo total mínimo. Os custos considerados são os de produção, estoque e preparação, sendo este último um custo fixo ao se decidir produzir o item i no período t. Considera-se também, que a quantidade de recursos utilizados na produção $e$ preparação, em cada período, é limitada.

O problema de dimensionamento de lotes pode ser dividido em monoestágio (único estágio) e multiestágio (vários estágios). Diz-se haver um único estágio quando os itens a serem produzidos são independentes, ou seja, nenhum segue ou antecede o outro. Diz-se multiestágio, o sistema de produção onde a produção de um item final depende da fabricação de seus componentes.

A seguir, apresentam-se formulações para o problema multiestágio, o qual é o sistema de produção estudado neste trabalho. 


\subsection{Sistema de Produção Multiestágio}

Denomina-se multiestágio o sistema de produção onde um item final é composto por outros componentes ou itens predecessores, isto é, a produção de um item final depende da fabricação de seus componentes que também devem ser produzidos ou comprados. Admite-se que os componentes podem ter suas próprias demandas, chamadas demandas independentes.

A estrutura de itens pode ser representada por um grafo orientado acíclico, onde se um item $\mathrm{i}$ é predecessor de $\mathrm{j}$, então $\mathrm{i}>\mathrm{j}$. Sendo assim, o item 1 é sempre considerado um item final.

As estruturas podem ser:

- Serial: onde cada item, com exceção do primeiro e do último, tem exatamente um sucessor e um predecessor.

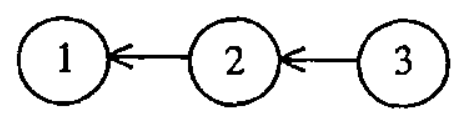

Figura 1.1 - Exemplo de uma estrutura serial.

- Montagem: representa uma estrutura mais complexa onde cada item pode ter vários predecessores, mas com a restrição de um único sucessor.

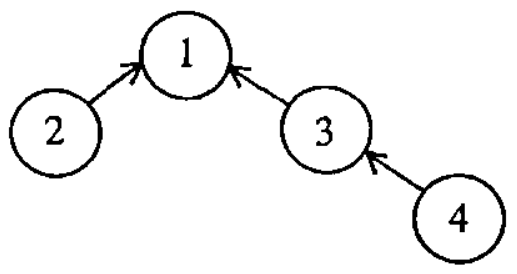

Figura 1.2 - Exemplo de uma estrutura de montagem.

- Geral: representa uma estrutura mais abrangente onde não há restrição quanto ao número de predecessores e sucessores de um item, exceto os itens finais que não possuem sucessores. 


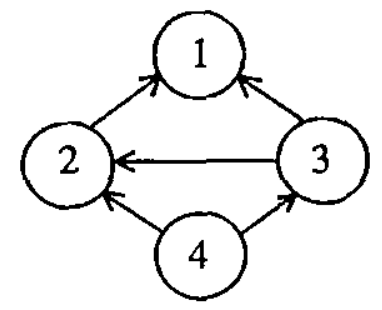

Figura 1.3 - Exemplo de uma estrutura geral.

Considere:

$\mathrm{S}_{\mathbf{i}}$ - conjunto dos itens sucessores imediatos do item $\mathrm{i}$.

$\mathrm{P}_{\mathrm{i}}$ - conjunto dos itens predecessores imediatos do item $\mathrm{i}$.

Pelo exemplo da estrutura geral acima (Figura 1.3) tem-se:

$\begin{array}{llll}S_{1}=\varnothing & S_{2}=\{1\} & S_{3}=\{1,2\} & S_{4}=\{2,3\} \\ P_{1}=\{2,3\} & P_{2}=\{3,4\} & P_{3}=\{4\} & P_{4}=\varnothing\end{array}$

Os modelos multiestágios estão formulados para o caso de estrutura geral, pois os modelos para as estruturas serial e de montagem podem ser vistos como casos particulares desta formulação. Os modelos estão apresentados em duas etapas. Primeiramente, utilizando estoque convencional e a seguir estoque de escalão.

É importante ressaltar que, nesse trabalho, o tempo de produção (lead time) é considerado nulo para todos os itens.

\subsubsection{Formulação em Estoque Convencional}

O modelo apresentado a seguir encontra-se em Clark e Armentano (1993) e Berretta (1997). O objetivo do modelo é determinar um plano de produção que minimize os custos de preparação, produção e estoque sujeito a um conjunto de restrições que inclui o atendimento de uma demanda preestabelecida e recursos limitados para produzir e preparar a produção.

Deve-se observar que a produção e o estoque de um item devem ser suficientes para suprir a demanda independente, e eventualmente uma quantidade para compor o lote dos itens sucessores.

Seja $a_{i j}$ a quantidade do item i necessária para compor uma unidade do item j. Como um exemplo, considere a estrutura de produto abaixo: 


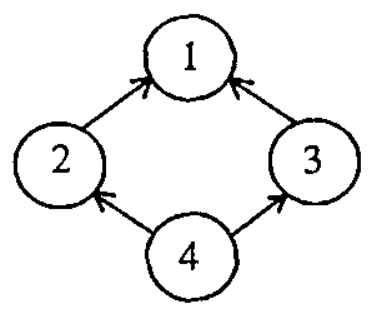

Figura 1.4 - Exemplo de uma estrutura de produto.

onde

$$
a_{2.1}=3 ; a_{3,1}=2 ; a_{4,2}=4 ; a_{4,3}=1
$$

e que os itens 2, 3 e 4 não tenham demanda independente. Suponha que foi decidido produzir 10 unidades do item 1, e que não haja estoque de qualquer item. Então a produção do item 2 deve ser de pelo menos 30 unidades $\left(10^{*} 3\right.$ ), do item 3 de 20 unidades (10*2) e do item 4 de pelo menos 140 unidades $(30 * 4+20 * 1)$.

Um modelo matemático é dado por:

Modelo [MI]

$$
\operatorname{Min} Z=\sum_{i=1}^{N} \sum_{i=1}^{T}\left(p_{i t} X_{i t}+h_{i t} I_{i t}+s_{i t} Y_{i t}\right)
$$

sujeito a:

$$
\begin{array}{ll}
I_{i, t-1}+X_{i t}-I_{i t}-\sum_{j \in S} S_{i j} X_{j t}=d_{i t} & i=1, \ldots, N ; t=1, \ldots, T \\
\sum_{i=1}^{N}\left(v_{i k t} X_{i t}+f_{i k t} Y_{i t}\right) \leq C P_{k t} & k=1, \ldots, K ; t=1, \ldots, T \\
X_{i t}-M_{i t} Y_{i t} \leq 0 & i=1, \ldots, N ; t=1, \ldots, T \\
X_{i t} \geq 0,11_{i t} \geq 0 & i=1, \ldots, N ; t=1, \ldots, T \\
Y_{i t} \in\{0,1\} & i=1, \ldots, N ; t=1, \ldots, T
\end{array}
$$

onde são utilizados os seguintes dados:

$$
\begin{array}{lll}
\mathrm{N} & - & \text { número de itens. } \\
\mathrm{T} & - & \text { número de períodos. } \\
\mathrm{K} & - & \text { número de recursos. } \\
\mathrm{p}_{\mathrm{it}} & - & \text { custo de produção de uma unidade do item i no período } t . \\
\mathrm{h}_{\mathrm{it}} & - & \text { custo de estocar uma unidade do item i no período t. } \\
\mathrm{s}_{\mathrm{it}} & - & \text { custo de preparação (setup). }
\end{array}
$$




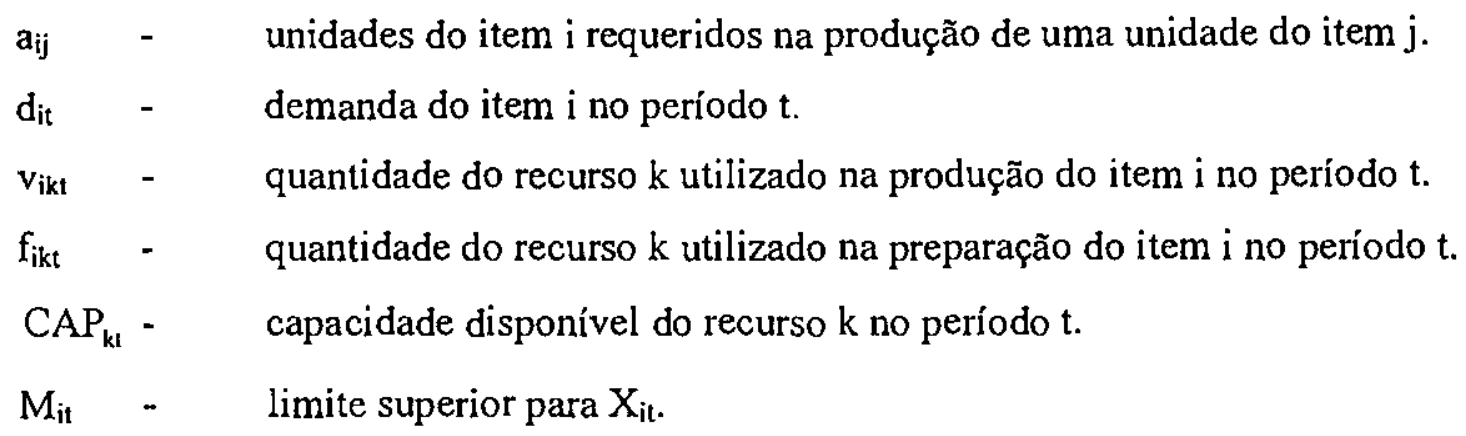

e as variáveis de decisões são:

$\mathrm{X}_{\mathrm{it}} \quad$ - $\quad$ unidades do item $\mathrm{i}$ produzidas no período $\mathrm{t}$.

$I_{\text {it }} \quad-\quad$ unidades do item i estocadas no período $t$.

$\mathrm{Y}_{\mathrm{il}} \quad$ - 1 se houver produção do item i no período $\mathrm{t}$.

0 caso contrário.

A função objetivo (1.1) minimiza o custo total que é formado pelo custo de produção, estoque e preparação de $\mathrm{N}$ itens ao longo de $\mathrm{T}$ períodos do horizonte de planejamento. Em (1.2) têm-se as equações de balanço entre as variáveis de estoque e produção, onde é determinado que a demanda de um item $\mathrm{i}$ em um período $\mathrm{t}\left(\mathrm{d}_{\mathrm{it}}\right)$ e a quantidade para os lotes de itens sucessores $\left(\sum_{j \in S_{i}} a_{i j} X_{j t}\right)$ sejam supridas pela combinação da produção em $t\left(X_{i l}\right)$ e pelo estoque em $t-1\left(I_{i, t-1}\right)$ e que o excedente ficará estocado em $t\left(I_{i 1}\right)$. As inequações (1.3) representam a utilização do recurso $k$ na preparação $\left(f_{i k t} Y_{i l}\right)$ e produção $\left(v_{i k t} X_{i l}\right)$ de todos os itens em um período $t$, sendo limitadas pela quantidade disponível do recurso no período $t$ $\left(\mathrm{CAP}_{\mathrm{k}_{1}}\right)$. As inequações (1.4) fornecem um limite superior para $\mathrm{X}_{\mathrm{it}}$, caso $\mathrm{Y}_{\mathrm{i}}=1$ e assegura $\mathrm{X}_{\mathrm{it}}=0$, caso $\mathrm{Y}_{\mathrm{it}}=0$.

Observe que, considerar sistemas de produção multiestágios faz com que o modelo torne-se não decomponivel por item nas restrições de balanceamento de estoque e produção. Desta forma, não é possível aplicar o algoritmo ótimo de Wagner e Whitin (1958). O algoritmo de Wagner e Whitin (1958) é um algoritmo ótimo, baseado em programação dinâmica para a resolução do problema de dimensionamento de lotes sem restrições de capacidade com um único item e pode ser aplicado a cada item separadamente se o modelo for decomponível por item. 


\subsubsection{Formulação em Estoque de Escalão}

Uma formulação que pode apresentar vantagens pode ser obtida adotando-se o conceito de estoque de escalão introduzido por Clark e Scarf (1960) e implementado por Afentakis et al. (1984).

Estoque de escalão de um item é a quantidade total do item presente no sistema, incluindo a quantidade do item em estoque mais a quantidade do item contido no estoque de seus sucessores.

Como exemplo, considere a estrutura da Figura 1.3.

A quantidade do item 1 existente no sistema é apenas o seu estoque, já que este não possui sucessor. Logo, seu estoque de escalão é seu próprio estoque convencional,

$$
\mathrm{E}_{1 \mathrm{t}}=\mathrm{I}_{1 \mathrm{t}} \text {. }
$$

$\mathrm{O}$ item 2 , além de ter seu próprio estoque, está presente no item $1\left(\mathrm{~S}_{2}=\{1\}\right)$, portanto seu estoque de escalão é

$$
E_{2 t}=I_{2 t}+a_{21} I_{l t} \text {. }
$$

No caso do item 3 tem-se:

$$
\begin{aligned}
& E_{3 t}=I_{3 t}+\quad \text { o próprio estoque } \\
& a_{32} I_{11}+a_{32} a_{21} I_{11}+\quad \text { quantidade do item } 3 \text { no estoque do item } 1 \\
& \mathrm{a}_{32} \mathrm{I}_{2 t} \quad \text { quantidade do item } 3 \text { no estoque do item } 2
\end{aligned}
$$

ou ainda,

$$
\begin{aligned}
& E_{31}=l_{31}+a_{31} I_{1 t}+a_{32}\left(a_{21} I_{11}+I_{2 t}\right) \\
& E_{31}=I_{31}+a_{31} E_{11}+a_{32} E_{21} .
\end{aligned}
$$

Da mesma maneira para o item 4:

$$
\begin{aligned}
E_{4 t}= & I_{4 t}+ \\
& a_{43} I_{3 t}+ \\
& a_{42} I_{2 t}+a_{43} a_{32} I_{2 t}+ \\
& a_{43} a_{32} a_{21} I_{1 t}+a_{43} a_{31} I_{1 t}+a_{42} a_{21} I_{1 t}
\end{aligned}
$$

ou ainda,

$$
E_{4 t}=I_{4 t}+a_{42} E_{2 t}+a_{43} E_{3 t} .
$$

Portanto, o esloque de escalão do item i no período té definido como:

$$
E_{i t}=I_{i t}+\sum_{j \in S_{i}} a_{i j} E_{j t} .
$$

Utilizando este conceito, é preciso definir o custo de estoque de escalão em termos de custo de estoque convencional. 
O custo de estoque de escalão é definido a partir do custo de estoque convencional de modo que haja um abatimento de custos de estoque convencional de itens predecessores, ou seja, é preciso que seja mantida a equivalência

$$
\sum_{i=1}^{N} \sum_{i=1}^{T} e_{i t} E_{i t}=\sum_{i=1}^{N} \sum_{i=1}^{T} h_{i t} I_{i t} .
$$

Para exemplificar, considere a estrutura de itens mostrada na figura abaixo.

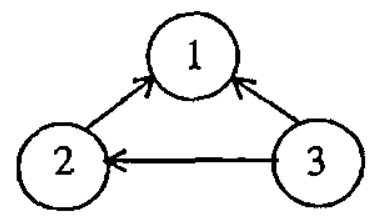

Figura 1.5 - Exemplo de uma estrutura geral.

Desenvolvendo (1.7) para a estrutura da Figura 1.5 tem-se,

$$
e_{1 t} E_{1 t}+e_{2 t} E_{2 t}+e_{3 t} E_{3 t}=h_{1 t} I_{1 t}+h_{2 t} l_{2 t}+h_{3 t} I_{3 t} \text {. }
$$

Utilizando a definição de estoque de escalão:

$$
\begin{aligned}
& e_{11} I_{1 t}+ \\
& e_{2 t}\left(I_{2 t}+a_{21} I_{1 t}\right) \\
& e_{3 t}\left(I_{3 t}+a_{31} I_{1 t}+a_{32}\left(I_{2 t}+a_{21} I_{1 t}\right)\right)=h_{1 t} I_{11}+h_{2 t} I_{2 t}+h_{3 t} I_{3 t} .
\end{aligned}
$$

Isolando os custos de estoque tem-se,

$$
\begin{aligned}
& h_{1 t}=e_{1 t}+e_{2 t} a_{21}+e_{3 t}\left(a_{31}+a_{32} a_{21}\right) \\
& h_{2 t}=e_{2 t}+e_{3 t} a_{32} \\
& h_{3 t}=e_{3 t}
\end{aligned}
$$

ou ainda,

$$
\begin{aligned}
& e_{3 t}=h_{3 t} \\
& e_{2 t}=h_{2 t}-a_{32} h_{3 t} \\
& e_{21}=h_{1 t}-a_{21} h_{2 t}-a_{31} h_{3 t}
\end{aligned}
$$

Logo, ao estoque de escalão $E_{i t}$, é atribuido um novo custo, que é definido como:

$$
\mathrm{e}_{\mathrm{it}}=\mathrm{h}_{\mathrm{it}}-\sum_{\mathrm{kef}} \mathrm{a}_{\mathrm{ji}} \mathrm{h}_{\mathrm{jt}} \text {. }
$$

O modelo [MI] pode então, ser reformulado em termos de estoque de escalão. Inicialmente, é examinada a equação de balanço (1.2), entre as variáveis de estoque e produção.

Considere a equação para o item 2, para o exemplo anterior. Utilizando estoque convencional, tem-se a equação de balanço dada por

$$
\mathrm{l}_{2, \mathrm{t}-1}+\mathrm{X}_{2 \mathrm{t}}-\mathrm{I}_{2 \mathrm{t}}=\mathrm{d}_{2 \mathrm{t}}+\mathrm{a}_{21} \mathrm{X}_{\mathrm{It}}
$$


sendo $X_{1 t}$ determinado a partir de

$$
I_{1, t-1}+X_{11}-I_{1 t}=d_{11} \text {. }
$$

Substituindo (1.9) em (1.10) tem-se,

$$
I_{2, t-1}+a_{21} I_{1, t-1}+X_{2 t}-I_{2 t}-a_{21} I_{1 t}=d_{2 t}+a_{21} d_{1 t}
$$

isto é,

$$
E_{2, t-1}+X_{2 t}-E_{2 t}=d_{2 t}+a_{2 t} d_{1 t} .
$$

Tem-se que a equação de balanço utilizando estoque de escalão não depende do tamanho dos lotes dos itens sucessores, mas sim de suas demandas. Assim, a equação de balanço entre as variáveis de estoque de escalão e produção para o item 2 fica definida como

$$
E_{2, t-1}+X_{2 t}-E_{2 t}=d_{2 t}+a_{21} d_{1 t} \text {. }
$$

Definindo demanda de escalão como a contabilização das demandas independentes e dependentes (a demanda dos itens sucessores), tem-se que esta é dada por,

$$
D_{i t}=d_{i t}+\sum_{j \in S_{i}} a_{i j} D_{j t} \text {. }
$$

Logo, a equação para o item 2 pode ser reescrita como:

$$
E_{i, t-1}+X_{i t}-E_{i t}=D_{i t}
$$

Tem-se ainda, que $o$ estoque de um item deve ser maior que zero $\left(I_{i t} \geq 0\right)$. Pela definição de $\mathrm{E}_{\mathrm{it}}$ tem-se,

$$
E_{i t} \geq \sum_{j \in S_{j}} a_{i j} E_{j t} .
$$

Portanto, é dada a seguinte formulação em termos de estoque de escalão:

Modelo [M2]

$$
\operatorname{Min} \sum_{i=1}^{N} \sum_{t=1}^{T}\left(e_{i t} E_{i t}+p_{i t} X_{i t}+s_{i t} Y_{i t}\right)
$$

sujeito a:

$$
\begin{array}{ll}
E_{i, 1-1}+X_{i t}-E_{i t}=D_{i t} & i=1, \ldots, N ; t=1, \ldots, T \\
\sum_{j e s} a_{i j} E_{j t}-E_{i t} \leq 0 & i=1, \ldots, N ; t=1, \ldots, T \\
\sum_{i=1}^{N}\left(v_{i k t} X_{i t}+f_{i k t} Y_{i t}\right) \leq C A P_{k t} & k=1, \ldots, N ; t=1, \ldots, T \\
X_{i t}-M_{i l} Y_{i t} \leq 0 & i=1, \ldots, N ; t=1, \ldots, T \\
X_{i t} \geq 0, E_{i l} \geq 0 & i=1, \ldots, N ; t=1, \ldots, T \\
Y_{i 1} \in\{0,1\} & i=1, \ldots, N ; t=1, \ldots, T
\end{array}
$$


A equivalência entre [M1] e [M2] é mostrada por Afentakis et al. (1986).

Observe que, utilizando o conceito de estoque de escalão, não há dependência entre os itens que aparece na equação (1.2) do modelo [M1]. A dependência encontra-se na equação (1.15) do modelo [M2]. No entanto, a aplicação de relaxação Lagrangiana nas restrições (1.15) e (1.16) tornam o problema resultante completamente decomponível em $\mathrm{N}$ problemas monoestágios, independentes e com capacidade infinita de produção. Isto torna possível a utilização do algoritmo de Wagner e Whitin (1958) para a resolução do problema Lagrangiano.

\subsection{Complexidade de Resol ução}

A primeira dificuldade que surge quando se considera sistema multiestágio de produção é a dependência entre os itens, o que torna o problema não decomponível.

Do ponto de vista de complexidade computacional, o problema de encontrar a solução ótima no problema multiestágio com recursos de produção limitados e custos de preparação é pertencente à classe $N P$-hard, pois o problema monoestágio já é $N P$-hard (Florian et $a l ., 1980)$. Em Maes et al. (1991) provou-se que determinar a existência de solução factível, para problemas com tempo de preparação (setup time), é NP-Completo.

Há duas abordagens para a resolução de problemas de dimensionamento de lotes com restrições de capacidade. A primeira é a abordagem exata que procura soluções ótimas, enquanto que a segunda é a abordagem heurística, que procura boas soluções e testa a qualidade comparando-as com limitantes ou soluções ótimas.

No entanto, os métodos que garantem solução ótima apresentam solução apenas para problemas pequenos, dentro de um tempo computacional razoável e para casos particulares (Lambrecht e Vanderveecken, 1978; Zangwill, 1969; Gabbay, 1979; Steinberg e Napier, 1980). A maior parte das pesquisas envolve simplificações do problema e o emprego de métodos heurísticos para a sua resolução e, mesmo assim, sem considerar tempos de preparação (Blackburn e Millen, 1984; Chiu e Lin, 1988; Maes et al., 1991; Maes e Van Wassenhove, 1991; Roll e Karni, 1991; Kuik et al., 1993; Billington et al., 1994).

Trabalhos que incluem tempos de preparação são poucos e na maioria deles são apresentadas heurísticas para casos especiais (Billington et al., 1986; Toklu e Wilson, 1992; Harrison e Lewis, 1996). Para casos mais gerais, incluindo tempos e custo de preparação, pode-se citar os trabalhos de Tempelmeier e Derstroff (1996), Clark e Armentano (1995), 
França et al. (1997), Berretta (1997) e Katok et al. (1998), que serão descritos na seção a seguir.

\subsection{Revisão Bibliográfica}

Nesta seção são descritos alguns trabalhos desenvolvidos na área de dimensionamento de lotes em sistemas multiestágios de produção, sendo apresentados somente os artigos que consideram as características das formulações apresentadas nesse capítulo.

Revisões amplas na área podem ser encontradas nos artigos de Bahl et al. (1987), Billington et al. (1983) e Kuik e Salomon (1994). Bahl et al. (1987) realizam uma revisão classificando vários trabalhos de acordo com o ambiente monoestágio e multiestágio e recursos limitados ou ilimitados de produção. Billington et al. (1983) fazem uma revisão mais objetiva na área multiestágio, apresentando uma formulação para o problema de dimensionamento de lotes com restrições de capacidade. O trabalho de Kuik e Salomon (1994) realiza uma boa classificação por diferentes componentes para modelagem do problema de dimensionamento de lotes, tais como taxa de demanda (contínua, discreta ou estocástica), função objetivo, estrutura de itens e restrições de capacidade.

Pela pequena dimensão dos problemas resolvidos pelos algoritmos ótimos, há um maior número de métodos heurísticos em desenvolvimento. Os trabalhos de Billington et al. (1986), Tempelmeier e Derstroff (1996), Tempelmeier (1997), França et al. (1997), Katok et al. (1998) e Kimms (1999) são alguns exemplos de métodos heurísticos para o caso onde há restrições de capacidade.

No artigo de Billington et al. (1986) é proposto um método heuristico baseado em relaxação Lagrangiana, utilizando a metodologia Branch and Bound, para o problema de dimensionamento de lotes multiestágio, com um único centro gargalo (centro de trabalho que limita a produção de toda a fábrica) no qual o tempo e custo de preparação são relevantes. A relaxação proposta não é a verdadeira relaxação Lagrangiana. São na verdade $N$ relaxações, uma para cada item, resolvidas dos itens finais até as matérias-primas, considerando um certo conjunto de multiplicadores de Lagrange. Caso a solução encontrada seja infactível para o modelo original, uma heurística baseada en transferências de produção tenta factibilizar a solução. A seguir, na fase dual, os multiplicadores lagrangianos são atualizados de forma a desencorajar a produção no estágio onde a capacidade de produção é limitada. Os testes computacionais envolvem estrutura serial e de montagem para estruturas com 5 itens com 
capacidade ilimitada de produção e no caso limitado, os exemplos para teste têm 1, 3 ou 5 itens finais e 5 níveis formando uma estrutura paralela (estruturas seriais em paralelo). No caso de 1 item final e 5 níveis (5 itens em série) os resultados mostram $29 \%$ a $62 \%$ de gap comparando a solução heurística com o limitante inferior obtido pela relaxação Lagrangiana. Também é relatado que em 8 exemplos, onde a solução ótima foi obtida, a heurística obtém soluções a menos de $1 \%$ do ótimo. Isto leva a crer o grande gap de dualidade existente.

Tempelmeier e Derstroff (1996) apresentam uma heurística para o problema de dimensionamento de lotes multiestágio considerando estrutura geral de produto, múltiplas restrições de capacidade e tempos de preparação, a qual é similar à apresentada por Billington et al. (1986). Utilizando a técnica da relaxação Lagrangiana, relaxa-se um grupo de restrições e o problema é decomposto em vários subproblemas com único item e sem restrições de capacidade. Da resolução destes subproblemas, obtém-se o valor do limitante inferior para um dado conjunto de multiplicadores de Lagrange. Os limitantes superiores são construídos através de um procedimento de factibilização que transfere produções entre períodos até atingir a factibilidade. As diferenças básicas deste para o método de Billington et al. (1986) estão na relaxação Lagrangiana e no procedimento de factibilização. A relaxação Lagrangiana no trabalho de Tempelmeier e Derstroff (1996) é resolvida de forma ótima e o procedimento de factibilização é um pouco mais sofisticado. O procedimento é testado extensivamente usando exemplos de diferentes dimensões, com ou sem tempos de preparação. A presença de tempos de preparação não afeta o desempenho do algoritmo. Soluções para exemplos pequenos são, em média, muito próximos do ótimo. Os testes que envolvem tempos de preparação utilizam exemplos com 10 e 40 itens e 4 e 16 períodos de planejamento. Nos exemplos com 40 itens obtêm-se soluções que estão a $16 \%$ do limitante inferior obtido por relaxação Lagrangiana, com 45 segundos em um PC 486-33Mhz.

No trabalho de Tempelmeier (1997) é considerado o planejamento de dimensionamento de lotes de um típico sistema MRP. Vários modelos alternativos para o dimensionamento de lotes são discutidos com a ajuda de pequenos problemas. Nesta aḅordagem, o dimensionamento de lotes item por item é substituído pela solução heurística do problema de dimensionamento de lotes multiestágio capacitado com tempo de preparação.

O trabalho de França et al. (1997) considera o problema de dimensionamento de lotes capacitado em sistemas multiestágios de manufatura. Os custos considerados são os de produção, estoque e preparação. Um método heurístico é construído sobre a formulação do problema em termos de estoque de escalão. A heurística é composta por quatro procedimentos. O inicial constrói uma solução que, geralmente, é infactível. A seguir, os 
outros três procedimentos, com distintos objetivos, tentam encontrar uma solução factível e de melhor custo, através de transferências da produção entre períodos. A qualidade das soluções encontradas é avaliada através de limitantes inferiores Lagrangianos. Para a análise do método heurístico foram gerados 360 exemplos considerando estrutura serial, geral e plana (onde o item I tem como predecessores os itens $2,3, \ldots, N$ e estes têm como sucessor apenas o item 1) com exemplos de 10,20 e 40 itens e 12 e 18 períodos de planejamento. Utilizando estrutura plana, obteve-se $1,23 \%$ e $4,69 \%$ de gap considerando custo baixo e alto de preparação, respectivamente. No caso da estrutura serial obteve-se $13,02 \%$ e $15,04 \%$ de gap e, para estrutura geral obteve-se $4,42 \%$ e $11,38 \%$ de gap considerando novamente custo baixo e alto de preparação, respectivamente. É importante ressaltar que os valores dos gaps calculados são comparados com um limitante inferior e, portanto, os resultados apresentados podem ser melhores do que os números indicam, ou seja, o valor do limitante inferior pode incorporar um gap de dualidade do problema.

Kimms (1999) apresenta um algoritmo genético para a resolução do problema de dimensionamento de lotes multiestágio capacitado, com múltiplas máquinas juntamente com o problema de seqüenciamento (scheduling problem). A eficiência do algoritmo é atribuída à representação da solução que usa uma matriz bidimensional com valores inteiros. $O$ procedimento é extremamente rápido quando comparado às técnicas baseadas em Busca Tabu, competindo também com essas técnicas no que se refere a capacidade de encontrar soluções factíveis.

Katok et al. (1998) introduzem um método heurístico para encontrar boas soluções factíveis para problemas de dimensionamento de lotes multiestágios, com estrutura de montagem, múltiplas restrições de recurso, custos e tempos de preparação não nulos. Foram gerados exemplos com 8,10,12,14 e 18 itens e 4, 5 e 6 períodos de planejamento. Avalia-se o desempenho desta heurística através da comparação de soluções ótimas de exemplos de problemas pequenos gerados aleatoriamente e, neste caso, a heuristica obteve soluções, em média, $4 \%$ piores do que o ótimo. Para exemplos médios, também gerados aleatoriamente, foi determinado um tempo de execução para o pacote CPLEX, utilizado para resolução ótima, e então, foi feita a comparação destes resultados com os resultados heurísticos. As soluções heurísticas para estes exemplos sđ̃o, em média, 26\% melhores do que as encontradas pelo pacote CPLEX.

Como já mencionado, há um maior número de métodos heurísticos propostos devido à pequena dimensão dos problemas resolvidos pelos algoritmos ótimos, sendo estes poucos e desenvolvidos para casos especiais. A proposta deste trabalho é desenvolver e analisar uma 
heuristica baseada em relaxação Lagrangiana para o problema de dimensionamento de lotes multiestágio com restrições de capacidade, incluindo tempos e custos de preparação. Assim, no próximo capítulo será apresentada a aplicação da técnica de relaxação Lagrangiana para a obtenção do limitante inferior para o problema abordado. 


\section{Capítulo 2}

\section{Aplicação de Relaxação Lagrangiana para a Obtenção do Limitante Inferior}

\subsection{Introdução}

Segundo Beasley (Reeves, 1993), encontrar boas soluções para problemas dificeis em otimização combinatória exige a consideração do cálculo do limitante superior que é tão próximo quanto possível do ótimo e do cálculo do limitante inferior que também é tão próximo quanto possível do ótimo.

Técnicas para gerar bons limitantes superiores são essencialmente métodos heurísticos. Além disso, para qualquer problema particular, podemos ter técnicas as quais são específicas para o problema sendo resolvido.

Uma técnica bem conhecida e usada para o cálculo do limitante inferior é a relaxação Lagrangiana a qual envolve:

- considerar uma formulação de programação inteira ou inteira-mista do problema;

- anexar os multiplicadores de Lagrange para algumas restrições nesta formulação, relaxando-as e inserindo-as na função objetivo;

- resolver o problema inteiro ou inteiro-misto resultante.

Após a resolução do problema inteiro ou inteiro-misto obtém-se um limitante inferior na solução ótima para o problema original. 
Ainda segundo Beasley (Reeves, 1993), existem algumas razões que justificam o uso da técnica de relaxação Lagrangiana. Muitos problemas de otimização combinatória consistem em um problema "fácil", complicado pela adição de restrições extras. A absorção destas restrições complicadas dentro da função objetivo, faz com que possa ser obtido e um problema fácil de resolver e a atenção pode então ser voltada para a escolha de valores numéricos para os multiplicadores de Lagrange. Além disso, experiências práticas com relaxação Lagrangiana têm indicado que esta fornece muitos limitantes inferiores bons e de razoável custo computacional.

A escolha de valores para os multiplicadores de Lagrange é a chave importante na qualidade dos limitantes inferiores gerados e, para isto, pode ser utilizado o método de otimização do subgradiente.

\subsection{Aplicação de Relaxação Lagrangiana}

Nesta seção é apresentada a aplicação da técnica de relaxação Lagrangiana para a obtenção de um limitante inferior para o problema abordado.

Como dito anteriormente, o problema representado pelo modelo [M2], sem o conjunto das restrições (1.15) e (1.16), reúne $N$ problemas monoestágio de dimensionamento de lotes com capacidade infinita de produção. Utilizando relaxação Lagrangiana, dualizam-se essas duas restrições, incluindo-as na função objetivo, como descrito a seguir.

Modelo [MR]

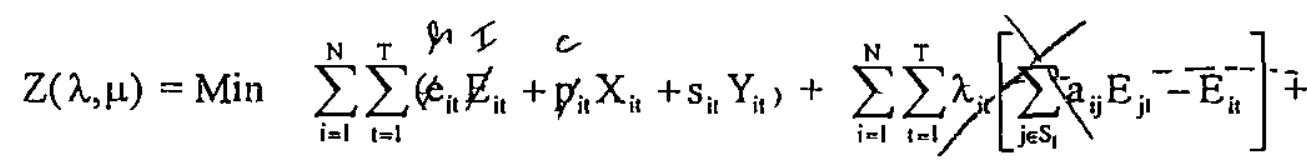

$$
\begin{aligned}
& \sum_{k=1}^{K} \sum_{t=1}^{T} \mu_{k t}^{L}\left[\sum_{i=1}^{N}\left(v_{i k t} X_{i t}+f_{i k t} Y_{i t}\right)-C A \dot{P}_{k t}\right]
\end{aligned}
$$

sujeito a:

$$
\begin{aligned}
& \sum_{i, t-1}+\mathrm{X}_{\mathrm{it}}-\mathrm{Z}_{\mathrm{it}}=D_{\mathrm{it}} \\
& \mathrm{X}_{\mathrm{it}}-\mathrm{M}_{\mathrm{it}} \mathrm{Y}_{\mathrm{it}} \leq 0 \\
& \mathrm{X}_{\mathrm{it}} \geq 0, \mathrm{E}_{\mathrm{it}} \geq 0 \\
& \mathrm{Y}_{\mathrm{it}} \in\{0, \mathrm{I}\}
\end{aligned}
$$

$$
\begin{aligned}
& i=1, \ldots, N ; t=1, \ldots, T \\
& i=1, \ldots, N ; t=1, \ldots, T \\
& i=1, \ldots, N ; t=1, \ldots, T \\
& i=1, \ldots, N ; t=1, \ldots, T
\end{aligned}
$$


onde

$$
\begin{array}{ll}
\lambda_{\mathrm{it}} \geq 0 & \mathrm{i}=1, \ldots, \mathrm{N} ; \mathrm{t}=1, \ldots, \mathrm{T} \\
\mu_{\mathrm{kt}} \geq 0 & \mathrm{k}=1, \ldots, \mathrm{K} ; \mathrm{t}=1, \ldots, \mathrm{T} \text { são os multiplicadores Lagrangianos }
\end{array}
$$

correspondentes ao conjunto de restrições (1.15) e (1.16), respectivamente.

Reordenando os termos da função objetivo:

$\sum_{i=1}^{N} \sum_{i=1}^{T}\left[\left(s_{i t}+\sum_{k=1}^{K} \mu_{k t} f_{i k t}\right) Y_{i t}+\left(p_{i t}+\sum_{k=1}^{K} \mu_{k t} v_{i k t}\right) X_{i t}\right]-\sum_{k=1}^{K} \sum_{i=1}^{T} \mu_{k t} \operatorname{CAP}_{k t}+\sum_{i=1}^{N} \sum_{t=1}^{T} e_{i t} E_{i t}+$ $\sum_{i=1}^{N} \sum_{i=1}^{T} \lambda_{i t}\left[\sum_{j \in S_{i}} a_{i j} E_{j t}-E_{i t}\right]=$

$\sum_{i=1}^{N} \sum_{t=1}^{T}\left[\left(s_{i t}+\sum_{k=1}^{K} \mu_{k t} f_{i k t}\right) Y_{i t}+\left(p_{i t}+\sum_{k=1}^{K} \mu_{k t} v_{i k t}\right) X_{i t}\right]-\sum_{k=1}^{K} \sum_{t=1}^{T} \mu_{k t} \operatorname{CAP}_{k t}+\sum_{i=1}^{N} \sum_{t=1}^{T}\left(e_{i t}-\lambda_{i t}\right) E_{i t}+$ $\sum_{i=1}^{N} \sum_{t=1}^{T} \lambda_{i t} \sum_{j \in S_{i}} a_{i j} E_{j i}$

Substituindo $j \in S_{i}$ por $j \in P_{i}$ ( $j$ e i ficam invertidos), tem-se:

$\sum_{i=1}^{N} \sum_{t=1}^{T}\left[\left(s_{i t}+\sum_{k=1}^{K} \mu_{k t} f_{i k t}\right) Y_{i t}+\left(p_{i t}+\sum_{k=1}^{K} \mu_{k t} v_{i k t}\right) X_{i t}\right]+\sum_{i=1}^{N}\left[\sum_{i=1}^{T}\left(e_{i t}-\lambda_{i t}\right)+\sum_{j \in P_{i}} a_{j i} \sum_{t=1}^{T} \lambda_{j t}\right] E_{i t}-$ $\sum_{k=1}^{K} \sum_{t=1}^{T} \mu_{k t} \operatorname{CAP}_{k t}$.

Então, reescrevendo o problema Lagrangiano temos:

Modelo [MR]

$$
\begin{aligned}
Z(\lambda, \mu)=\min & \sum_{i=1}^{N}\left[\sum_{l=1}^{T}\left[\left(s_{i t}+\sum_{k=1}^{K} \mu_{k t} f_{i k t}\right) Y_{i t}+\left(p_{i t}+\sum_{k=1}^{K} \mu_{k l} v_{i k t}\right) X_{i t}\right]+\left[\sum_{t=1}^{T}\left(e_{i t}-\lambda_{i t}\right)+\sum_{j \in P_{i}} a_{j i} \sum_{t=1}^{T} \lambda_{j t}\right] E_{i t}\right] \\
& -\sum_{k=1}^{K} \sum_{t=1}^{T} \mu_{k t} \operatorname{CAP}_{k t}
\end{aligned}
$$

sujeito a:

$$
\begin{array}{ll}
E_{i, t-1}+X_{i t}-E_{i t}=D_{i t} & i=1, \ldots, N ; t=1, \ldots, T \\
X_{i t}-M_{i t} Y_{i t} \leq 0 & i=1, \ldots, N ; t=1, \ldots, T \\
X_{i t} \geq 0, E_{i t} \geq 0 & i=1, \ldots, N ; t=1, \ldots, T \\
Y_{i t} \in\{0,1\} & i=1, \ldots, N ; t=1, \ldots, T
\end{array}
$$


onde:

$$
\begin{array}{lll}
\left(\mathrm{s}_{\mathrm{it}}+\sum_{\mathrm{k}=1}^{\mathrm{K}} \mu_{\mathrm{kt}} \mathrm{f}_{\mathrm{ikt}}\right) & \text { custo Lagrangiano de preparação. } \\
\left(\mathrm{p}_{\mathrm{it}}+\sum_{\mathrm{k}=1}^{\mathrm{K}} \mu_{\mathrm{kt}} \mathrm{v}_{\mathrm{ikl}}\right) & - & \text { custo Lagrangiano de produção. }
\end{array}
$$

$\left[\sum_{t=1}^{T}\left(e_{i t}-\lambda_{i t}\right)+\sum_{j \in P_{i}} a_{j i} \sum_{i=1}^{T} \lambda_{j t}\right] \quad-\quad$ custo Lagrangiano de estoque de escalão.

$\sum_{k=1}^{K} \sum_{t=1}^{T} \mu_{k t} \operatorname{CAP}_{k t} \quad$ - parcela fixa da função objetivo.

Observe novamente que o problema [MR] decompõe-se em $N$ problemas monoestágios de dimensionamento de lotes com capacidade infinita de produção (um para cada componente).

Portanto, para cada i, resolve-se o problema:

$Z_{i}(\lambda, \mu)=\sum_{t=1}^{T}\left[\left(s_{i t}+\sum_{k=1}^{K} \mu_{k t} f_{i k t}\right) Y_{i t}+\left(p_{i t}+\sum_{k=1}^{K} \mu_{k t} v_{i k t}\right) X_{i t}\right]+\left[\sum_{i=1}^{T}\left(e_{i t}-\lambda_{i t}\right)+\sum_{j \in P_{t}} a_{j i} \sum_{i=1}^{T} \lambda_{j t}\right] E_{i t}$

sujeito a:

$$
\begin{array}{lr}
E_{i, s-1}+X_{i 1}-E_{i t}=D_{i t} & t=1, \ldots, T \\
X_{i t}-M_{i t} Y_{i t} \leq 0 & t=1, \ldots, T \\
X_{i t} \geq 0, E_{i t} \geq 0 & t=1, \ldots, T \\
Y_{i t} \in\{0,1\} & t=1, \ldots, T
\end{array}
$$

Pode-se utilizar o algoritmo de Wagner e Whitin (1958) para a resolução de cada um dos $\mathrm{N}$ problemas. O limitante inferior para o problema representado pelo modelo [M2] é dado por:

$$
Z(\lambda, \mu)=\sum_{i=1}^{N} Z_{i}(\lambda, \mu)-\sum_{k=1}^{K} \sum_{t=1}^{T} \mu_{k t} \operatorname{CAP}_{k t}
$$

Neste trabalho, utiliza-se a informação dos multiplicadores de Lagrange com 0 propósito de obter novos custos de produção, preparação e estoque. 
Com a resolução do problema Lagrangiano tem-se um limitante inferior para o problema representado pelo modelo $[\mathrm{ME}]$, mas sua solução provavelmente é infactível, pois foram relaxados dois grupos de restrições. No próximo capítulo será descrita a heurística que, usando as informações dos custos Lagrangianos, busca soluções factiveis de boa qualidade. 


\section{Capítulo 3}

\section{Heurística para a Resolução do Problema}

\subsection{Introdução}

Neste capítulo, apresenta-se a heurística que utiliza a técnica de relaxação Lagrangiana no modelo com estoque de escalão [M2] para a obtenção de soluções para o problema considerando custos de produção, preparação e estoque e, também, uma quantidade limitada de recursos para produção e preparação de cada item.

A heurística é baseada no trabalho de França et al. (1997), o qual não incorpora as informações do problema Lagrangiano na sua resolução. A heurística Lagrangiana pode possuir os seguintes procedimentos:

Pl - Procedimento para a Obtenção da Solução Inicial.

P2 - Procedimento de Factibilização.

P3 - Procedimento de Melhoria.

P4 - Procedimento de Alteração.

P5 - Procedimento para a Atualização dos Multiplicadores de Lagrange.

No procedimento para a obtenção da solução inicial (P1), a solução de partida é gerada pela aplicação seqüencial do algoritmo de Wagner e Whitin (1958) ao problema [M1], ignorando as restrições de capacidade (1.3). Dessa forma, não garante que a solução encontrada seja factível para o problema original. A seguir, caso a solução encontrada em P1 seja infactível, o procedimento de factibilização (P2) é aplicado na tentativa de obter uma solução factível. Uma solução infactível se caracteriza por periodos onde a quantidade de 
recursos disponíveis não é suficiente para suprir a produção planejada. Assim, tenta-se transferir produção de períodos infactíveis para outros perfodos.

Caso tenha sido encontrada uma solução factível (em P1 ou em P2), o procedimento de melhoria (P3) tenta encontrar melhores soluções a partir da obtida anteriormente. Neste procedimento são realizados movimentos com o objetivo de reduzir o custo e permitindo exploração apenas de regiōes factíveis. Ao final, um ótimo local é atingido. Se encontrarmos uma solução infactível em P2, o procedimento de alteração (P4) é aplicado para a obtenção de novas soluções, mesmo infactíveis ou de pior custo, com o objetivo de obter um novo ponto de partida para o procedimento $\mathrm{P} 2$.

Em seguida, para a atualização dos multiplicadores de Lagrange, o procedimento P5 utiliza a otimização do subgradiente, fornecendo novos custos de produção, preparação e estoque. Estes custos serão utilizados para encontrar uma nova solução inicial usando o algoritmo de Wagner e Whitin (1958).

Para a resolução do problema serão consideradas heurísticas que utilizam a técnica de relaxação Lagrangiana. Uma heurística, é composta pelos cinco procedimentos (P1, P2, P3, P4 e P5) descritos anteriormente. Também, será utilizada outra heurística composta pelos procedimentos P1, P2, P3 e P5. O que difere esta da primeira heurística é a presença do procedimento de alteração (P4).

Nas heurísticas, os procedimentos são executados até que um critério de parada seja atingido.

A seguir, os procedimentos P1, P2, P3, P4 e P5 são descritos detalhadamente.

\subsection{Obtenção da Solução Inicial - Procedimento P1}

O algoritmo de Wagner e Whitin (1958) é um algoritmo de Programação Dinâmica que resolve facilmente o problema de um único item monoestágio, sem restrições de capacidade, fornecendo um plano ótimo que visa minimizar os custos de produção, preparação e estoque.

Dessa forma, considere o modelo [M1], apresentado no Capítulo 1, sem o conjunto de restrições de capacidade. 
Modelo [M1']

$\operatorname{Min} Z=\sum_{i=1}^{N} \sum_{i=1}^{T}\left(p_{i t} X_{i t}+h_{i t} I_{i t}+s_{i t} Y_{i t}\right)$

sujeito a:

$$
\begin{array}{ll}
I_{i, t-1}+X_{i t}-I_{i t}-\sum_{j \in S_{i}} a_{i j} X_{j t}=d_{i t} & i=1, \ldots, N ; t=1, \ldots, T \\
X_{i t}-M_{i t} Y_{i t} \leq 0 & i=1, \ldots, N ; t=1, \ldots, T \\
X_{i t} \geq 0, I_{i t} \geq 0 & i=1, \ldots, N ; t=1, \ldots, T \\
Y_{i t} \in\{0,1\} & i=1, \ldots, N ; t=1, \ldots, T
\end{array}
$$

A idéia do procedimento P1 é aplicar o algoritmo de Wagner e Whitin (1958) para cada item do modelo [M1'] separadamente.

Inicialmente, aplica-se o algoritmo aos itens finais $\left(i / S_{i}=\varnothing\right)$. A seguir, para cada item $i$ tal que $S_{\mathrm{i}} \neq \varnothing$, o algoritmo de Wagner e Whitin (1958) é aplicado após o cálculo de uma nova demanda $\left(\mathrm{d}_{\mathrm{it}}{ }^{\prime}\right)$, que depende da solução dos sucessores imediatos de $\mathrm{i}\left(\sum_{\mathrm{j} \in \mathrm{S}_{\mathrm{i}}} \mathrm{a}_{\mathrm{ij}} \mathrm{X}_{\mathrm{jt}}\right)$ e da própria demanda de $\mathrm{i}\left(\mathrm{d}_{\mathrm{it}}\right)$, isto é,

$$
\mathrm{d}_{\mathrm{it}}{ }^{\prime}=\mathrm{d}_{\mathrm{it}}+\sum_{\mathrm{je} \mathrm{S}_{\mathrm{i}}} \mathrm{a}_{\mathrm{ij}} \mathrm{X}_{\mathrm{jt}} \text {. }
$$

Após $\mathrm{N}$ aplicações do algoritmo de Wagner e Whitin (1958), uma para cada item, obtém-se uma sequêencia de soluções monoestágio que quando reunidas, formam uma solução para o problema [M1'].

Como as restrições de capacidade foram ignoradas, provavelmente a solução é infactível em relação ao consumo de recursos para o problema [M1] e conseqüentemente para o problema [M1'].

Neste trabalho, uma solução é considerada infactivel se em algum período $t$, a produção planejada neste período consome uma quantidade de recursos maior que a disponivel, ou seja, as restrições de capacidade são violadas, dadas por

$$
\sum_{i=i}^{N}\left(v_{i k t} X_{i t}+f_{i k t} Y_{i t}\right)>C_{A} P_{k t} \quad \text { para pelo menos um } k=1, \ldots, K \text {. }
$$

Chamamos de Excesso(t) a infactibilidade de cada período que contabiliza o excedente de recursos utilizados em relação à capacidade disponivel no periodo t. É definido como 


$$
\operatorname{Excesso}(t)=\sum_{k=1}^{k}\left[\frac{\sum_{i=1}^{N}\left(v_{i k !} X_{i t}+f_{i k t} Y_{i t}\right)-\operatorname{CAP}_{k t}}{\operatorname{CAP}_{k t}}\right]^{+}
$$

onde $[a]^{+}=\left\{\begin{array}{l}0 \text { se } a \leq 0 \\ a \text { se } a>0\end{array}\right.$.

Observe por (3.1) que Excesso (t) é sempre positivo e, dessa forma, não informa se há sobra de recursos no período $t$.

Uma solução que obedeça às restrições (1.14) e (1.15), ou seja,

$$
\begin{array}{ll}
E_{i, l-1}+X_{i t}-E_{i t}=D_{i t} & i=1, \ldots, N ; t=1, \ldots, T \\
\sum_{j \in S_{i}} a_{i j} E_{j t}-E_{i t} \leq 0 & i=1, \ldots, N ; t=1, \ldots, T
\end{array}
$$

é chamada de uma solução com factibilidade inter-escalão. Neste procedimento, a factibilidade inter-escalão é preservada devido à ordem dos itens para a aplicação do algoritmo de Wagner e Whitin (1958), pois a produção de um item é planejada após a determinação da produção de seus itens sucessores.

Ao final deste procedimento, caso a solução encontrada seja infactível, ou seja, Excesso(t) $>0$ para algum $t$, o procedimento de factibilização (P2) é utilizado na tentativa de obter uma solução factível. Caso seja encontrada uma solução factível, é feita a tentativa de melhora da solução através do procedimento de melhoria (P3).

\subsection{Factibilização - Procedimento $P 2$}

Esse procedimento tenta obter uma solução factível a partir de uma infactível (França et al., 1997). Como dito anteriormente, uma solução é considerada infactível se em algum período $t$, a produção planejada neste perfodo consome uma quantidade de recursos maior que a disponível.

A cada período $t$ infactível, é feita uma tentativa para transferir uma quantidade de produção de um item $i$ do período $t$ (período infactível) para outro período tl (período destino) com $\mathrm{tl} \neq \mathrm{t}$, até que o período $\mathrm{t}$ se torne factível.

Assim ,uma transferência é caracterizada por:

$$
\begin{array}{ll}
\text { q } & \text { quantidade } \\
\text { i } & \text { item }
\end{array}
$$


t período origem

Uma transferência pode ser para trás quando $t i<t$, ou para frente quando $t l>t$. Para efetuar as transferências é preciso saber qual a quantidade máxima a ser transferida e, também, deve-se determinar quanto transferir de forma a eliminar a infactibilidade em um determinado período $t$. Finalmente, sabendo quais as possibilidades de transferências que podem ser efetuadas, ter um mecanismo para avaliação de cada transferência para poder realizar uma escolha mais criteriosa.

Cada um desses cálculos é explicado a seguir.

- Quantidade Máxima a ser Transferida - $M_{i, t, t}$

Dado um item $\mathrm{i}$, um período $t$ e um período $t l, \mathrm{M}_{\mathrm{i}, \mathrm{t}, \mathrm{l}}$ representa a quantidade máxima possível a ser transferida da produção do item i no período t a um outro período tl, respeitando as restrições (1.14) e (1.15), ou seja, a factibilidade inter-escalão é preservada.

Considere a estrutura da figura a seguir para determinar a quantidade máxima a ser transferida $\left(\mathrm{M}_{\mathrm{i}, \mathrm{t}, \mathrm{l}}\right)$.

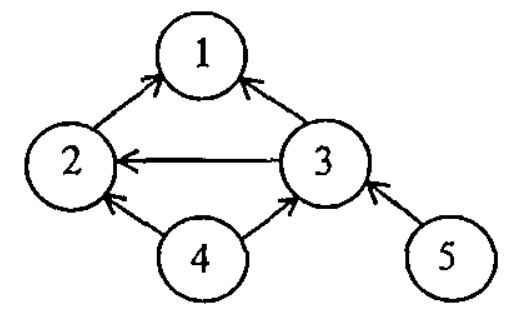

Figura 3.1 - Exemplo de estrutura de itens.

Suponha que exista produção do item 3 no período t e que parte de sua produção será transferida para um periodo tl. O período tl pode ser anterior ou posterior a $t$. Dessa forma, será analisada a seguir, a transferência para um período anterior e, em seguida, para um periodo posterior.

\section{Transferência para um periodo anterior}

Para a transferência para um período anterior, suponha que se deseja transferir uma quantidade q da produção do item 3 do período $t$ para o período $t$, de modo que $t l<t$. 
Note, pela restrição (1.14), dada por

$$
E_{i, t-1}+X_{i t}-E_{i t}=D_{i t}
$$

que caso seja efetuada a transferência, o estoque de escalão do item 3 do período t ao período tl-1 será acrescido de q unidades. Dessa forma a equação (1.15), dada por

$$
\sum_{j e s} a_{i j} E_{j t}-E_{i t} \leq 0
$$

precisa ser analisada para $\mathrm{i}=3$.

A equação (1.15) pode ser reescrita por

$$
E_{i \mathrm{i}} \geq \sum_{\mathrm{j} \in S_{\mathrm{l}}} \mathrm{a}_{\mathrm{ij}} E_{\mathrm{jl}}
$$

Assim, é preciso analisar onde 3 é um dos itens sucessorcs de $\mathrm{i}\left(3 \in \mathrm{S}_{\mathrm{i}}\right)$, ou ainda, todas as inequações onde $i$ é um predecessor do item $3\left(i \in P_{3}\right)$, isto é,

$$
\begin{array}{ll}
E_{4 \delta} \geq a_{43} E_{3 \delta}+a_{42} E_{2 \delta} & i=4, \delta=t l, \ldots, t-1 \\
E_{5 \delta} \geq a_{53} E_{3 \delta} & i=5, \delta=t l, \ldots, t-1
\end{array}
$$

ou ainda, após a transferência,

$$
\begin{array}{ll}
E_{4 \delta} \geq a_{43} E_{3 \delta}+a_{42} E_{2 \delta}+a_{43} q & i=4, \delta=t l, \ldots, t-1 \\
E_{5 \delta} \geq a_{53} E_{3 \delta}+a_{53} q & i=5, \delta=t l, \ldots, t-1 .
\end{array}
$$

Isolando-se q, obtém-se a quantidade máxima permitida para a transferência do item 3 do período t para o período tl, a qual é:

$$
\mathrm{q} \leq M_{3, \mathrm{t}, \mathrm{l}}=\min \left\{\min _{\delta=t 1, \ldots, 1-1,1}\left\{\frac{E_{4 \delta}-a_{43} E_{3 \delta}-a_{42} E_{2 \delta}}{a_{43}}, \frac{E_{5 \delta}-a_{53} E_{3 \delta}}{a_{53}}\right\}, X_{3 t}\right\}
$$

ou ainda,

$$
q \leq M_{3, t, 1}=\min \left\{\min _{\substack{\delta=t, \ldots, t-1 \\ j \in \mathbb{P}_{3}}}\left\{\frac{E_{j \delta}-\sum_{m \in S_{j}} a_{j m} E_{m \delta}}{a_{j 3}}\right\}, X_{31}\right\} .
$$

Pode-se interpretar essa quantidade da seguinte forma:

- como haverá um acréscimo no estoque de escalão do item 3 entre os períodos $t$ e $t-1$, os estoques dos itens predecessores imediatos do item 3 (itens 4 e 5), após a transferência, precisam ser suficientes para continuar a atender o estoque de escalão do item 3 nos períodos tl a t-1;

- além disso, a quantidade a ser transferida do item 3 não deve ser maior que a produção do item 3 no período $t\left(X_{31}\right)$. 
Dessa forma , para uma estrutura geral qualquer, a quantidade máxima permitida para a transferência do item $\mathrm{i}$ do período $\mathrm{t}$ para o período $\mathrm{t}$, com $\mathrm{tl}<\mathrm{t}$, pode ser obtida por

$$
M_{i, \ell, 11}= \begin{cases}\min \left\{M_{i, t, 11+1}, \min _{j \in P i}\left\{N_{i, j, 11}\right\}\right\} & \text { se } t>t \\ X_{i l} & \text { se } t l=t\end{cases}
$$

onde

$$
N_{i, t, t l}=\frac{E_{j, 0}-\sum_{m \in S_{j}} a_{j m} E_{i m, 11}}{a_{j i}} .
$$

Note, por (3.2), que em perfodos onde há produção de todos os itens, sempre existe uma quantidade, de pelo menos um item, que pode ser transferida, pois a limitação ocorre para itens que possuem predecessores e sempre existe pelo menos um item que não possui predecessor. Pela figura (3.1), verifica-se que sempre é possível transferir parte da produção do item 5 para um período anterior.

\section{Transferência para um periodo posterior}

Para a transferência para um período posterior, suponha que se deseja transferir uma determinada quantidade $q$ da produção do item 3 do período t para o período tl, de modo que $\mathrm{tl}>\mathrm{t}$.

Note, pela restrição (1.14), dada por

$$
E_{i, t-1}+X_{i t}-E_{i t}=D_{i t}
$$

que caso seja efetuada a transferência, o estoque de escalão do item 3 do período $t$ ao período tl-1 será reduzido de q unidades. Dessa forma a equação (1.15), dada por

$$
\sum_{j \in S_{i}} a_{i j} E_{j t}-E_{i t} \leq 0
$$

precisa ser analisada para $\mathrm{i}=3$.

A equação (1.15) pode ser reescrita por

$$
E_{i l} \geq \sum_{j \in s_{i}} a_{i j} E_{j i} .
$$

Assim,

$$
\mathrm{E}_{3 \delta} \geq \mathrm{a}_{31} \mathrm{E}_{1 \delta}+\mathrm{a}_{32} \mathrm{E}_{2 \delta} \quad \mathrm{i}=3, \delta=\mathrm{t}, \ldots, \mathrm{tl}-1
$$

ou ainda, após a transferência 


$$
\mathrm{E}_{3 \delta}-\mathrm{q} \geq \mathrm{a}_{31} \mathrm{E}_{1 \delta}+\mathrm{a}_{32} \mathrm{E}_{2 \delta} \quad \mathrm{i}=3, \delta=\mathrm{t}, \ldots, \mathrm{t} \mathrm{t}-1 .
$$

Isolando-se q, tem-se a quantidade máxima permitida para a transferência do item 3 do período $t$ para o período $t l$, a qual é

$$
\mathrm{q} \leq \mathrm{M}_{\mathrm{i}, \mathrm{t}, \mathrm{tl}}=\min \left\{\min _{\delta=\mathrm{t}_{1, \ldots, \mathrm{ll}-1}}\left\{\mathrm{E}_{3 \delta}-\mathrm{a}_{31} \mathrm{E}_{1 \delta}-\mathrm{a}_{32} \mathrm{E}_{2 \delta}\right\}, \mathrm{X}_{31}\right\} .
$$

Pode-se interpretar essa quantidade da seguinte maneira:

- o estoque de escalão do item 3 após a transferência será reduzido e, ainda, deve ser suficiente para atender o estoque de escalão dos itens sucessores imediatos (itens 1 e 2), nos períodos t a tl-1;

- além disso, a quantidade não pode ser superior à produção no período $t\left(\mathrm{X}_{3 \mathrm{t}}\right)$.

Dessa forma, para uma estrutura geral qualquer, a quantidade máxima permitida para transferência do item i do período $t$ para o período $t l$, com $t l>t$, pode ser obtida por

$$
M_{i, t, t l}=\left\{\begin{array}{ll}
\min \left\{M_{i, 1, t+1}, E_{i, t 1}-\sum_{j \in S_{i}} a_{i j} E_{j, t l-t}\right\} & \text { se } t I>t \\
X_{i t} & \text { se } t l=t
\end{array} .\right.
$$

Pela expressão acima (3.3), observa-se que podem existir períodos onde não há itens que possam ser transferidos, isto é, a quantidade máxima a ser transferida obedecendo às restrições de estoque de escalão é zero. Assim, não será possível factibilizar o período em questão. Neste caso, a análise passa para o próximo período infactível.

\section{- Quantidade para Elininar o Excesso - Q $i t k$}

Suponha que em um período $t, o$ Excesso(t) $>0$. Observe que em (3.1), que há uma parcela referente a cada recurso $k$ para a definição de Excesso. Seja Q suficiente do item i para eliminar exatamente o uso do excesso do recurso $k$ no período $t$, sendo dada por

$$
Q_{i k t}=\frac{\sum_{j=1}^{N}\left[\left(v_{j k t} X_{j t}+f_{j k t} Y_{j t}\right)-C A P_{k t}\right]}{v_{i k t}} \quad \text { se } Q_{i t k}<M_{i, t, t 1 \cdot}
$$

Note que $Q_{i t k}$ indica se existe uma quantidade menor que $M_{i, t, 1}$ que possa reduzir a parcela do recurso $\mathrm{k}$ em Excesso(t) a zero, de modo que não haja sobra de recursos $\mathrm{k}$ no período t. 


\section{- Teste da Razão}

O Teste da Razão é utilizado para avaliar um movimento (q,i,t,tl), quantificando um valor, chamado de Razão, e dessa forma auxiliar na escolha entre os vários movimentos disponíveis durante a execução dos procedimentos. Dada uma transferência (q,i,t,tl), calculase a Razão associada a esta transferência da seguinte forma

$$
\text { Razão }=\frac{\alpha \cdot \Delta \text { custo }+\beta \cdot \text { penalidade }}{\Delta \text { excesso }} .
$$

O $\Delta$ custo é a variação no custo que uma determinada transferência $(q, i, t, t)$ causa, sendo dada em termos percentuais por

$$
\Delta \text { custo }=\frac{\Delta \text { custo_produção }+\Delta \text { custo_estoque }+\Delta \text { custo_preparação }}{\text { custo_total }}
$$

onde

- $\Delta$ custo_produção $=q \cdot\left(c_{i, 1}-c_{i, 1}\right) ;$

$-\Delta$ custo_estoque $=\left\{\begin{array}{ll}+\mathrm{q} \cdot \sum_{\delta=t l}^{\mathrm{t}-1} \mathrm{e}_{\mathrm{i}, \delta} & \text { para } \mathrm{tl}<\mathrm{t} \\ -\mathrm{q} \cdot \sum_{\delta=1}^{\mathrm{t}-1} \mathrm{e}_{\mathrm{i}, \delta} & \text { para } \mathrm{tl}>\mathrm{t}\end{array}\right.$;

- $\Delta$ custo_preparação $=\Delta S 1-\Delta S 2$, onde $\left\{\begin{array}{l}\Delta S 1= \begin{cases}\mathrm{s}_{\mathrm{i}, \mathrm{ll}} & \text { se } \mathrm{X}_{\mathrm{i}, 1}=0 \\ 0 & \text { caso contrário }\end{cases} \\ \Delta \mathrm{S} 2=\left\{\begin{array}{ll}\mathrm{s}_{\mathrm{it}} & \text { se } \mathrm{X}_{\mathrm{it}}=\mathrm{q} \\ 0 & \text { caso contrário }\end{array} \text {. }\right.\end{array}\right.$

Observe que $\Delta$ custo_preparação depende do lote no período $t$ ter sido transferido todo e, da existência ou não, de produção do item i no período tl.

O $\Delta$ custo é positivo em transferências para períodos anteriores, na maioria das vezes, pois há um aumento no estoque e, conseqüentemente, no custo. A transferência de um lote inteiro pode amenizar este fato, podendo tornar o $\Delta$ custo negativo, pois há possibilidade de ocorrer uma redução nos custos de preparação. Já em transferências para períodos posteriores, - $\Delta$ custo é, geralmente, negativo, podendo ser positivo quando houver uma divisão de lotes entre períodos.

A penalidade é um valor acrescido à Razão que depende dos excessos no período t e tl após a transferência. É função do Excesso(t) após a transferência e de um eventual aumento no Excesso(tl), sendo dada por

$$
\text { Penalidade }=\text { Exc_depois }(t)[\text { Excesso_depois }(t \mathrm{l})-\text { Excesso_antes }(\mathrm{t})]
$$

onde 
- Exc_antes $(\mathrm{t})=$ Excesso(t) utilizando a solução anterior à transferência;

- Exc_depois $(\mathrm{t})=$ Excesso(t) supondo que a transferência tenha sido efetuada.

Observe por (3.1) que são contabilizados apenas os valores positivos, isto é, se em um período houver folga na capacidade, o valor do Excesso(t) é zero e não um valor negativo. Dessa forma, cada uma das parcelas na expressão (3.7) é positiva. Além disso, Excesso_depois(tl) é sempre maior ou igual a Excesso_antes(tl), pois sua produção aumenta após a transferência. Assim, a penalidade contabilizada é sempre um valor positivo, ou zero, se a solução antes e depois da transferência analisada for factível.

Após o cálculo do $\Delta$ custo e penalidade, é feita uma soma ponderada das parcelas de modo que seja dada uma importância maior, ou para a variação do excesso, ou para a alteração do custo. Os valores adotados para $\alpha$ e $\beta$ são descritos na próxima seção.

Terminado o cálculo acima é contabilizada a variação no valor do excesso no período $t$ em $\Delta$ excesso dada por

$$
\Delta \text { excesso }=\text { Excesso_antes }(\mathrm{t})-\text { Excesso_depois }(\mathrm{t}) \text {. }
$$

Ao tratar de soluções factíveis, ao final desses cálculos, tem-se em Razão, qual a alteração no custo que uma transferência $(\mathrm{q}, \mathrm{i}, \mathrm{t}, \mathrm{tl})$ causa. Quando a solução antes e/ou depois da transferência é infactível, a Razão, contabiliza um custo penalizado, considerando a variação no consumo dos recursos em excesso.

\subsubsection{Busca de Soluções Factíveis}

Assim, como dito anteriormente, o procedimento de factibilização (P2) tenta obter uma solução factível a partir de uma infactível. Então, dado um período $t$ infactível, tenta-se transferir parte da produção de um item i para um período $\mathrm{t}$, com $\mathrm{tl} \neq \mathrm{t}$. O procedimento é dividido em dois passos: Progressivo e Regressivo. Os dois passos são explicados a seguir.

\section{- Passo Regressivo}

São analisados os períodos $\mathrm{t}=\mathrm{T}, \ldots, 2 \mathrm{e}$ a cada período $\mathrm{t}$ infactível são feitas tentativas de transferências para períodos anteriores a t. São consideradas todas as transferências $(q, i, t, t l)$ onde $q$ são as quantidades $\mathrm{M}_{\mathrm{i}, \mathrm{L}, \mathrm{l}}$ e $\mathrm{Q}_{\text {itk }}$ (para $\mathrm{k}=1,2, \ldots, \mathrm{K}$ ); $\mathrm{i}$ são todos os itens que possuem produção no período $\mathrm{t}, \mathrm{t} l=\mathrm{t}-1, \ldots, \delta$ onde $\delta=$ primeiro periodo anterior a t que exista produção do item $\mathrm{i}$ analisado ou 1. Para cada uma das transferências analisadas, a que obtiver menor Razão é escolhida como a transferência a ser realizada. Em cada período são feitas 
transferências até que o perfodo $t$ se torne factível ou que não seja possível sua execução devido a não existir q $>0$. A seguir, o próximo periodo, na sequuência descrita, é analisado. Ao final deste passo, se uma solução infactível for encontrada, executa-se o passo Progressivo. Caso contrário, o procedimento de factibilização (P2) é finalizado.

\section{- Passo Progressivo}

Aqui são analisados os períodos $t=1, \ldots, T-1$ e é similar ao anterior. A cada período $t$ infactível são feitas tentativas de transferências para periodos posteriores a t. As transferências candidatas são todas as ( $\mathrm{q}, \mathrm{i}, \mathrm{t}, \mathrm{t} \mathrm{l})$, onde $\mathrm{q}$ e $\mathrm{i}$ são as mesmas do passo Regressivo e $\mathrm{t}=\mathrm{t}-1, \ldots, \delta$ onde $\delta$ é o primeiro período posterior a $t$, onde haja produção do item i analisado ou $T$. Para todas as transferências analisadas, a que obtiver menor Razão é escolhida como a transferência a ser realizada. As transferências são executadas até que o período $t$ se torne factível ou que não seja possível sua execução devido a não existir q $>0$, e assim o próximo período, na sequência descrita, é analisado.

A soma ponderada no cálculo da Razão é feita de tal forma que $\alpha=1$ e $\beta=n$, onde n é o número do ciclo, isto é,

$$
\begin{aligned}
& 1^{\circ} \text { Passo Regressivo e Progressivo: } \alpha=1 \text { e } \beta=1, \\
& 2^{\circ} \text { Passo Regressivo e Progressivo: } \alpha=1 \text { e } \beta=2, \\
& 3^{\circ} \text { Passo Regressivo e Progressivo: } \alpha=1 \text { e } \beta=2
\end{aligned}
$$

e assim sucessivamente.

Dessa forma, quanto maior o número de ciclos no procedimento de factibilização maior a dificuldade em encontrar uma solução factível.

Observe também que podem existir períodos $t$ infactíveis onde não é possível efetuar transferências pelo fato de $\mathrm{M}_{\mathrm{i}, \mathrm{t}, \mathrm{t}}=0$ para todo $\mathrm{i}$ e tl analisado e isto pode ocorrer em qualquer um dos passos.

Os dois passos, Regressivo e Progressivo, são repetidos até que uma solução factível seja obtida ou un contador de passos atinja o limite máximo pré-especificado. Neste caso, o método falha.

A seguir, são apresentados os pseudo-códigos dos passos Regressivo e Progressivo, considerando que: 
- tem_chance = variável lógica que indica se não há mais transferências possíveis de serem realizadas.

- $\left(\mathrm{q}_{0}, \mathrm{i}_{\mathrm{o}}, \mathrm{t}, \mathrm{tl}_{\mathrm{o}}\right)=$ transferência que obteve menor Razão.

- $\mathrm{R}_{\min }=$ valor da menor Razão. 


\section{- Passo Regressivo de Factibilização}

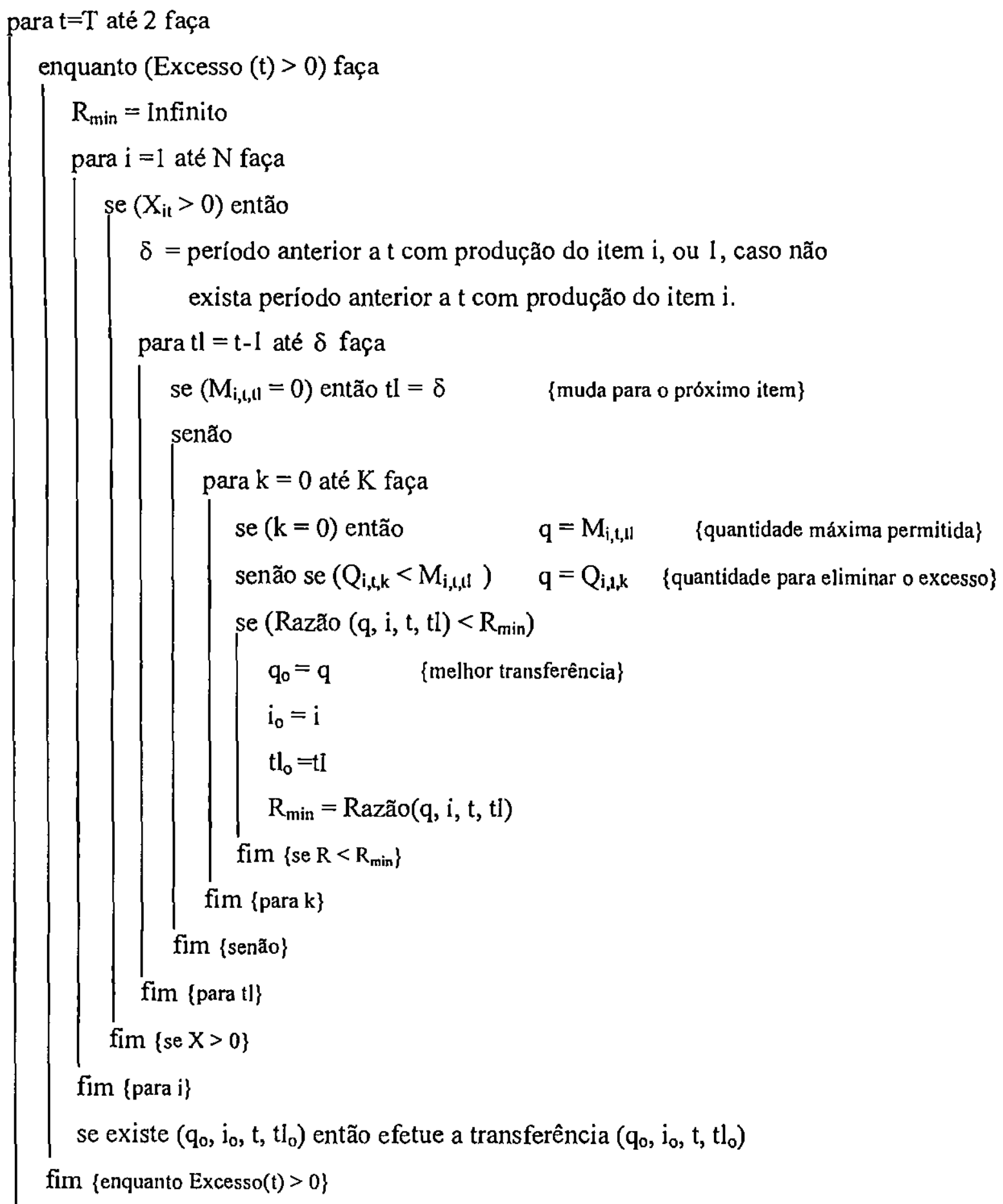

fim \{para t\}

Ao final do passo Regressivo, caso uma solução factível não tenha sido obtida, o passo Progressivo é aplicado. 
- Passo Progressivo de Factibilização

para $t=1$ até $T-1$ faça

tem_chance $=$ sucesso

enquanto (Excesso $(t)>0$ e tem_chance) faça

$\mathrm{R}_{\min }=$ lnfinito

para $\mathrm{i}=1$ até $\mathrm{N}$ faça

se $\left(X_{i t}>0\right)$ então

$\delta=$ período posterior à t com produção do item $\mathrm{i}$, ou $\mathrm{T}$, caso não

exista período posterior a t com produção do item $\mathrm{i}$.

para $t \mathrm{l}=\mathrm{t}+\mathrm{l}$ até $\delta$ faça

se $\left(M_{i, \ell, U}=0\right)$ então $t l=\delta \quad$ \{muda para o próximo item

senão

para $\mathrm{k}=0$ até $\mathrm{K}$ faça

e $(k=0)$ então $\quad q=M_{i, l, l l} \quad$ \{quantidade máxima permitida\}

senão se $\left(Q_{i, l, k}<M_{i, L, 1}\right) \quad q=Q_{i, L, k} \quad$ \{quantidade para eliminar o excesso\}

se (Razão $\left.(q, i, t, t)<R_{\min }\right)$

$\mathrm{q}_{\mathrm{o}}=\mathrm{q} \quad$ \{melhor transferência\}

$\mathrm{i}_{0}=\mathrm{i}$

$\mathrm{tl}_{\mathrm{o}}=\mathrm{tl}$

$R_{\min }=\operatorname{Razão}(q, i, t, t)$

fim $\left\{\right.$ se $\left.R<R_{\min }\right\}$

fim $\{$ para $k\}$

fim \{senão\}

fim $\{$ para tl\}

fim $\{$ se $X>0\}$

fim para i\}

se existe $\left(q_{0}, i_{o}, t, t l_{0}\right)$ então efetue a transferência $\left(q_{o}, i_{0}, t, t l_{o}\right)$

senão tem_chance $=$ fracasso

fim \{enquanto Excesso $(t)>0$ \}

fim \{para t\} 
Se ao final do passo Progressivo, não foi possivel obter uma solução factível, o passo Regressivo é aplicado novamente. Os dois passos são continuamente executados, até que uma solução factível seja obtida ou um contador de passos atinja um limite pré-especificado.

\subsection{Melhoria - Procedimento P3}

A partir de uma solução factível para o problema [M2], este procedimento tenta encontrar uma solução com menor custo, sem permitir infactibilidade.

O mecanismo é similar ao procedimento de factibilização (P2), isto é, se baseia em transferência de partes da produção entre períodos, no entanto, são permitidas apenas as transferências que não infactibilizem a solução e que causam maior redução no valor da função objetivo.

Como no procedimento de factibilização (P2), as transferências são feitas para trás e, a seguir, para frente. Assim, o procedimento de melhoria é dividido em dois passos: Passo Regressivo e Passo Progressivo.

As quantidades analisadas para a transferência são duas. Uma é a quantidade máxima que pode ser transferida do item i do período t para o período tl, de tal modo que o estoque de escalão permita $\left(\mathrm{M}_{\mathrm{i}, \mathrm{t}, \mathrm{t}}\right)$ e não provoque infactibilidade no período destino (tl) da transferência. A outra é a quantidade aleatória, menor que a quantidade máxima anteriormente calculada. Utiliza-se esta última para ajudar a impedir a ocorrência de ciclagem entre as execuções dos procedimentos. A ciclagem ocorre quando após um determinado número de iterações da heurística, o algoritmo atinge uma configuração anteriormente visitada.

A quantidade máxima permitida de uma transferência $(\mathrm{q}, \mathrm{i}, \mathrm{t}, \mathrm{tl})$ é dada por:

$$
F_{i, t, 11}=\min \left\{M_{i, t, t 1}, \min _{k=1, \ldots, K}\left\{G_{i, k, 11}\right\}\right\} .
$$

onde $G_{i, k, t l}$ é a quantidade máxima do item i que pode ser transferida para o período tl de tal modo que o Excesso (t) não seja maior que zero.

Pode-se escrever $G_{i, k, t l}$ para um determinado recurso $k$ como,

$$
G_{i, k, t 1}=\left\{\begin{array}{ll}
\frac{J_{k, t 1}}{v_{i k t}} & \text { se } X_{i 1}>0 \\
\frac{J_{k 1}-f_{i k t}}{v_{i k t}} & \text { caso contrário }
\end{array} .\right.
$$


onde $J_{i k \mathfrak{l}}=\mathrm{CAP}_{\mathrm{k} t}-\sum_{\mathrm{i}=1}^{\mathrm{N}}\left(\mathrm{v}_{\mathrm{ikt}} \mathrm{X}_{\mathrm{it}}+\mathrm{f}_{\mathrm{ik} \mathbf{1}} \mathrm{Y}_{\mathrm{it}}\right)$, representando a quantidade de recursos do tipo $\mathrm{k}$ não utilizados no periodo tl.

Como exemplo, considere o plano de produção abaixo com $N=2, T=2$ e $K=1$. Por conveniência, o índice $\mathrm{K}$ será omitido durante a descrição do exemplo.

Seja $f_{i t}$ e $v_{i t}$ constantes no tempo e com valores 60 e 20 (para $f_{i t}$ ) e 2 e 1 (para $v_{i t}$ ) para $\mathrm{i}=1,2$ respectivamente. Considere também $\mathrm{CAP}_{\mathrm{t}}=210$.

\begin{tabular}{|}
\multicolumn{3}{c}{ perfodo } \\
\begin{tabular}{|c|c|c|}
\hline & 1 & 2 \\
\hline 1 & 50 & 30 \\
\hline 2 & 0 & 40 \\
\hline
\end{tabular}
\end{tabular}

A disponibilidade de recursos em cada período é:

$$
\begin{aligned}
& J_{1}=210-[(60 * 1+50 * 2)+0]=210-160=50 . \\
& J_{2}=210-[(60 * 1+30 * 2)+(20+40 * 1)]=210-180=30 .
\end{aligned}
$$

Dessa forma, as quantidades dos itens 1 e 2 que podem ser transferidas para o período 1, sem causar infactibilidade, são:

$$
\begin{aligned}
& \mathrm{G}_{11}=50 / 2=25 \\
& \mathrm{G}_{21}=(50-20) / 1=30 .
\end{aligned}
$$

$\mathrm{E}$ as quantidades que podem ser transferidas para o período 2 são:

$$
\begin{aligned}
& \mathrm{G}_{12}=30 / 2=15 . \\
& \mathrm{G}_{22}=30 / 1=30 .
\end{aligned}
$$

Supondo que as transferências sendo analisadas são $(q, 1,2,1)$, ou seja, transferência do item 1 do período 2 para o perfodo 1. Assim, a quantidade máxima permitida será $F_{1,2,1}=\min \left\{M_{1,2,1}, 25\right\}$. Supondo que $F_{1,2,1}$ tenha sido 25 unidades, as quantidades analisadas para as transferências serão 25 e uma quantidade aleatória entre 0 e 25 .

Para a avaliação dos movimentos, a Razão foi modificada para não aceitar movimentos que piorem o valor da função objetivo, sendo escrita como,

$$
\text { Razão }=\left\{\begin{array}{ll}
\Delta \text { custo } & \text { se } \Delta \text { custo }<0 \\
\infty & \text { caso contrário }
\end{array} .\right.
$$

Como dito anteriormente, o procedimento de melhoria é dividido nos passos Progressivo e Regressivo. 
As transferências no passo Regressivo geralmente causam um aumento no custo total quando não houver transferências de todo o lote. Já no passo Progressivo, há uma chance maior de ocorrer redução nos custos, pois além dos custos de produção e/ou preparação há uma redução nos custos de estoque.

Contudo, em ambos os passos há a possibilidade de não haver transferências candidatas em um determinado período. Isto pode acontecer devido ao estoque de escalão $\left(\mathrm{M}_{\mathrm{i}, \mathrm{l}, \mathrm{l}}=0\right)$ ou porque as transferências não reduzem o valor da função objetivo sem causar infactibilidade. Nesse caso, o próximo período, dentro da lógica do algoritmo, é analisado.

Os dois passos são sucessivamente executados, até que um passo Regressivo e um Progressivo não tenham efetuado nenhuma transferência, terminando com uma solução igual, ou inelhor, do que a inicial.

A seguir são mostrados os pseudo-códigos dos dois passos. 
para $t=T$ até 2 faça

$\mathrm{R}_{\min }=$ Infinito

para $\mathrm{i}=1$ até $\mathrm{N}$ faça

se $\left(X_{i t}>0\right)$ então

para $\mathrm{tl}=\mathrm{t}-1$ até 1 faça

se $\left(q=F_{i, t, 1}=0\right)$ então $t=1 \quad$ (muda para o próximo item

senão

para $\mathrm{k}=0$ até 1 faça

se $(\mathrm{k}=0)$ então $\quad \mathrm{q}=\mathrm{F}_{\mathrm{i}, \mathrm{t}, \mathrm{Il}} \quad$ \{quantidade máxima permitida\}

senão $\quad \mathrm{q}=\mathrm{U}\left[0, \mathrm{~F}_{\mathrm{i}, \mathrm{t}, \mathrm{l}}\right] \quad$ \{quantidade aleatória\}

se $\left(\operatorname{Razão}(q, i, t, t)<R_{\text {min }}\right) \quad$ \{melhor transferência

$\mathrm{q}_{\mathrm{o}}=\mathrm{q}$

$\mathrm{i}_{\mathbf{0}}=\mathrm{i}$

$\mathrm{tl}_{\mathrm{o}}=\mathrm{tl}$

$\mathrm{R}_{\min }=\operatorname{Razão}(\mathrm{q}, \mathrm{i}, \mathrm{t}, \mathrm{tl})$

fim $\left\{\right.$ se $R<R_{\min }$ \}

fim \{para $k\}$

fim \{senão\}

firn $\{$ para tl\}

fim $\{$ se $X>0\}$

fim \{para i\}

se existe $\left(\mathrm{q}_{o}, \mathrm{i}_{o}, t, \mathrm{t}_{\mathrm{o}}\right)$ então efetue a transferência

fim \{para t\} 
- Passo Progressivo de Melhoria

para $t=1$ até $T-1$ faça

$\mathrm{R}_{\min }=$ Infinito

para $\mathrm{i}=1$ até $\mathrm{N}$ faça

se $\left(X_{i t}>0\right)$ então

para $t \mathrm{l}=\mathrm{t}+1$ até $\mathrm{T}$ faça

se $\left(\mathrm{F}_{\mathrm{i}, 1, \mathrm{ll}}=0\right)$ então $\mathrm{tl}=\mathrm{T} \quad$ \{muda para o próximo item

senão

para $\mathrm{k}=0$ até 1 faça

$\begin{array}{llc}\text { se }(\mathrm{k}=0) \text { então } & \mathrm{q}=\mathrm{F}_{\mathrm{i}, \mathrm{l}, \mathrm{ll}} \quad \text { \{quantidade máxima permitida\} } \\ \text { senão } & \mathrm{q}=\mathrm{U}\left[0, \mathrm{~F}_{\mathrm{i}, \mathrm{l}, \mathrm{l}}\right] & \text { \{quantidade aleatória\} }\end{array}$

se $\left(\operatorname{Razão}(q, i, t, t)<R_{\min }\right) \quad$ (melhor transferência\}

$\mathrm{q}_{\mathrm{o}}=\mathrm{q}$

$\mathrm{i}_{\mathrm{o}}=\mathrm{i}$

$\mathrm{tl}_{\mathrm{o}}=\mathrm{tl}$

$R_{\min }=\operatorname{Razão}(q, i, t, t)$

fim \{se $R<R_{\min }$ \}

fim \{para k\}

fim \{senão\}

fim \{para tl\}

fim $\{$ se $X>0\}$

fim \{para i\}

se existe $\left(\mathrm{q}_{0}, \mathrm{i}_{0}, t, \mathrm{tl}_{\mathrm{o}}\right)$ então efetue a transferência

fim \{para t\} 


\subsection{Alteração - Procedimento P4}

O procedimento de alteração (P4) tem como objetivo reconfigurar a solução de modo que ao seu final seja obtido um novo ponto de partida para o procedimento de factibilização (P2). Este procedimento parte de uma solução infactível, permitindo seu término em uma região factível ou não.

É composto de apenas um passo, onde para cada item é efetuada uma transferência $(\mathrm{q}, \mathrm{i}, \mathrm{t}, \mathrm{tl})$. Os períodos $\mathrm{t}$ (período origem) e $\mathrm{tl}$ (período destino) são determinados a partir de uma ordenação prévia dos períodos segundo a quantidade dos recursos não utilizados em cada período. A cada item é feita a tentativa de transferência do periodo mais "apertado" para o mais "folgado" em termos de recursos disponíveis. Posteriormente, será realizada a explicação da ordenação dos períodos.

A partir da ordenação dos períodos t e tl são feitas tentativas de transferência para o item analisado. Aqui não há avaliação dos movimentos candidatos, a primeira transferência possivel, de acordo com a ordem determinada pelo algoritmo, é a executada. Após a execução de uma transferência, o próximo item é analisado. A cada item tenta-se a realização de uma única transferência e, após a análise dos $\mathrm{N}$ itens, o procedimento passa por um teste de parada, que pode ser um determinado número de iterações ou uma medida do grau de infactibilidade da solução.

A seguir é mostrado o pseudo-código do procedimento de alteração. 


\section{- Procedimento de Alteração}

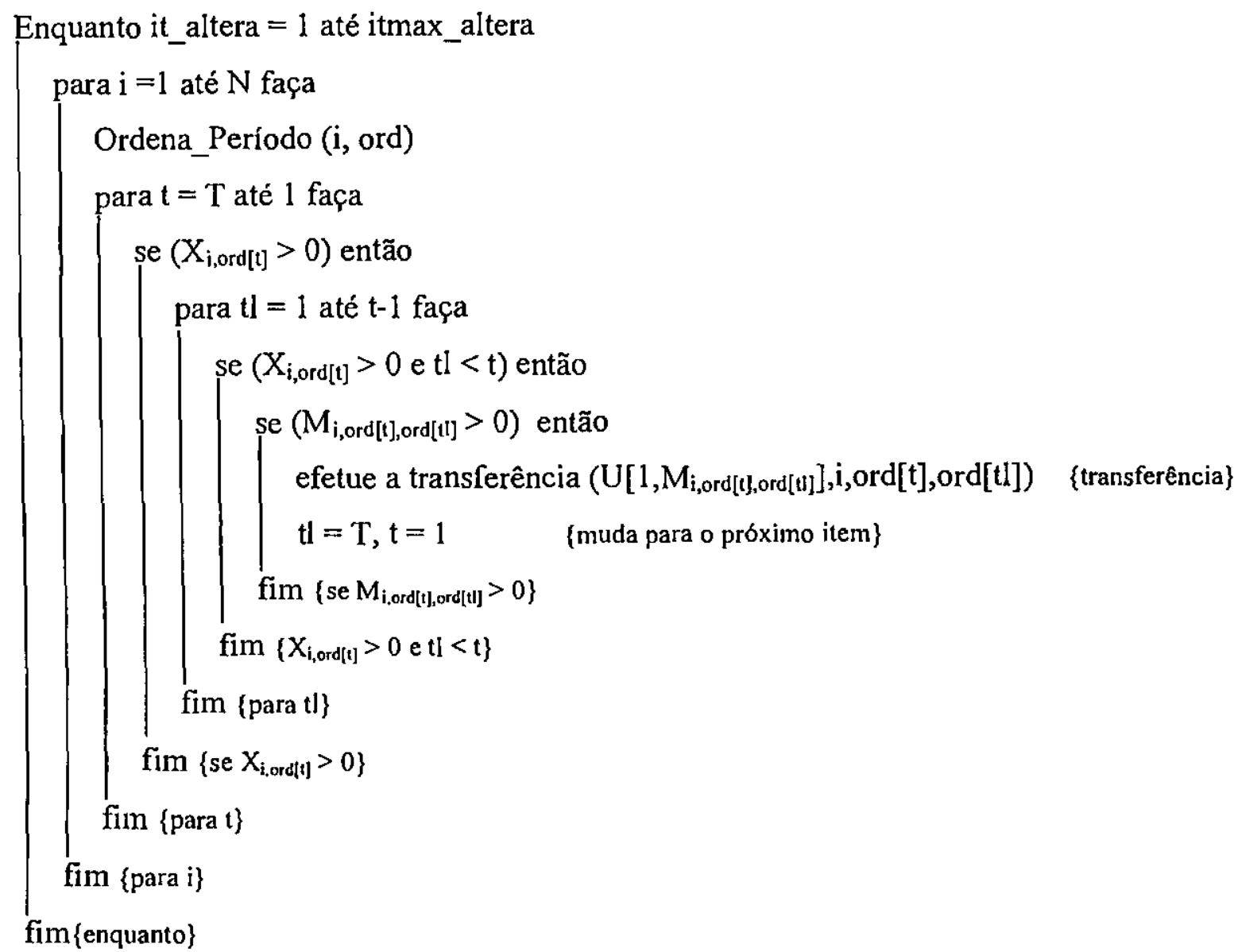


A seguir, é mostrada a explicação da ordenação dos períodos.

\section{Ordena_Período}

Esta função especifica a ordem na qual os períodos são analisados como origem e destino para as transferências. Os períodos ordenados são armazenados em um vetor com nome ord no pseudo-código. A ordenação dos períodos é feita em ordem decrescente em relação à quantidade de recursos não utilizada em cada período, ou seja, da Folga(t) em cada período,

$$
\text { Folga }(t)=\sum_{k=1}^{K}\left[\frac{\operatorname{CAP}_{k t}-\sum_{i=1}^{N}\left(v_{i k t} X_{i t}+f_{i k t} Y_{i t}\right)}{\operatorname{CAP}_{k t}}\right]
$$

Observe que Folga(t) assume tanto valores positivos quanto negativos, no entanto, o mesmo não acontece com Excesso(t), o qual assume somente valores não negativos.

Como exemplo, considere o problema com períodos de produção. Suponha ainda que a Folga(t) calculada por (3.8), em cada um deles seja como mostra a tabela abaixo:

\begin{tabular}{||c|c|c|c|c|c|c||}
\hline \hline$T$ & 1 & 2 & 3 & 4 & 5 & 6 \\
\hline Folga $(\mathrm{t})$ & 10 & -10 & 13 & -5 & -1 & 9 \\
\hline Ord $[\mathrm{t}]$ & 3 & 1 & 6 & 5 & 4 & 2 \\
\hline
\end{tabular}

Note que em ord[t] os períodos são ordenados por ordem decrescente de folga.

No pseudo-código observe que, dado um item, o procedimento tentará as seguintes transferências:

$\mathrm{t}=2$ para $\mathrm{tl}=3$,

$\mathrm{t}=2$ para $\mathrm{tl}=1$,

$\mathrm{t}=2$ para $\mathrm{tl}=6$,

$\mathrm{t}=2$ para $\mathrm{tl}=5$,

$\mathrm{t}=2$ para $\mathrm{tl}=4$,

$\mathrm{t}=4$ para $\mathrm{t}=2$,

e assim por diante. 
Após a execução deste procedimento, a solução obtida provavelmente será infactível. Assim, o procedimento de factibilização é aplicado. Caso seja encontrada uma solução factível (em P2 ou em P4), o procedimento de melhoria é aplicado.

\subsection{Atualização dos Multiplicadores de Lagrange - Procedimento P5}

Este procedimento utiliza a otimização do subgradiente para atualização dos multiplicadores de Lagrange, fornecendo dessa forma novos custos Lagrangianos de produção, preparação e estoque. Estes custos são utilizados para encontrar uma nova solução inicial usando o algoritmo de Wagner e Whitin (1958).

A atualização dos multiplicadores de Lagrange é feita pelo método do subgradiente. Dessa forma, dados os valores iniciais dos multiplicadores de Lagrange, o método de otimização do subgradiente gera uma seqüência de multiplicadores, movendo-se na direção do subgradiente por uma distância dada por um determinado passo.

Os multiplicadores de Lagrange das restrições (1.15) e (1.16) são atualizados de acordo com as equações abaixo:

$$
\begin{aligned}
& \lambda_{i t}^{\prime}=\operatorname{máx}\left\{0 ; \lambda_{i t}^{1-1}+\alpha^{\prime}\left(\sum_{j \in S_{i}} a_{i j} E_{j t}-E_{j t}\right)\right\} \quad i=1, \ldots, N ; t=1, \ldots, T . \\
& \mu_{\mathrm{it}}^{\mathrm{l}}=\operatorname{máx}\left\{0 ; \mu_{\mathrm{it}}^{\mathrm{l}-1}+\alpha^{\prime}\left(\sum_{\mathrm{i}=1}^{\mathrm{N}} \mathrm{v}_{\mathrm{ikt}} \mathrm{X}_{\mathrm{it}}+\mathrm{f}_{\mathrm{ikt}} \mathrm{Y}_{\mathrm{it}}-\mathrm{CAP}_{\mathrm{kt}}\right)\right\} \quad \mathrm{k}=1, \ldots, \mathrm{K} ; \mathrm{t}=1, \ldots, \mathrm{T} \text {. }
\end{aligned}
$$

Neste trabalho, para maximizar a função dual $Z(\lambda, \mu)$, dado por $(2.1)$, com o propósito de obter um limitante inferior, o método do subgradiente é utilizado incorporando as modificações propostas por Camerini et al.(1975), ou seja, o tamanho do passo ( $\left.\alpha^{\prime}\right)$ na iteração 1 é atualizado utilizando as propostas a) e c) do Camerini et al.(1975).

Na proposta a) do Camerini et al.(1975), o tamanho do passo é dado por um valor fixo $\left(\alpha^{\prime}=10^{-5}\right)$.

$\mathrm{Na}$ proposta c), o tamanho do passo $\left(\alpha^{\prime}\right)$ para a atualização dos multiplicadores depende da diferença (gap) entre o valor mínimo da função objetivo, o qual é dado pelo limitante superior e do corrente limitante inferior e da norma euclidiana dos desvios das restrições críticas (no caso, das restrições 1.15 e 1.16), ou seja, 


$$
\alpha^{\prime}=\frac{\text { limitante superior - limitante inf erior }}{\left(\sum_{j \in S_{i}} a_{i j} E_{j t}-E_{j t}\right)^{2}+\left(\sum_{i=1}^{N} v_{i k t} X_{i t}+f_{i k t} Y_{i t}-C A P_{k t}\right)^{2}}
$$

Utilizou-se um limite de iterações pré-fixado do método do subgradiente na tentativa de se obter o melhor limitante inferior.

Deste modo, os multiplicadores de Lagrange são atualizados fornecendo novos custos para o algoritmo de Wagner e Whitin (1958), e assim, a cada iteração da heurística, tem-se uma nova solução inicial.

A seguir é mostrado o pseudo-código do procedimento de atualização dos multiplicadores de Lagrange. 
- Procedimento de Atualização dos Multiplicadores de Lagrange

melhor_limite $=$-Infinito

se (iter $=1)$ então

$\lambda_{t}=0, \mu_{k t}=0$

fim $\{$ se iter $=1\}$

para it=1 até it_max_grad faça

Calc_custo_relaxado

Calc_limite_inferior

se (limite_inferior $>$ melhor_limite) então

melhor_limite $=$ limite_inferior

fim \{limite_inferior $>$ melhor_limite $\}$

se (iter $=$ it_max_grad) então fim

Şenão

Calc_prod

se it $=1$ então

Calc_a

senão Calc_c

fim $\{i t=1\}$

fim \{senăo\}

Atualiza_custos

fim $\{$ it $\}$ 
onde:

- iter: contador de iterações da heurística;

- Calc_custo_relaxado: calcula os custos da função Lagrangiana, ou seja,

$$
\begin{array}{lll}
\left(\mathrm{s}_{\mathrm{it}}+\sum_{\mathrm{k}=1}^{\mathrm{K}} \mu_{\mathrm{kt}} \mathrm{f}_{\mathrm{ikt}}\right) & - & \text { custo Lagrangiano de preparação, } \\
\left(\mathrm{p}_{\mathrm{it}}+\sum_{\mathrm{k}=1}^{\mathrm{K}} \mu_{\mathrm{kt}} \mathrm{v}_{\mathrm{ikt}}\right) & - & \text { custo Lagrangiano de produção, } \\
{\left[\sum_{t=1}^{\mathrm{T}}\left(\mathrm{e}_{\mathrm{it}}-\lambda_{\mathrm{it}}\right)+\sum_{\mathrm{j} \in \mathrm{P}_{\mathrm{i}}} \mathrm{a}_{\mathrm{ji}} \sum_{\mathrm{i}=1}^{\mathrm{T}} \lambda_{\mathrm{jt}}\right]} & - & \text { custo Lagrangiano de estoque de escalão. }
\end{array}
$$

- Calc_limite_inferior: encontra um limite inferior usando o algoritmo de Wagner e Whitin (1958);

- Calc_prod: calcula o produto do gradiente com a direção utilizada na última iteração;

- Calc_a: utiliza a proposta a) do Camerini el al. (1975) para a atualização do $\lambda_{\mathrm{it}}$ e $\mu_{\mathrm{kt}}$;

- Calc_c: utiliza a proposta c) do Camerini el al. (1975) para a atualização do $\lambda_{i t}$ e $\mu_{\mathrm{kt}}$;

- Atualiza_custos: atualiza os custos de produção, preparação e estoque de escalão.

\subsection{Algoritmos das Heurísticas}

Apresenta-se a seguir, o pseudo-código das heurísticas testadas nesse trabalho. A heurística, é composta pelos cinco procedimentos (P1, P2, P3, P4 e P5) descritos anteriormente.

A heurística também foi testada reunindo apenas os procedimentos $\mathrm{P} 1, \mathrm{P} 2, \mathrm{P} 3$ e P5. O que difere esta da anterior é a presença do procedimento de alteração (P4).

Considere:

- iter - contador de iterações;

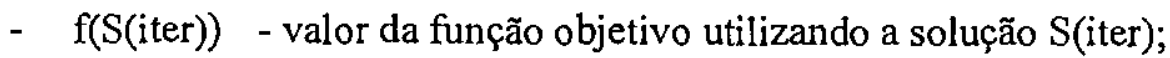

- S* - solução incumbente;

- iter_max - número máximo de iterações da heurística. 
Algoritmo da Heurística utilizando o Procedimento P4

$\mathrm{f}\left(\mathrm{S}^{*}\right)=\infty$

para iter $=1$ até iter_max faça

$S($ iter $)=$ solução de partida $(W W)$

se (S(iter) é infactível) então

$\mathrm{S}($ iter $)=$ Factibilizacão

fim

se (S(iter) é factível) então

$\mathrm{S}($ iter $)=$ Melhoria

se $f(S($ iter $))<f\left(S^{*}\right)$ então $S^{*}=S($ iter $)$

Atualiza_Mult

fim

senão

S(iter) = Alteração

fim

fim \{para iter

Se $S^{*}$ é infactível então o método falhou.

senão $S^{*}$ é a melhor solução encontrada.
$\{$ Procedimento P1\}

\{Procedimento P2\}

\{Procedimento P3\}

\{Procedimento P5\}

\{Procedimento P4\} 
․ Algoritmo da Heurística sem o Procedimento P4

$f\left(S^{*}\right)=\infty$

para iter $=1$ até iter_max faça

$S($ iter $)=$ solução de partida (WW)

\{Procedimento PI\}

se (S(iter) é infactível) então

$\mathrm{S}($ iter $)=$ Factibilizacão $\quad$ \{Procedimento $\mathrm{P} 2$ \}

fim

se (S(iter) é factível) então

$S($ iter $)=$ Melhoria

\{Procedimento P3\}

se $f(S($ iter $))<f\left(S^{*}\right)$ então $S^{*}=S($ iter $)$

fim

Atualiza_Mult

\{Procedimento P5\}

fim \{para iter\}

Se $\mathrm{S}^{*}$ é infactível então o método falhou .

senão S* é a melhor solução encontrada. 
Foram consideradas duas formas diferentes de resolução de ambas heurísticas. Uma das maneiras é a que utilizou-se os custos relaxados nos procedimentos P2 e P3, isto é, com a atualização dos multiplicadores de Lagrange obtêm-sc novos custos Lagrangianos de produção, preparação e estoque que foram utilizados nesses procedimentos. A outra é que foram utilizados os custos originais nos procedimentos P2 e P3.

\section{Comentários:}

- iter_max é o número máximo de iterações para a heurística, ou ainda, um tempo máximo para sua execução. O procedimento de factibilização tem seu próprio contador interno e é finalizado quando um número máximo de itcrações, também definido internamente, é atingido. $O$ procedimento de melhoria termina quando são executados dois passos (um Regressivo e um Progressivo), sem que nenhuma transferência tenha sido executada. $O$ procedimento de alteração é finalizado após itmax_altera iterações. Quando itmax_altera é igual a 1 , o procedimento termina depois de completada a análise dos $\mathrm{N}$ itens. $\mathrm{O}$ procedimento para a atualização dos multiplicadores de Lagrange utiliza a otimização do subgradiente para obter novos custos de produção, preparação e estoque e este possui um contador interno, sendo executado por 30 iterações.

- O procedimento de melhoria é executado apenas quando uma solução factível é encontrada. Enquanto não for encontrada, os procedimcntos de factibilização e alteração são executados sucessivamente até que uma solução factível seja obtida ou o contador $\mathrm{r}$ atinja o limite de iter_max. O procedimento de alteração é executado somente se no procedimento de factibilização não for encontrada uma solução factível. O procedimento de factibilização é aplicado somente quando uma solução infactível é gerada.

- A heurística não garante que uma solução factível seja encontrada. Também não é capaz de identificar se um problema é infactível, isto é, o fato de não ser encontrada uma solução factível até o final da heurística não implica que o problema seja infactível. 


\section{Capítulo 4}

\section{Resultados Computacionais}

\subsection{Introdução}

Neste capítulo são descritos os resultados dos testes computacionais realizados com o objetivo de avaliar os métodos heurísticos apresentados no capítulo anterior.

A comparação dos custos alcançados pelas heurísticas é a principal medida de desempenho. Também utilizamos um limitante inferior obtido pela aplicação de relaxação Lagrangiana, como visto no Capítulo 2, como parâmetro para comparação. Para um grupo de problemas de menor dimensão, os resultados foram comparados com o valor ótimo obtido através do pacote CPLEX, que contém rotinas para a resolução de problemas contendo variáveis inteiras e contínuas através do método Branch and Bound.

As implementações foram realizadas em linguagem $\mathrm{C}$ e os testes foram realizados em um Pentium II $400 \mathrm{MHz}$. Os parâmetros utilizados para a geração dos exemplos numéricos utilizados nos testes computacionais serão descritos detalhadamente a seguir.

\subsection{Geração dos Exemplos Numéricos}

A realização dos testes computacionais foi feita com exemplos numéricos gerados aleatoriamente através de uma distribuição uniforme. Os intervalos de valores utilizados para tal geração estão descritos na tabela abaixo, sendo baseados no trabalho de Berretta (1997). 
Tabela 4.1 - Parâmetros para a geração dos dados dos exemplos.

\begin{tabular}{||c|c|c|c||}
\hline \multicolumn{2}{|c|}{ PARÂMETRO } & INTERVALO & OBSERVAÇÃo \\
\hline custo unitário de produção & $p_{\mathrm{it}}$ & $\mathrm{U}[1.5,2]$ & - \\
\hline \multirow{2}{*}{ custo de preparação } & & $\mathrm{U}[5,95]$ & $\begin{array}{c}\text { custo baixo de } \\
\text { preparação }\end{array}$ \\
\cline { 3 - 5 } & \multirow{2}{*}{$\mathrm{s}_{\mathrm{it}}$} & $\mathrm{U}[50,950]$ & $\begin{array}{c}\text { custo alto de } \\
\text { preparação }\end{array}$ \\
\hline custo de estoque de escalão & $\mathrm{e}_{\mathrm{it}}$ & $\mathrm{U}[0.2,0.4]$ & - \\
\hline recurso unitário para produção & $\mathrm{v}_{\mathrm{ikt}}$ & $\mathrm{U}[150,250]$ & para k=1 \\
\hline recurso para preparação & $\mathrm{f}_{\mathrm{ikt}}$ & $\mathrm{U}[1.5,2.5]$ & para k=1 \\
\hline demanda & \multirow{2}{*}{$\mathrm{d}_{\mathrm{it}}$} & $\mathrm{U}[0,180]$ & para itens finais \\
\cline { 3 - 5 } & & $\mathrm{U}[0,18]$ & para demais itens \\
\hline
\end{tabular}

A quantidade de itens $(\mathrm{N})$ e o número de períodos $(\mathrm{T})$ estão indicados nas tabelas que descrevem cada grupo de exemplos para testes. O parâmetro $\mathrm{a}_{\mathrm{ij}}$ e a quantidade de recursos $(\mathrm{K})$ foram escolhidos serem constantes no valor 1 .

Para a capacidade $\left(\mathrm{CAP}_{\mathrm{t}}\right)$ foram realizados cálculos para que os valores deste parâmetro estejam relacionados com a quantidade de recursos necessários e os valores de demanda gerados.

Inicialmente foi utilizada a solução obtida com a política lote-por-lote, ou seja, para cada período $t$, calcula-se a quantidade de recursos utilizada caso a produção neste período seja exatamente a demanda do período, isto é,

$$
C_{t}=\sum_{i=1}^{N}\left\{\begin{array}{cl}
\left(f_{i t}+v_{i t} D_{i t}\right) & \text { se } D_{i t} \neq 0 \\
0 & \text { caso contrário }
\end{array} t=1, \ldots, T .\right.
$$

A partir desse valor foi calculada uma média de tal modo que a quantidade de um determinado recurso $\mathrm{k}$ em cada período t seja a mesma, isto é,

$$
\mathrm{C}_{\mathrm{t}} \leftarrow \frac{\sum_{\delta \mathrm{a} i}^{\mathrm{T}} \mathrm{C}_{\delta}}{\mathrm{T}} \quad \mathrm{t}=1, \ldots, \mathrm{T} .
$$

Assim, os problemas foram divididos em duas categorias, segundo a disponibilidade de recursos:
$\mathrm{cI}$ : fazendo $\mathrm{CAP}_{\mathbf{t}}=\mathrm{C}_{\mathrm{t}}$
$t=1, \ldots, T$
c2: fazendo $\mathrm{CAP}_{\mathrm{t}}=1.1 * \mathrm{C}_{\mathrm{t}}$
$t=1, \ldots, T$. 
Desta forma, os problemas que consideram cl são os com capacidade que chamamos de normal e os que consideram c2 são os chamados de folgados.

O grupo de exemplos escolhido para teste, é caracterizado por:

- Estruturas de produto consideradas;

- Quantidade de itens ;

- Quantidade de períodos;

- Custos de preparação considerados;

- Quantidade de recursos disponíveis por períodos;

- Quantidade de sementes utilizadas para a geração dos dados.

As estruturas gerais, consideradas neste trabalho, estão descritas nas figuras a seguir.

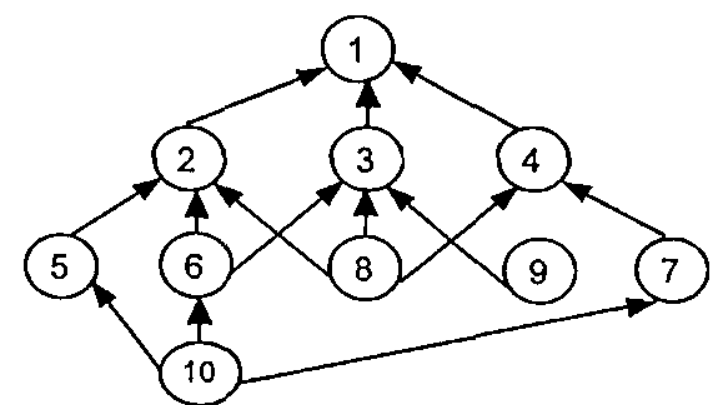

Figura 4.1 - Estrutura de produtos para $\mathrm{N}=10$ encontrada em (Clark, 1990).

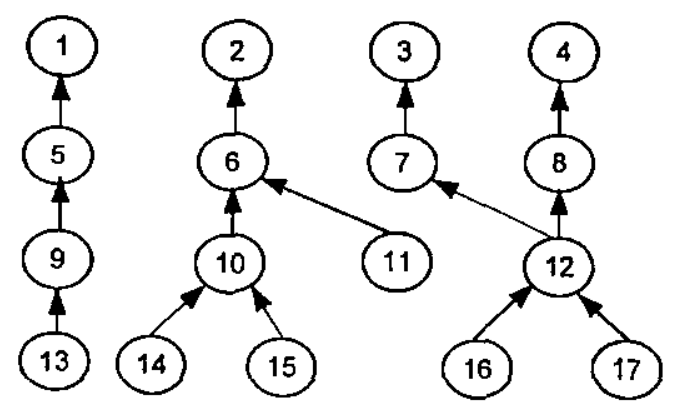

Figura 4.2 - Estrutura de produtos para $\mathrm{N}=17$ (Maes e McClain, 1991). 


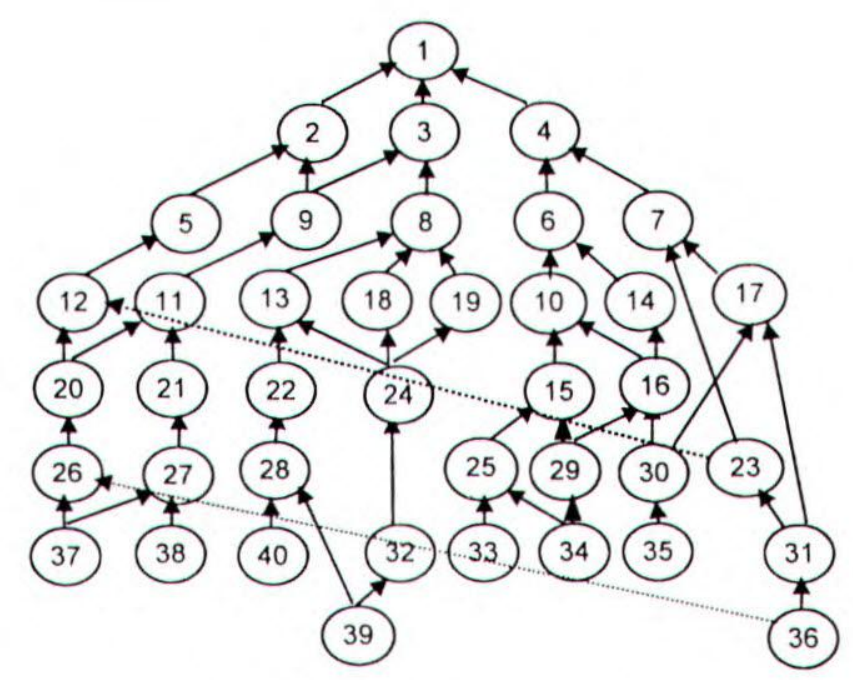

Figura 4.3 - Estrutura de produtos para $\mathrm{N}=40$ encontrada em (Clark, 1990).

As tabelas a seguir (4.2 e 4.3) apresentam os grupos de exemplos gerados para os testes.

Tabela 4.2 - Grupo 1 de exemplos para teste.

\begin{tabular}{||c|c||}
\hline \multicolumn{2}{|c||}{ GRUPO 1 } \\
\hline Estrutura & serial e geral \\
\hline $\mathrm{N}$ & 3,6 e 10 \\
\hline $\mathrm{T}$ & 6 e 12 \\
\hline Custo de preparação & baixo e alto \\
\hline Capacidade disponível & $\mathrm{cl} \mathrm{e} \mathrm{c2}$ \\
\hline Sementes & 5 \\
\hline Total & $\mathbf{2 4 0}$ \\
\hline
\end{tabular}


Tabela 4.3 - Grupo 2 de exemplos para teste.

\begin{tabular}{|c|c|}
\hline \multicolumn{2}{|c|}{ GRUPO 2 } \\
\hline Estrutura & serial e geral \\
\hline $\mathrm{N}$ & $10,17 \mathrm{e} 40$ \\
\hline $\mathrm{T}$ & $12 \mathrm{e} 18$ \\
\hline Custo de preparação & baixo e alto \\
\hline Capacidade disponivel & $\mathrm{cl} \mathrm{e} \mathrm{c2}$ \\
\hline Sementes & 5 \\
\hline Total & $\mathbf{2 4 0}$ \\
\hline
\end{tabular}

\subsection{Algumas Considerações}

Os resultados apresentados são obtidos considerando alguns parâmetros encontrados na heurística. Alguns desses parâmetros são descritos a seguir.

- O procedimento P2 foi executado utilizando um número de ciclos (execução de um passo Regressivo e um Progressivo) igual a 6, ou seja, após a execução de 6 passos Regressivos e Progressivos sem a obtenção de uma solução factível, o procedimento P2 é finalizado. No trabalho de Berretta (1997), através de testes foi observado que um número maior de ciclos não ajuda na obtenção de soluções factíveis em maior quantidade.

- No procedimento P4, o teste de parada utilizado foi uma quantidade máxima de transferências permitida, sendo esta uma quantidade proporcional a quantidade de itens $(\mathrm{N})$.

- No procedimento P5, foram realizadas 30 iterações do método do subgradiente incorporando as modificações propostas por Camerini et al. (1975). Realizaram-se testes utilizando diferentes números de iterações do método do subgradiente, e foi observado que o número de iterações não apresenta influência no valor do limitante inferior do problema.

- O teste de parada utilizado para as heurísticas foi o tempo de execução, sendo este proporcional ao tamanho do exemplo sendo resolvido $\left(\mathrm{N}^{*} \mathrm{~T}\right)$. Os testes apresentados foram executados durante $\mathrm{N}^{*} \mathrm{~T}$ segundos 


\subsection{Resultados das Heurísticas Utilizando o Grupo 1}

A seguir, será apresentada a análise dos resultados das heurísticas utilizando o Grupo 1, ou seja, o grupo de exemplos de dimensão menor. Para a análise dos resultados foi calculada a porcentagem de exemplos onde a heurística consegue obter solução factível. Além disso, para avaliar a qualidade das soluções, calculamos o gap entre o valor obtido pela heurística e um limitante inferior obtido pela aplicação de relaxação Lagrangiana. Será também apresentada a análise da heurística HR2 quanto aos excessos de todas as soluções finais (soluções factíveis e infactíveis) e dos exemplos onde não foi possível encontrar solução factível. Ainda, será apresentada a comparação do valor da solução da heurística com valor o ótimo obtido pelo pacote CPLEX 4.0. A tabela 4.4 descreve estes valores com as respectivas nomenclaturas.

Tabela 4.4 - Descrição das legendas utilizadas para análise dos resultados.

\begin{tabular}{||l|l||}
\hline$\%$ FAC & Porcentagem de exemplos onde foi obtida solução factível. \\
\hline$\%$ GAP & $\begin{array}{l}\text { Média entre os gaps das soluções obtidas, onde gap representa a diferença } \\
\text { percentual entre a solução atingida pela heurística e um limitante inferior obtido } \\
\text { pela aplicação de relaxação Lagrangiana. }\end{array}$ \\
\hline GapO & $\begin{array}{l}\text { Diferença percentual entre a solução atingida pela heurística e valor ótimo obtido } \\
\text { pelo pacote CPLEX. }\end{array}$ \\
\hline
\end{tabular}

A tabela 4.5 descreve a nomenclatura utilizada para cada uma das heurísticas. 
Tabela 4.5 - Descrição da nomenclatura das heurísticas.

\begin{tabular}{||l|l||}
\hline H0 & $\begin{array}{l}\text { Heurística do trabalho de França et al. (1997) composta pelos procedimentos P1, } \\
\text { P2, P3 e P4. }\end{array}$ \\
\hline HR1 & $\begin{array}{l}\text { Heurística composta pelos procedimentos P1, P2, P3, P4 e P5 utilizando os custos } \\
\text { relaxados nos procedimentos P2 e P3. }\end{array}$ \\
\hline HR2 & $\begin{array}{l}\text { Heurística composta pelos procedimentos P1, P2, P3 e P5 utilizando os custos } \\
\text { relaxados nos procedimentos P2 e P3. }\end{array}$ \\
\hline HR3 & $\begin{array}{l}\text { Heurística composta pelos procedimentos P1, P2, P3 P4 e P5 utilizando os custos } \\
\text { originais nos procedimentos P2 e P3. }\end{array}$ \\
\hline HR4 & $\begin{array}{l}\text { Heurística composta pelos procedimentos P1, P2, P3 e P5 utilizando os custos } \\
\text { originais nos procedimentos P2 e P3. }\end{array}$ \\
\hline
\end{tabular}

\subsubsection{Obtenção de Soluções Factíveis}

Os gráficos 4.1 a 4.4 mostram, respectivamente, a porcentagem de exemplos onde foi possível obter pelo menos uma solução factível. Estes resultados estão distribuídos de acordo com a estrutura de produto e número de itens considerando custo baixo e alto de preparação e capacidade normal e folgada.

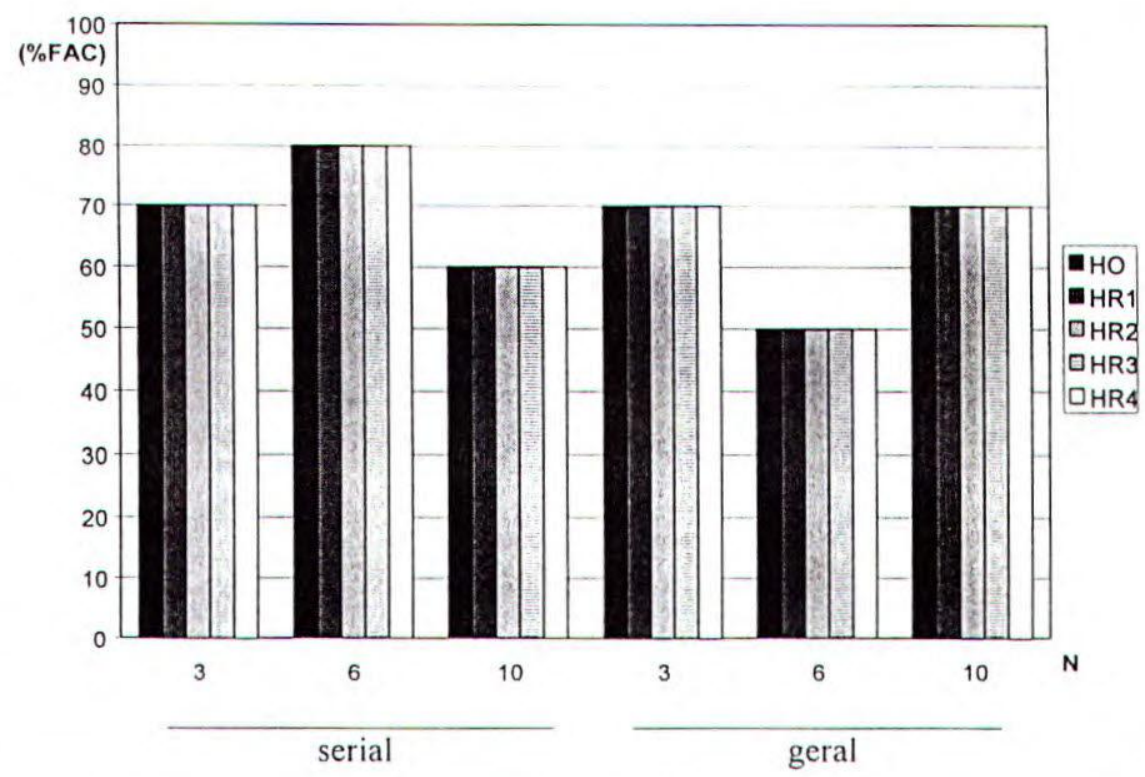

Gráfico 4.1 - Porcentagem de exemplos onde foi atingida solução factível (\%FAC) pelas diferentes heurísticas considerando custo baixo de preparação e capacidade normal. 


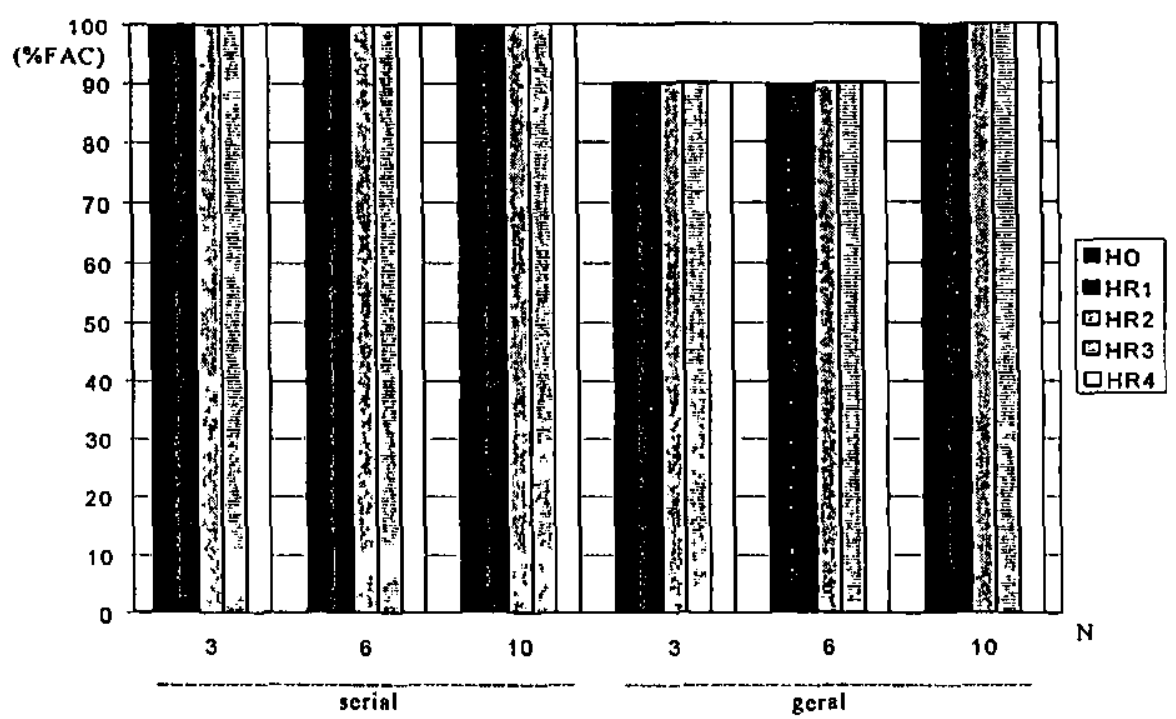

Gráfico 4.2 - Porcentagem de exemplos onde foi atingida solução factivel (\%FAC) pelas diferentes heuristicas considerando custo baixo de preparação e capacidade folgada.

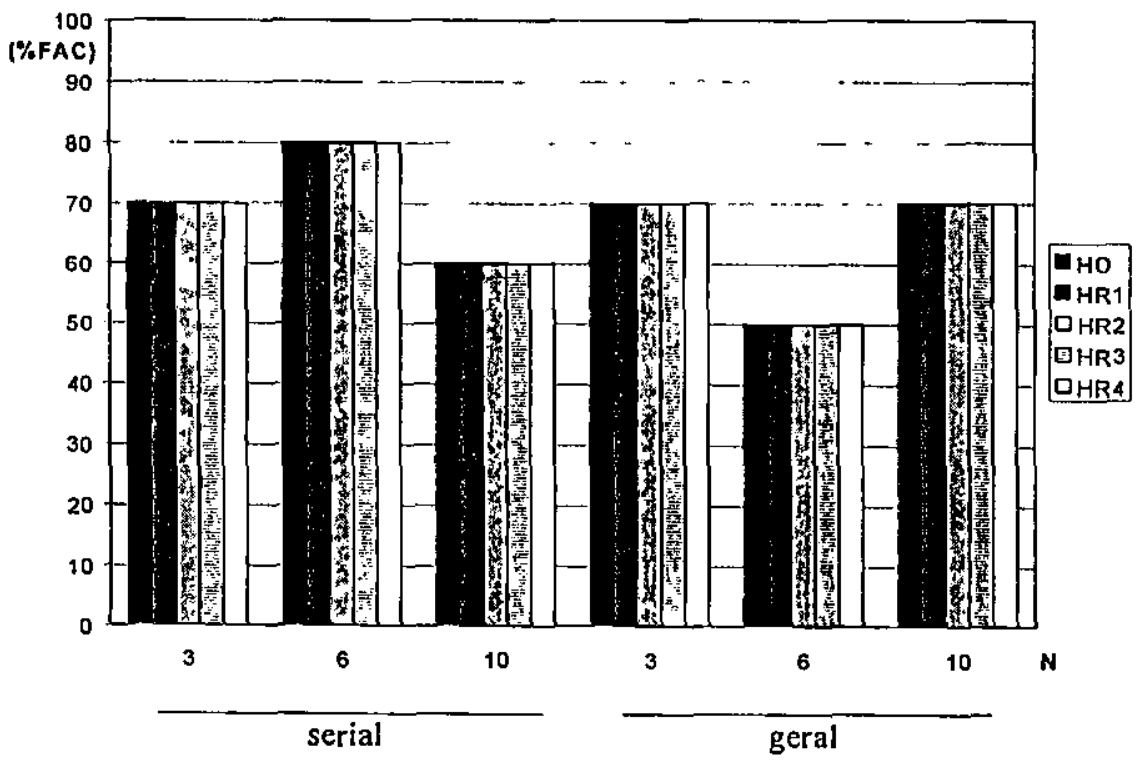

Gráfico 4.3 - Porcentagem de exemplos onde foi atingida solução factivel (\%FAC) pelas diferentes heuristicas considerando custo alto de preparaçăo e capacidade normal. 


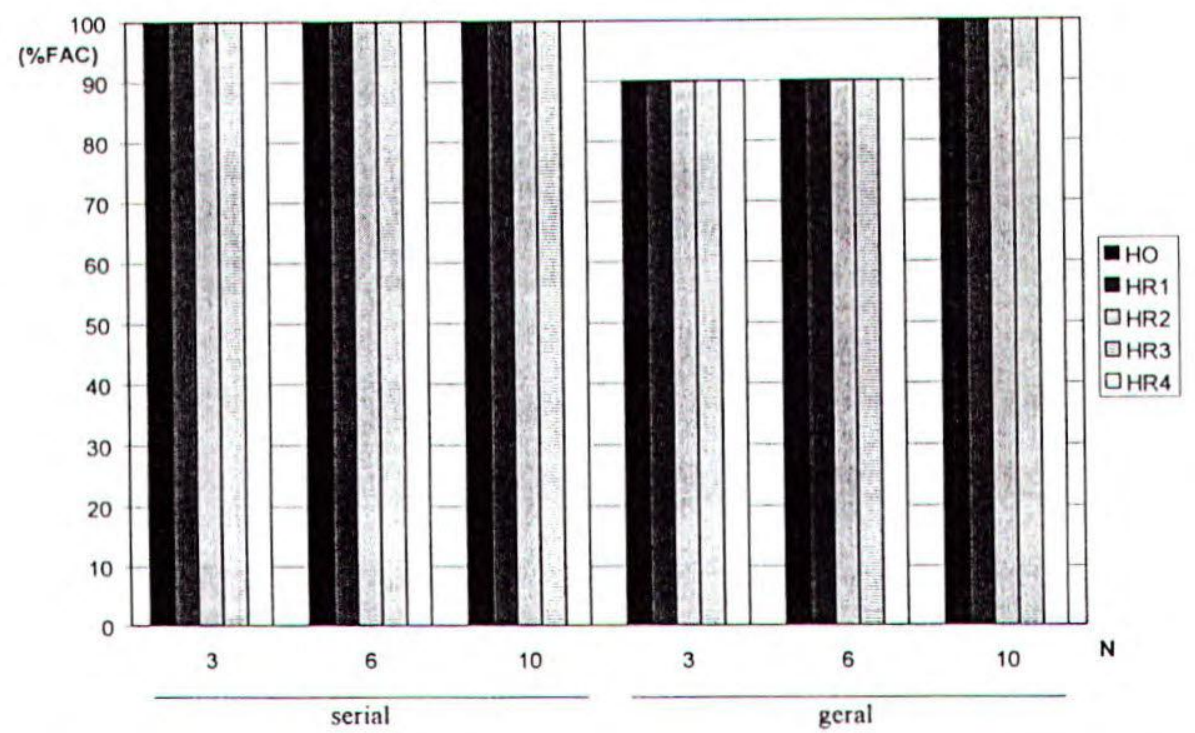

Gráfico 4.4 - Porcentagem de exemplos onde foi atingida solução factivel (\%FAC) pelas diferentes heuristicas considerando custo alto de preparação e capacidade folgada.

Note pelos gráficos 4.1 e 4.3 que todas as heurísticas conseguiram obter a mesma porcentagem de soluções factíveis considerando capacidade normal tanto para custo baixo quanto para custo alto de preparação. O mesmo acontece (gráficos 4.2 e 4.4) considerando capacidade folgada tanto para custo baixo quanto para custo alto de preparação.

Como era esperado, houve um aumento de \%FAC com o aumento da capacidade disponível.

As tabelas 4.6, 4.7, 4.8 e 4.9 indicam a média dos exemplos onde foi possível obter solução factível nas distintas estruturas de produto.

Tabela 4.6 - Porcentagem de exemplos onde foi atingida solução factivel (\%FAC) pelas heurísticas considerando custo baixo de preparação e capacidade normal.

\begin{tabular}{||c|c|c|c|c|c||}
\hline \multirow{2}{*}{ ESTRUTURA } & H0 & HR1 & HR2 & HR3 & HR4 \\
\cline { 2 - 6 } & \%FAC & \%FAC & \%FAC & \%FAC & $\% \mathrm{FAC}$ \\
\hline Serial & 70,0 & 70,0 & 70,0 & 70,0 & 70,0 \\
\hline Geral & 63,3 & 63,3 & 63,3 & 63,3 & 63,3 \\
\hline Média & $\mathbf{6 6 , 7}$ & $\mathbf{6 6 , 7}$ & $\mathbf{6 6 , 7}$ & $\mathbf{6 6 , 7}$ & $\mathbf{6 6 , 7}$ \\
\hline
\end{tabular}


Tabela 4.7 - Porcentagem de exemplos onde foi atingida solução factível (\%FAC) pelas heurísticas considerando custo baixo de preparação e capacidade folgada.

\begin{tabular}{||c|c|c|c|c|c||}
\hline \multirow{2}{*}{ ESTRUTURA } & H0 & HR1 & HR2 & HR3 & HR4 \\
\cline { 2 - 6 } & \%FAC & \%FAC & \%FAC & \%FAC & $\%$ FAC \\
\hline Serial & 100,0 & 100,0 & 100,0 & 100,0 & 100,0 \\
\hline Geral & 93,3 & 93,3 & 93,3 & 93,3 & 93,3 \\
\hline Média & $\mathbf{9 6 , 7}$ & $\mathbf{9 6 , 7}$ & $\mathbf{9 6 , 7}$ & $\mathbf{9 6 , 7}$ & $\mathbf{9 6 , 7}$ \\
\hline
\end{tabular}

Tabela 4.8 - Porcentagem de exemplos onde foi atingida solução factível (\%FAC) pelas heurísticas considerando custo alto de preparação e capacidade normal.

\begin{tabular}{|c|c|c|c|c|c||}
\hline \multirow{2}{*}{ ESTRUTURA } & H0 & HR1 & HR2 & HR3 & HR4 \\
\cline { 2 - 6 } & \%FAC & \%FAC & \%FAC & \%FAC & \%FAC \\
\hline Serial & 70,0 & 70,0 & 70,0 & 70,0 & 70,0 \\
\hline Geral & 63,3 & 63,3 & 63,3 & 63,3 & 63,3 \\
\hline Média & $\mathbf{6 6 , 7}$ & $\mathbf{6 6 , 7}$ & $\mathbf{6 6 , 7}$ & $\mathbf{6 6 , 7}$ & $\mathbf{6 6 , 7}$ \\
\hline
\end{tabular}

Tabela 4.9 - Porcentagem de exemplos onde foi atingida solução factível (\%FAC) pelas heurísticas considerando custo alto de preparação e capacidade folgada.

\begin{tabular}{|c|c|c|c|c|c||}
\hline \multirow{2}{*}{ ESTRUTURA } & H0 & HR1 & HR2 & HR3 & HR4 \\
\cline { 2 - 6 } & \%FAC & \%FAC & \%FAC & \%FAC & \%FAC \\
\hline Serial & 100,0 & 100,0 & 100,0 & 100,0 & 100,0 \\
\hline Geral & 93,3 & 93,3 & 93,3 & 93,3 & 93,3 \\
\hline Média & $\mathbf{9 6 , 7}$ & $\mathbf{9 6 , 7}$ & $\mathbf{9 6 , 7}$ & $\mathbf{9 6 , 7}$ & $\mathbf{9 6 , 7}$ \\
\hline
\end{tabular}

Pelas tabelas acima pode-se concluir que as heurísticas para os exemplos com estrutura serial conseguiram obter uma porcentagem maior de soluções factíveis em relação aos exemplos com estrutura geral tanto para custo baixo e alto de preparação quanto para capacidade normal e folgada. Como dito anteriormente, como esperado, para capacidade folgada a porcentagem de soluções factíveis para ambas estruturas foi maior do que para capacidade normal. 


\subsubsection{Qualidade das Soluções}

Nesta seção, é mostrada a qualidade do custo das soluções das heurísticas. Os gráficos 4.5, 4.6, 4.7 e 4.8 mostram, respectivamente, o valor médio dos gaps obtidos agrupados por quantidade de itens e estrutura de produto. Vale ressaltar que os gaps foram calculados apenas nos exemplos onde as heurísticas conseguem obter pelo menos uma solução factível.

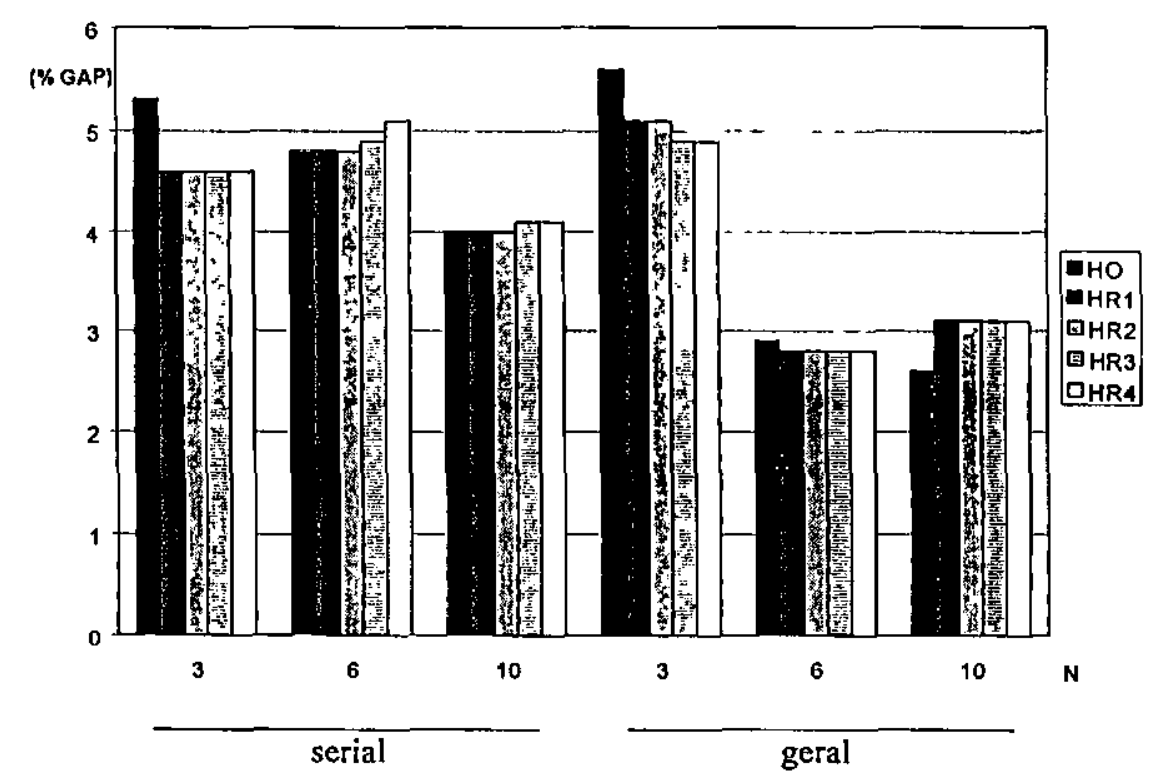

Gráfico 4.5 - Qualidade das soluções obtidas (\%GAP) pelas diferentes heurísticas considerando custo baixo de preparaçāo e capacidade normal.

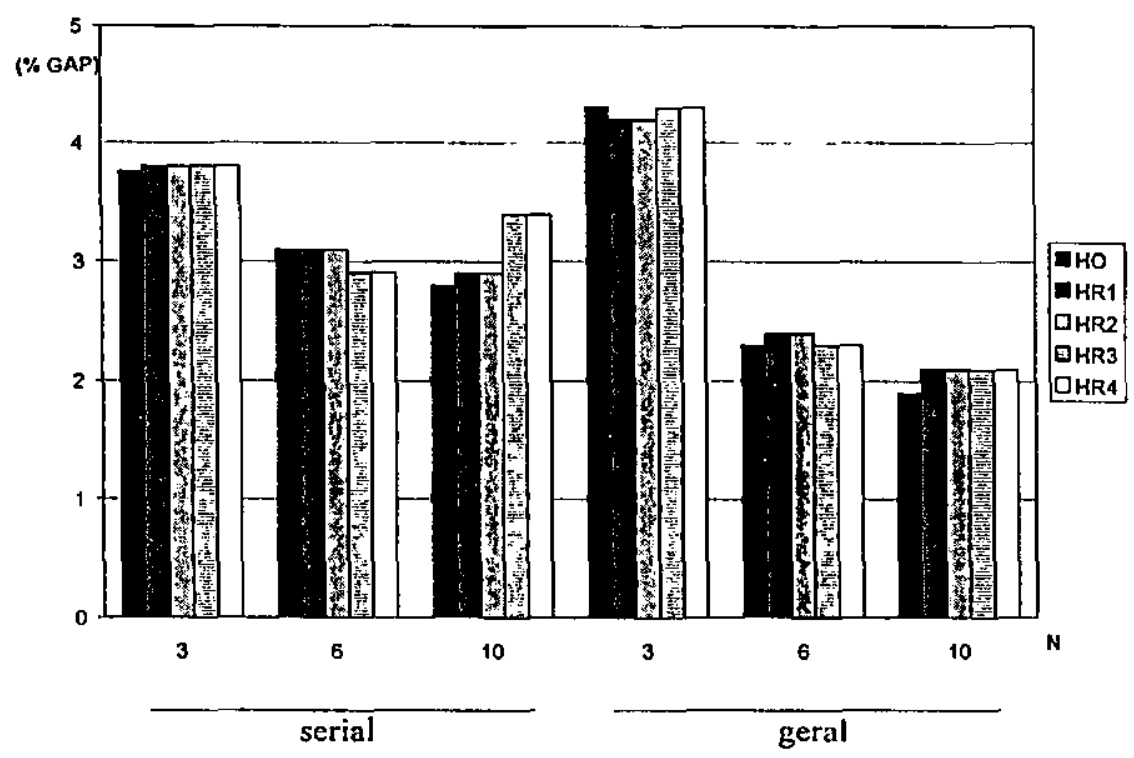

Gráfico 4.6 - Qualidade das soluções obtidas (\%GAP) pelas diferentes heurísticas considerando custo baixo de preparação e capacidade folgada. 


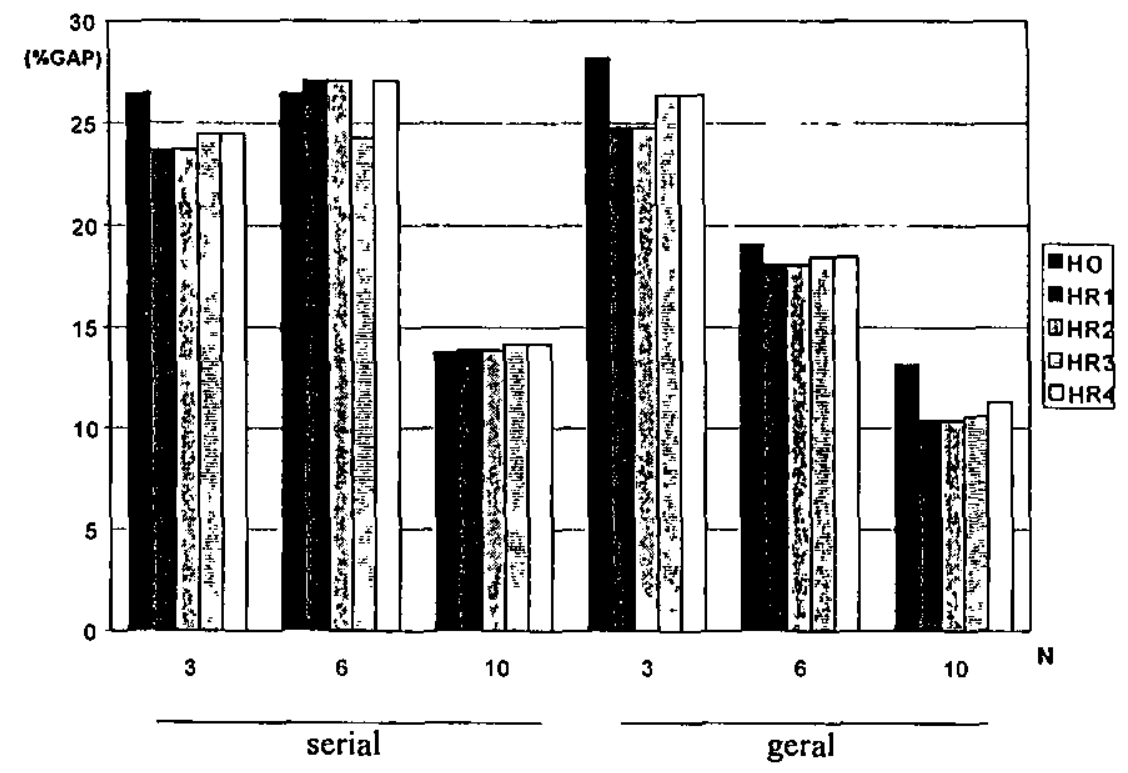

Gráfico 4.7-Qualidade das soluçø̃es obtidas (\%GAP) pelas diferentes heuristicas considerando custo alto de preparação e capacidade normal.

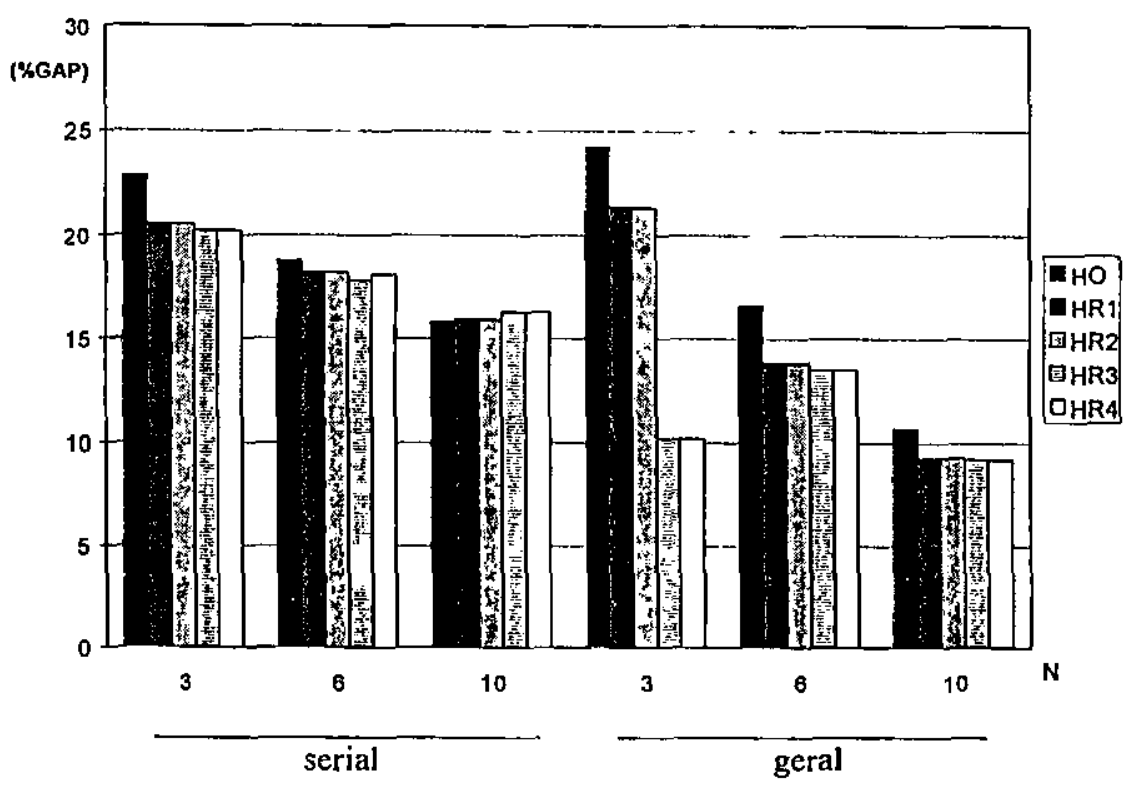

Gráfico 4.8 - Qualidade das soluções obtidas (\%GAP) pelas diferentes heurísticas considerando custo alto de prepa ração e capacidade folgada. 
As tabelas abaixo apresentam o gap médio em cada uma das estruturas.

Tabela 4.10 - Qualidade das soluções obtidas (\%GAP) pelas diferentes heuristicas considerando custo baixo de preparação e capacidade normal.

\begin{tabular}{||c|c|c|c|c|c|c||}
\hline \multirow{2}{*}{ ESTRUTURA } & \multirow{2}{*}{$\% \mathrm{FAC}$} & $\mathrm{H} 0$ & $\mathrm{HR} 1$ & HR2 & HR3 & HR4 \\
\cline { 3 - 7 } & & \%GAP & \%GAP & \%GAP & \%GAP & \%GAP \\
\hline Serial & 70,0 & 4,7 & 4,4 & 4,4 & 4,6 & 4,7 \\
\hline Geral & 63,3 & 3,7 & 3,7 & 3,7 & 3,6 & 3,6 \\
\hline Média & $\mathbf{6 6 , 7}$ & $\mathbf{4 , 2}$ & $\mathbf{4 , 1}$ & $\mathbf{4 , 1}$ & $\mathbf{4 , 1}$ & $\mathbf{4 , 2}$ \\
\hline
\end{tabular}

Tabela 4.11 - Qualidade das soluçð̃es obtidas (\%GAP) pelas diferentes heurísticas considerando custo baixo de preparação e capacidade folgada.

\begin{tabular}{||c|c|c|c|c|c|c||}
\hline \multirow{2}{*}{ ESTRUTURA } & \multirow{2}{*}{ \%FAC } & H0 & HR1 & HR2 & HR3 & HR4 \\
\cline { 3 - 7 } & & \%GAP & \%GAP & \%GAP & \%GAP & \%GAP \\
\hline Serial & 100,0 & 3,2 & 3,2 & 3,2 & 3,4 & 3,4 \\
\hline Geral & 93,3 & 2,8 & 2,8 & 2,8 & 2,8 & 2,9 \\
\hline Média & $\mathbf{9 6 , 7}$ & $\mathbf{3 , 0}$ & $\mathbf{3 , 0}$ & $\mathbf{3 , 0}$ & $\mathbf{3 , 1}$ & $\mathbf{3 , 2}$ \\
\hline
\end{tabular}

Tabela 4.12 - Qualidade das soluções obtidas (\%GAP) pelas diferentes heurísticas considerando custo alto de preparação e capacidade normal.

\begin{tabular}{||c|c|c|c|c|c|c||}
\hline \multirow{2}{*}{ ESTRUTURA } & \multirow{2}{*}{$\%$ FAC } & H0 & HR1 & HR2 & HR3 & HR4 \\
\cline { 3 - 7 } & & \%GAP & \%GAP & \%GAP & \%GAP & \%GAP \\
\hline Serial & 70,0 & 22,8 & 22,0 & 22,0 & 21,4 & 22,4 \\
\hline Geral & 63,3 & 20,3 & 17,7 & 17,7 & 18,4 & 18,7 \\
\hline Média & $\mathbf{6 6 , 7}$ & $\mathbf{2 1 , 6}$ & $\mathbf{1 9 , 9}$ & $\mathbf{1 9 , 9}$ & $\mathbf{1 9 , 9}$ & $\mathbf{2 0 , 6}$ \\
\hline
\end{tabular}


Tabela 4.13 - Qualidade das soluções obtidas (\%GAP) pelas diferentes heuristicas considerando custo alto de preparação e capacidade folgada.

\begin{tabular}{|c|c|c|c|c|c|c|}
\hline \multirow{2}{*}{ ESTRUTURA } & \multirow{2}{*}{$\% \mathrm{FAC}$} & $\mathrm{H} 0$ & $\mathrm{HR} 1$ & HR2 & HR3 & HR4 \\
\cline { 3 - 7 } & & $\% \mathrm{GAP}$ & \%GAP & \%GAP & \%GAP & $\% \mathrm{GAP}$ \\
\hline Serial & 100,0 & 19,1 & 18,2 & 18,2 & 18,1 & 18,2 \\
\hline Geral & 93,3 & 16,6 & 14,4 & 14,4 & 14,7 & 14,7 \\
\hline Média & $\mathbf{9 6 , 7}$ & $\mathbf{1 7 , 9}$ & $\mathbf{1 6 , 3}$ & $\mathbf{1 6 , 3}$ & $\mathbf{1 6 , 4}$ & $\mathbf{1 6 , 5}$ \\
\hline
\end{tabular}

Considerando custo baixo de preparação, observe pelo gráfico 4.5 , que para 3 itens tanto para estrutura serial quanto estrutura geral, a qualidade dos custos das heurísticas foram melhores comparado a H0. Para estrutura geral e 6 itens, todas as heurísticas também apresentaram melhores soluções em relação a H0. Pelo gráfico 4.6 note que para estrutura serial e 6 itens, as heuristicas HR3 e HR4 apresentaram melhores soluções. Já para estrutura geral e 3 itens a qualidade dos custos das heurísticas HR1 e HR2 foram melhores comparado a Ho.

No entanto, considerando custo alto de preparação, note pelo gráfico 4.7 , que para estrutura geral, todas as heurísticas apresentaram melhores soluções comparadas a H0. Pelo gráfico 4.8, observe que para estrutura geral a qualidade dos custos foi consideravelmente melhor em relação a $\mathrm{H} 0$ principalmente para 3 itens considerando as heurísticas HR3 e HR4. Para estrutura serial, também foi possível obter melhores soluções para 3 e 6 itens em relação a H0.

Pelas tabelas 4.10 ressalta-se que em média as heurísticas HRI, HR2 e HR3 foram ligeiramente melhores do que a H0. Pela tabela 4.11, observa-se que as heurísticas estudadas neste trabalho apresentaram os mesmos resultados em relação a H0. Já pelas tabelas $4.12 \mathrm{e}$ 4.13, observa-se que considerando custo alto de preparação tanto para capacidade normal quanto para folgada, as heurísticas HRI, HR2, HR3 e HR4 apresentaram resultados melhores do que a $\mathrm{H} 0$ para as distintas estruturas de produto.

Pelos resultados obtidos, pode-se dizer que a incorporação das informações do problema Lagrangiano ajudou a melhorar a qualidade das soluções. No entanto, esses resultados não apresentaram diferenças relevantes quanto a inclusão ou não do procedimento P4 e da consideração ou não de custos relaxados nos procedimentos utilizados.

É importante ressaltar que os valores dos gaps calculados são comparados com o limitante inferior e assim, os resultados apresentados podem ser melhores do que os números 
indicam, ou seja, o valor do limitante inferior pode incorporar um gap de dualidade do problema. Além disso, esse gap de dualidade pode ser diferente para distintas estruturas de produto e dessa forma, comparar gaps médios de diferentes estruturas pode levar a conclusões erradas.

Na próxima seção será feita a comparação dos resultados obtidos pela heurística com o valor ótimo obtido pelo pacote CPLEX, o qual justificará a afirmação do parágrafo anterior.

\subsubsection{Análise de Alguns Resultados Utilizando a Heurística HR2}

Nesta seção será apresentada a análise de resultados utilizando a heurística HR2. Será apresentada a análise dos excessos nos exemplos onde não foi possível encontrar solução factível. A seguir, será apresentada a comparação do resultado da heurística com o resultado ótimo utilizando para isto o pacote CPLEX 4.0.

\subsubsection{Análise dos Excessos}

Quando o programa encontra uma solução infactível, o mesmo informa qual a melhor solução infactível encontrada, onde "melhor" pode significar a solução com menor excesso médio ou a solução como menor excesso máximo encontrado em um período. Assim, temos a informação da melhor solução em relação ao excesso médio e em relação ao excesso máximo.

A seguir, são apresentados os resultados da heurística HR2 de acordo com a estrutura de produto e custo de preparação. $\mathrm{Na}$ tabela 4.14 são analisadas todas as soluções finais. Dessa forma, a média está sendo realizada com as soluções factíveis e infactíveis. Na tabela 4.15 a análise é feita apenas com os exemplos onde não foi possível encontrar solução factível e nesta tabela têm-se algumas linhas em branco, pois em todos os exemplos foi possível encontrar pelo menos uma solução factível.

Será utilizada a seguinte notação nas tabelas a seguir (tabelas 4.14 e 4.15):

Exc - excesso médio por período.

Exc_max - o maior excesso encontrado em um período.

Exc_T - porcentagem de períodos com excesso. 
Tabela 4.14 - Média dos excessos da heuristica nas soluçoes factf́veis e infactlveis.

\begin{tabular}{|c|c|c|c|c|c|c|c|c|c|c|c|c|}
\hline \multirow[t]{2}{*}{ Estrutura } & \multirow{2}{*}{$\begin{array}{l}\text { Custo de } \\
\text { Preparação }\end{array}$} & \multirow[t]{2}{*}{ CAP } & \multirow[t]{2}{*}{$\%$ FAC } & \multicolumn{3}{|c|}{ Antes } & \multicolumn{3}{|c|}{$\begin{array}{c}\text { Melhor Excesso } \\
\text { Médio }\end{array}$} & \multicolumn{3}{|c|}{$\begin{array}{l}\text { Melhor Excesso } \\
\text { Máximo }\end{array}$} \\
\hline & & & & Exc & Exc_max & Exc_T & Exc & Exc_max & Exc_T & Exc & Exc_max & Exc_T \\
\hline \multirow{4}{*}{ serial } & \multirow{2}{*}{ baixo } & $\mathrm{cl}$ & 70,0 & 16,8 & 86,7 & 0,4 & 0,9 & 7,9 & 0,1 & 1,3 & 5,9 & 0,1 \\
\hline & & $c 2$ & 100,0 & 8,2 & 36,5 & 0,4 & 0,0 & 0,0 & 0,0 & 0,0 & 0,0 & 0,0 \\
\hline & \multirow{2}{*}{ alto } & $\mathrm{cl}$ & 70,0 & 24,7 & 159,7 & 0,3 & 1,1 & 9,7 & 0,1 & 1,5 & 6,6 & 0,1 \\
\hline & & $c 2$ & 100,0 & 20,0 & 117,1 & 0,2 & 0,0 & 0,0 & 0,0 & 0,0 & 0,0 & 0,0 \\
\hline \multirow{4}{*}{ geral } & \multirow{2}{*}{ baixo } & $\mathrm{cl}$ & 63,3 & 21,7 & 105,1 & 0,4 & 1,6 & 11,9 & 0,1 & 1,8 & 11,3 & 0,1 \\
\hline & & c2 & 93,3 & 13,0 & 55,6 & 0,4 & 0,1 & 1,1 & 0,0 & 0,1 & 1,0 & 0,0 \\
\hline & \multirow{2}{*}{ alto } & $\mathrm{c} 1$ & 63,3 & 32,8 & 205,1 & 0,3 & 1,9 & 13,5 & 0,1 & 2,0 & 11,0 & 0,1 \\
\hline & & $c 2$ & 93,3 & 25,5 & 144,3 & 0,3 & 0,3 & 2,5 & 0,0 & 0,3 & 2,5 & 0,0 \\
\hline
\end{tabular}

Tabela 4.15 - Média dos excessos da heurística nas soluções infactlveis.

\begin{tabular}{|c|c|c|c|c|c|c|c|c|c|c|c|c|}
\hline \multirow[t]{2}{*}{ Estrutura } & \multirow{2}{*}{$\begin{array}{c}\text { Custo de } \\
\text { Preparação }\end{array}$} & \multirow[t]{2}{*}{ CAP } & \multirow[t]{2}{*}{$\% F A C$} & \multicolumn{3}{|c|}{ Antes } & \multicolumn{3}{|c|}{$\begin{array}{c}\text { Melhor Excesso } \\
\text { Médio }\end{array}$} & \multicolumn{3}{|c|}{ Melhor Excesso Máximo } \\
\hline & & & & Exc & Exc_max & Exc_T & Exc & Exc_ma & Exc_T & Exc & Exc_max & Exc_T \\
\hline \multirow{2}{*}{ serial } & baixo & $\begin{array}{l}\mathrm{cl} \\
\mathrm{c} 2\end{array}$ & $\begin{array}{c}70,0 \\
100,0\end{array}$ & 20,9 & 133,5 & 0,3 & 3,4 & 32,0 & 0,2 & 5,1 & 22,6 & 0,4 \\
\hline & alto & $\begin{array}{l}\mathrm{c} 1 \\
\mathrm{c} 2\end{array}$ & $\begin{array}{c}70,0 \\
100,0\end{array}$ & 25,0 & 163,8 & 0,3 & 3,4 & 30,5 & 0,2 & 4,5 & 22,9 & 0,3 \\
\hline \multirow{2}{*}{ geral } & baixo & $\begin{array}{l}\mathrm{cl} \\
\mathrm{c} 2\end{array}$ & $\begin{array}{l}63,3 \\
93,3\end{array}$ & $\begin{array}{c}27,6 \\
6,1\end{array}$ & $\begin{array}{r}162,3 \\
28,3\end{array}$ & $\begin{array}{l}0,3 \\
0,1\end{array}$ & $\begin{array}{l}4,1 \\
0,5\end{array}$ & $\begin{array}{c}30,1 \\
5,7\end{array}$ & $\begin{array}{l}0,2 \\
0,1\end{array}$ & $\begin{array}{l}4,8 \\
0,7\end{array}$ & $\begin{array}{r}28,5 \\
4,8\end{array}$ & $\begin{array}{l}0,2 \\
0,1\end{array}$ \\
\hline & alto & $\begin{array}{l}\mathrm{cl} \\
\mathrm{c} 2\end{array}$ & $\begin{array}{l}63,3 \\
93,3\end{array}$ & $\begin{array}{r}33,4 \\
7,4\end{array}$ & $\begin{array}{c}194,0 \\
38,5\end{array}$ & $\begin{array}{l}0,3 \\
0,1\end{array}$ & $\begin{array}{l}5,3 \\
1,7\end{array}$ & $\begin{array}{r}34,2 \\
12,5\end{array}$ & $\begin{array}{l}0,2 \\
0,1\end{array}$ & $\begin{array}{l}5,5 \\
1,7\end{array}$ & $\begin{array}{l}28,5 \\
12,5\end{array}$ & $\begin{array}{l}0,3 \\
0,1\end{array}$ \\
\hline
\end{tabular}


A heurística quando não encontra solução factível informa duas soluçбes factíveis para posterior análise, melhor excesso médio e menor excesso máximo.

Na tabela 4.14 considerando estrutura serial, custo baixo de preparação e capacidade $\mathrm{cl}$ e analisando o melhor excesso médio temos inicialmente $16,8 \%$ de excesso médio com $0,4 \%$ de períodos infactíveis ( $86,7 \%$ de excesso máximo) e terminamos com $0,9 \%$ de excesso médio em $0,1 \%$ dos períodos infacíveis ( $7,9 \%$ de excesso máximo). Se analisarmos apenas os exemplos onde não foi possível encontrar solução factível na tabela 4.15 , temos $20,9 \%$ de excesso médio com $0,3 \%$ de períodos infactíveis (133,5\% de excesso máximo) inicialmente e terminamos com $3,4 \%$ de excesso médio com $0,2 \%$ de períodos infactíveis $(32 \%$ de excesso máximo). Observe que a solução infactível pode ter excesso máximo muito alto. Note que o excesso máximo foi consideravelmente reduzido (de 133,5\% para 32\%).

Se analisarmos a solução infactível com o menor excesso máximo encontrado, temos na tabela 4.14 considerando estrutura serial, custo baixo de preparação e capacidade $\mathrm{cl}$, um excesso médio final um pouco maior $(1,3 \%)$, mas um excesso máximo final de $5,9 \%$. Observe que o excesso máximo foi reduzido de 7,9\% para 5,9\%. Nos exemplos onde não foi encontrada solução factível (tabela 4.15), o excesso máximo final encontrado foi de $22,6 \%$ com $0,4 \%$ de períodos infactíveis e na solução com melhor excesso médio temos $32 \%$ de excesso máximo com $0,2 \%$ de períodos infactíveis.

\subsubsection{Resultados Utilizando o CPLEX}

O pacote CPLEX contém rotinas para a resolução de problemas contendo variáveis inteiras e contínuas, através do método Branch and Bound.

Nesta seção, são feitas comparações entre o resultados da heurística HR2 com a solução ótima. O grupo de exemplos utilizado para teste foi de parte do Grupo 1, sendo composto de 160 exemplos agrupados como mostra a tabela abaixo. 
Tabela 4.16 - Descrição dos exemplos gerados para teste.

\begin{tabular}{||c|c||}
\hline Estrutura & serial e geral \\
\hline $\mathrm{N} \times \mathrm{T}$ & $3 \times 6,3 \times 12,6 \times 6 \mathrm{e} 10 \times 6$ \\
\hline Custo de preparação (setup) & baixo e alto \\
\hline Capacidade disponível & $\mathrm{cl} \mathrm{e} \mathrm{c2}$ \\
\hline Sementes & 5 \\
\hline Total & $\mathbf{1 6 0}$ \\
\hline
\end{tabular}

Os resultados obtidos são mostrados nas tabelas 4.17 e 4.18, onde GapO é a diferença percentual de custo entre a heurística e o ótimo, e GapL é o gap de custo da heurística comparando com o limitante inferior lagrangiano, isto é,

$$
\begin{gathered}
\text { GapO }=\left(\frac{\text { custo da heurística }- \text { custo da solução ótima }}{\text { custo da solução ótima }}\right) * 100 \\
\text { GapL }=\left(\frac{\text { custo da heurística - valor do limitante inferior }}{\text { valor do limitante inferior }}\right) * 100 .
\end{gathered}
$$

Os resultados onde aparece o símbolo * indica que o CPLEX foi executado de tal forma que a solução obtida tenha tolerância de $1 \%$ para o ótimo.

Foi possível obter solução ótima através do CPLEX em 136 exemplos dos 160, ou seja, não foi possível obter solução ótima em 24 exemplos. 
Tabela 4.17 - Gaps para problemas com estrutura serial.

\begin{tabular}{|c|c|c|c|c|c|c|c|c|c|}
\hline \multirow{2}{*}{$\begin{array}{l}\text { Custo de } \\
\text { Preparação }\end{array}$} & \multirow{2}{*}{ Capacidade } & \multicolumn{2}{|c|}{$3 \times 6$} & \multicolumn{2}{|c|}{$3 \times 12$} & \multicolumn{2}{|c|}{$6 \times 6$} & \multicolumn{2}{|c|}{$10 \times 6$} \\
\hline & & GapL & GapO & GapL & GapO & GapL & GapO & GapL & GapO \\
\hline \multirow{12}{*}{ Baixo } & \multirow{5}{*}{$\mathrm{c} 1$} & - & - & 3,8 & 0,0 & 7,1 & 4,6 & 4,0 & 1,6 \\
\hline & & - & - & - & - & 5,7 & 1,5 & - & - \\
\hline & & 2,2 & 0,0 & 4,1 & 0,1 & - & - & - & - \\
\hline & & 4,9 & 0,2 & 5,1 & $0,6^{*}$ & 5,1 & 0,0 & 1,6 & 0,0 \\
\hline & & 5,4 & 0,0 & 6,8 & 1,5 & 3,4 & 0,6 & 6,0 & 0,9 \\
\hline & Média & 4,2 & 0,1 & 5,0 & 0,6 & 5,3 & 1,7 & 3,9 & 0,8 \\
\hline & \multirow{5}{*}{ c2 } & 2,4 & 0,1 & 3,8 & 0,5 & 1,7 & 0,0 & 0,9 & 0,2 \\
\hline & & 4,8 & 0,5 & 4,3 & 1,1 & 4,8 & 1,8 & 1,3 & 0,1 \\
\hline & & 1,7 & 0,0 & 3,4 & 0,0 & 0,7 & 0,3 & 4,0 & 0,5 \\
\hline & & 3,7 & 0,4 & 3,3 & $0,5^{*}$ & 3,4 & 0,4 & 1,6 & 0,0 \\
\hline & & 4,9 & 1,4 & 5,8 & 1,1 & 2,4 & 0,7 & 5,6 & 1,0 \\
\hline & Média & 3,5 & 0,5 & 4,1 & 0,8 & 2,6 & 0,6 & 2,7 & 0,4 \\
\hline \multirow{12}{*}{ Alto } & \multirow{5}{*}{$\mathrm{cl}$} & - & - & 14,3 & 0,0 & 32,6 & 19,6 & 11,5 & 0,1 \\
\hline & & - & - & - & - & 26,0 & 0,0 & - & - \\
\hline & & 20,3 & 4,1 & 32,6 & 6,6 & - & - & - & - \\
\hline & & 35,7 & 3,5 & 18,8 & 1,0 & 42,4 & 0,0 & 11,7 & 0,2 \\
\hline & & 24,8 & 3,3 & 15,1 & 0,0 & 14,1 & 2,0 & 9,8 & 3,5 \\
\hline & Média & 26,9 & 3,6 & 20,2 & 1,9 & 28,8 & 5,2 & 11,0 & 1,3 \\
\hline & \multirow{5}{*}{ c2 } & 26,8 & 0,9 & 11,1 & 0,0 & 17,4 & 0,0 & 10,8 & 0,4 \\
\hline & & 51,4 & 3,7 & 16,4 & $0,9^{*}$ & 15,1 & 3,8 & 25,7 & 0,9 \\
\hline & & 16,5 & 0,0 & 13,7 & 0,0 & 12,7 & 0,0 & 33,2 & 0,0 \\
\hline & & 17,5 & 0,0 & 14,1 & 1,8 & 20,9 & 0,6 & 9,6 & 3,6 \\
\hline & & 21,4 & 6,1 & 15,4 & 0,0 & 15,2 & 1,0 & 10,5 & 3,6 \\
\hline & Média & 26,7 & 2,1 & 14,1 & 0,5 & 16,3 & 1,1 & 18,0 & 1,7 \\
\hline
\end{tabular}


Tabela 4.18 - Gaps para problemas com estrutura geral.

\begin{tabular}{|c|c|c|c|c|c|c|c|c|c|}
\hline \multirow{2}{*}{$\begin{array}{l}\text { Custo de } \\
\text { Preparação }\end{array}$} & \multirow{2}{*}{ Capacidade } & \multicolumn{2}{|c|}{$3 \times 6$} & \multicolumn{2}{|c|}{$3 \times 12$} & \multicolumn{2}{|c|}{$6 \times 6$} & \multicolumn{2}{|c|}{$10 \times 6$} \\
\hline & & GapL & GapO & GapL & GapO & GapL & GapO & GapL & GapO \\
\hline \multirow{12}{*}{ Baixo } & \multirow{5}{*}{$\mathrm{cl}$} & - & - & 4,6 & 0,0 & - & - & 2,0 & 0,6 \\
\hline & & - & - & - & - & 1,9 & 0,1 & - & - \\
\hline & & 3,7 & 0,0 & 4,9 & 0,3 & - & - & 2,0 & 0,0 \\
\hline & & 5,8 & 1,1 & 5,0 & 0,5 & 1,4 & 0,3 & 4,6 & 1,0 \\
\hline & & 5,1 & 0,0 & 6,5 & 0,2 & 3,0 & 0,3 & 3,0 & 1,2 \\
\hline & Média & 4,9 & 0,4 & 5,3 & 0,3 & 2,1 & 0,2 & 2,9 & 0,7 \\
\hline & \multirow{5}{*}{$\mathrm{c} 2$} & - & - & 3,4 & 0,1 & 3,3 & 0,3 & 0,8 & 0,4 \\
\hline & & 4,2 & 0,4 & 3,2 & 0,2 & 2,1 & 0,8 & 1,6 & 0,7 \\
\hline & & 3,7 & 0,0 & 4,2 & $0,1^{*}$ & 1,0 & 0,2 & 1,8 & $0,2^{*}$ \\
\hline & & 4,1 & 0,3 & 4,1 & $1,0^{*}$ & 1,1 & 0,2 & 4,4 & $1,2^{*}$ \\
\hline & & 4,9 & 0,1 & 6,0 & $0,3^{*}$ & 3,0 & 1,2 & 1,7 & $0,5^{*}$ \\
\hline & Média & 4,2 & 0,2 & 4,2 & 0,3 & 2,1 & 0,5 & 2,1 & 0,6 \\
\hline \multirow{12}{*}{ Alto } & \multirow{5}{*}{$\mathrm{cl}$} & - & - & 22,1 & 0,6 & - & - & 8,4 & $1,0^{*}$ \\
\hline & & - & - & - & - & 26,2 & 3,8 & - & - \\
\hline & & 21,7 & 0,0 & 26,5 & 1,9 & - & - & 9,7 & $2,1^{*}$ \\
\hline & & 36,3 & 0,4 & 19,1 & $0,6^{*}$ & 20,5 & 2,8 & 4,7 & 0,0 \\
\hline & & 23,2 & 1,5 & 22,3 & $0,7^{*}$ & 22,7 & 0,9 & 8,9 & $1,9^{*}$ \\
\hline & Média & 27,1 & 0,6 & 22,5 & 1,0 & 23,1 & 2,5 & 7,9 & 1,3 \\
\hline & \multirow{5}{*}{$c 2$} & - & - & 15,9 & $3,1^{*}$ & 10,9 & 0,0 & 7,4 & $2,1^{*}$ \\
\hline & & 38,7 & 0,1 & 18,7 & $0,0^{*}$ & 15,4 & 2,6 & 12,0 & $3,1^{*}$ \\
\hline & & 24,2 & 3,3 & 21,4 & $0,0^{*}$ & 10,2 & 1,5 & 8,4 & $1,9^{*}$ \\
\hline & & 17,4 & 1,2 & 12,6 & 1,6 & 15,6 & 2,4 & 6,9 & 1,8 \\
\hline & & 19,2 & 3,9 & 19,4 & $1,1^{*}$ & 16,4 & 0,0 & 8,0 & 1,6 \\
\hline & Média & 24,9 & 2,1 & 17,6 & 1,2 & 13,7 & 1,3 & 8,5 & 2,1 \\
\hline
\end{tabular}


$\mathrm{Na}$ tabela 4.17 , note que para o problema $3 \times 6 \mathrm{com}$ capacidade $\mathrm{cl}$ e custo baixo de preparação, a média do GapO é $0,1 \%$ e do GapL é de $4,2 \%$, ou seja, a heurística encontrou na média o valor muito próximo do ótimo para estes problemas. Para os problemas $3 \times 12,10 \times 6$, GapO é na média em torno de $1 \%$ enquanto o GapL é de quase $5 \%$. Para capacidade c2, os GapO são em torno de $1 \%$ para todos os problemas enquanto o GapL é em torno de 4\%. Já para custo alto de preparação tanto para c1 quanto para c2, os GapL são bem maiores (em torno de $30 \%$ ) e os GapO são em torno de 5\%. Observa-se que $3 \times 12$ com capacidade c2 o GapO é de $0,6 \%$ enquanto o GapL é de $14,1 \%$, o que indica que na média os valores encontrados pela heurística foram muito próximos do ótimo.

Para os problemas com estrutura geral com custo baixo de preparação a heurística atinge resultados em torno de $0,5 \%$ do valor ótimo enquanto o GapL fica em torno de $5 \%$. Para problemas com custo alto de preparação o GapL é um pouco maior, mas na média alguns problemas apresentam GapO em torno de $1 \%$ e outros em torno de 2,5\% (tabela 4.18 ), o que mostra que a heurística conseguiu obter bons resultados.

Na tabela a seguir, apresenta-se um resumo dos resultados onde Io significa o número de exemplos onde a solução ótima foi obtida pelo CPLEX.

Tabela 4.19 - Resumo dos resultados.

\begin{tabular}{||c|c|c|c|cc||}
\hline \hline \multirow{3}{*}{ Estrutura } & $\begin{array}{c}\text { Custo de } \\
\text { Preparação }\end{array}$ & Capacidade & Io & GapL & GapO \\
\hline \multirow{3}{*}{ serial } & baixo & $\mathrm{cl}$ & $15 / 20$ & 4,6 & 0,8 \\
& alto & & $15 / 20$ & 21,7 & 3,0 \\
\cline { 2 - 6 } & baixo & $\mathrm{c} 2$ & $20 / 20$ & 3,2 & 0,6 \\
& alto & & $20 / 20$ & 18,8 & 1,4 \\
\hline \multirow{3}{*}{ geral } & baixo & c1 & $14 / 20$ & 3,8 & 0,4 \\
& alto & & $14 / 20$ & 20,2 & 1,1 \\
\cline { 2 - 6 } & baixo & c2 & $19 / 20$ & 3,2 & 0,4 \\
& alto & $19 / 20$ & 16,2 & 1,7 \\
\hline \multicolumn{1}{|c|}{ Média } & $\mathbf{1 3 6 / 1 6 0}$ & $\mathbf{1 1 , 5}$ & $\mathbf{1 , 2}$ \\
\hline
\end{tabular}


Pelas tabelas $4.17,4.18$, nas quais são apresentados os resultados para estrutura serial e geral, e pela tabela 4.19 observou-se que a partir de comparações feitas com o valor ótimo, o valor obtido pela heurística é melhor do que os números indicaram até agora. Pela tabela 4.19, observa-se que nestes 136 exemplos, dos $11,5 \%$ de GapL, 10,5 desses pontos são relativos a um gap de dualidade e a solução está verdadeiramente a 1,2\% do ótimo. Portanto, pode-se dizer que os valores dos gaps mostrados até o momento são bem melhores do que os indicados.

\subsection{Resultados das Heurísticas Utilizando o Grupo 2}

A seguir, serão apresentados os resultados das heurísticas utilizando o Grupo 2. Para sua análise, como feito para o Grupo 1 , foi calculada a porcentagem de exemplos onde a heurística consegue obter solução factível. Ainda, para avaliar a qualidade das soluções, é calculado o gap entre o valor obtido pela heurística e um limitante inferior obtido pela aplicação de relaxação Lagrangiana. Será também apresentada a análise da heurística HR2 quanto aos excessos de todas as soluções finais (soluções factíveis e infactíveis) e dos exemplos onde não foi possível encontrar solução factível. Também será mostrada a evolução da solução incumbente durante a execução da heurística e finalmente, o ganho obtido nos valores dos custos da heurística H0 e HR2.

\subsubsection{Obtenção de Soluções Factíveis}

Nesta seção será mostrado o resultado obtido com as heurísticas testadas, sendo analisada a obtenção de soluções factíveis. Para a análise dos resultados foi calculada a porcentagem de exemplos onde as heurísticas conseguem obter soluções factíveis.

Na seção 4.2 está descrita a geração de exemplos para teste, onde utilizou-se o Grupo 2 , composto de 240 exemplos. 


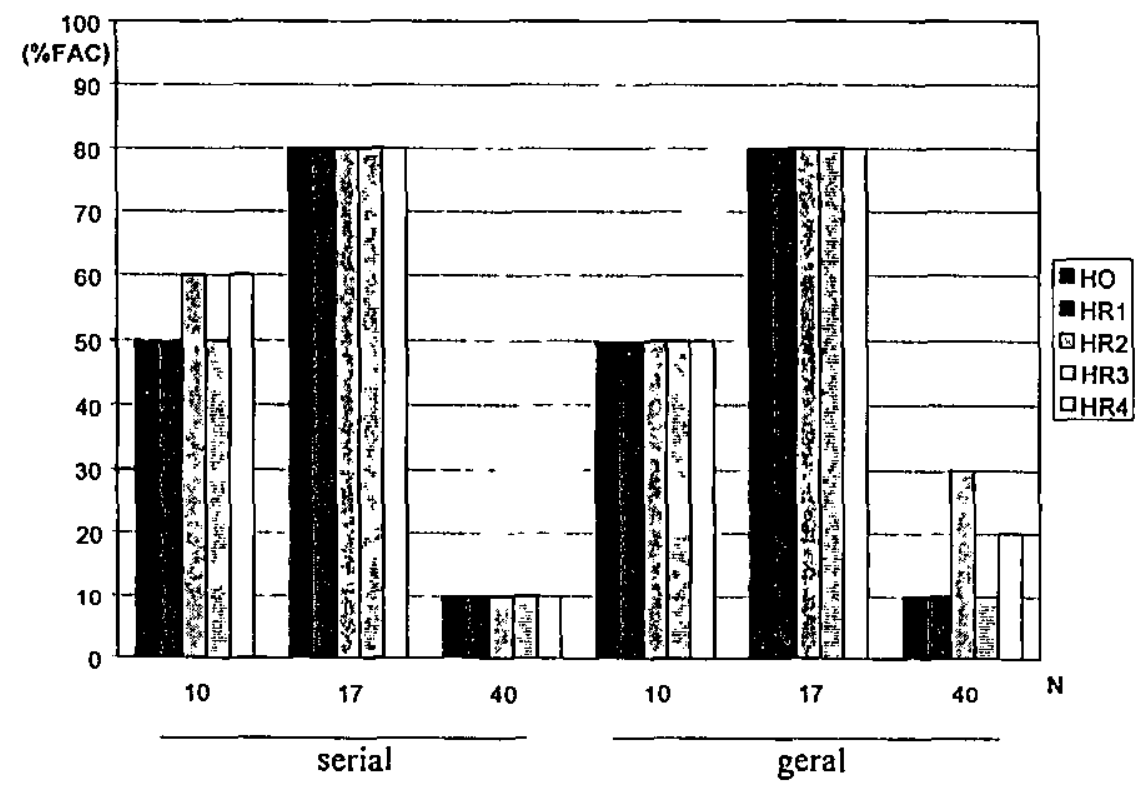

Gráfico 4.9 - Porcentagem de exemplos onde foi atingida solução factivel (\%FAC) pelas heurísticas considerando custo baixo de preparação e capacidade normal.

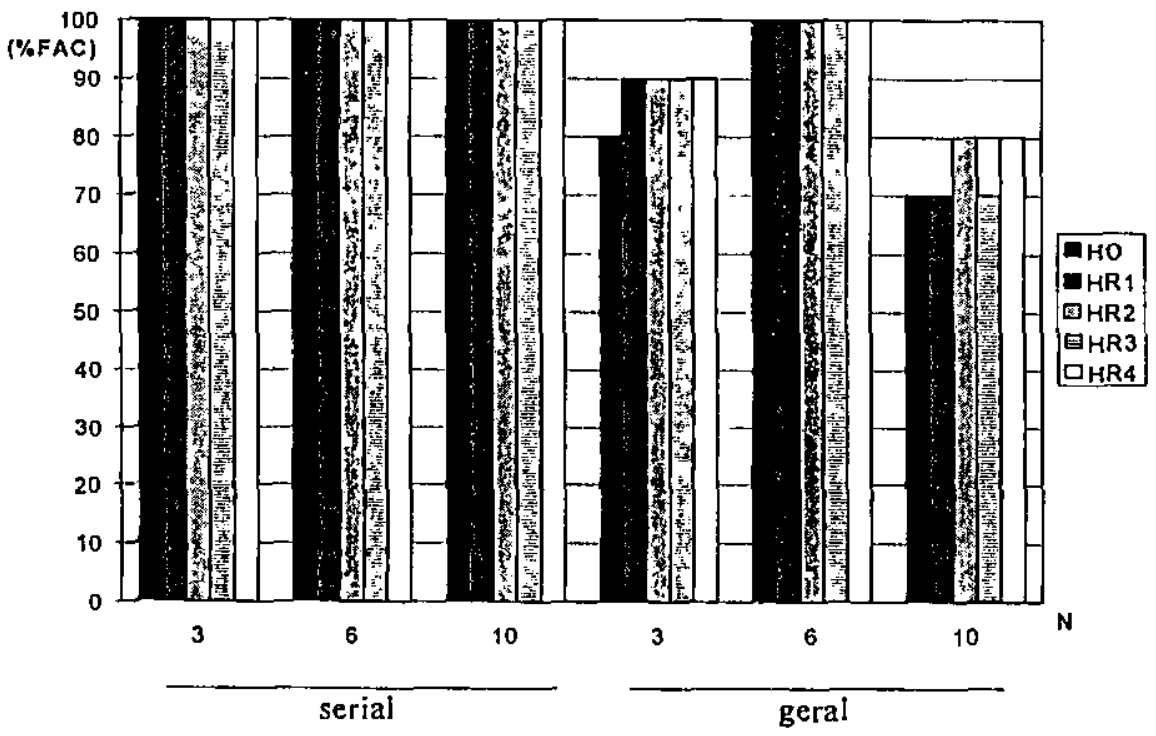

Gráfico 4.10 - Porcentagem de exemplos onde foi atingida solução factível (\%FAC) pelas heurísticas considerando custo baixo de preparação e capacidade folgada. 


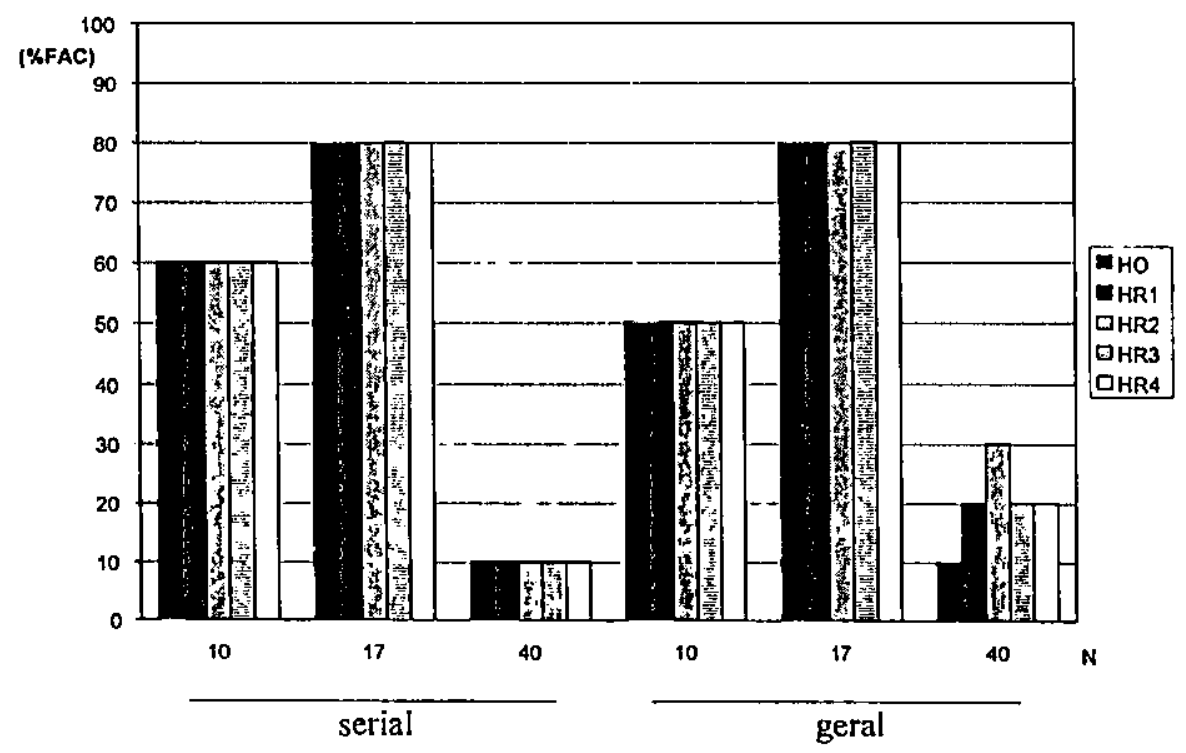

Gráfico 4.11 - Porcentagem de exemplos onde foi atingida solução factível (\%FAC) pelas heuristicas considerando custo alto de preparação e capacidade normal.

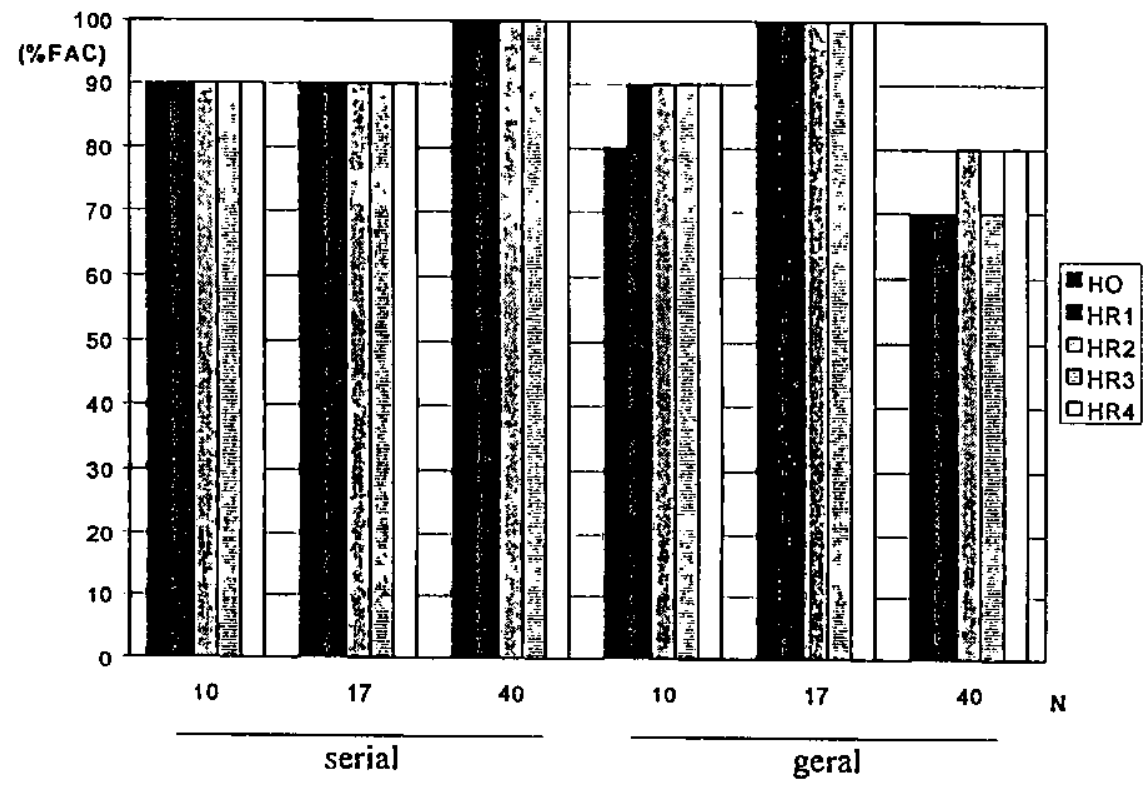

Gráfico 4.12 - Porcentagem de exemplos onde foi atingida solução factível (\%FAC) pelas heurísticas considerando custo alto de preparação e capacidade folgada. 
Os gráficos 4.9 a 4.12 mostram, a porcentagem de exemplos onde foi possível obter solução factível, sendo agrupados por quantidade de item e estrutura de produto.

Em relação a H0, observe pelo gráfico 4.9 que as heurísticas HR2 e HR4 conseguiram obter um número maior de soluções factíveis para 10 itens e estrutura serial e, 40 itens e estrutura geral. Pelo gráfico 4.11, observe que o mesmo acontece com 40 itens e estrutura geral. Considerando custo alto de preparação (gráficos 4.10 e 4.12) note que as heurísticas estudadas neste trabalho conseguiram obter um número maior de soluções factíveis para $10 \mathrm{e}$ 40 itens.

Em geral, pode-se dizer que a heurística HR2 conseguiu obter uma porcentagem maior de soluções factiveis entre todas as heurísticas aqui apresentadas.

As tabelas abaixo mostram respectivamente, a média por estrutura de \%FAC.

Tabela 4.20 - Porcentagem de exemplos onde foi atingida solução factível (\%FAC) pelas heurísticas considerando custo baixo de preparação e capacidade normal.

\begin{tabular}{||c|c|c|c|c|c||}
\hline \multirow{2}{*}{ ESTRUTURA } & H0 & HR1 & HR2 & HR3 & HR4 \\
\cline { 2 - 6 } & \%FAC & \%FAC & \%FAC & \%FAC & \%FAC \\
\hline Serial & 46,7 & 46,7 & 50,0 & 46,7 & 50,0 \\
\hline Geral & 46,7 & 46,7 & 53,3 & 46,7 & 50,0 \\
\hline Média & $\mathbf{4 6 , 7}$ & $\mathbf{4 6 , 7}$ & $\mathbf{5 1 , 7}$ & $\mathbf{4 6 , 7}$ & $\mathbf{5 0 , 0}$ \\
\hline
\end{tabular}

Tabela 4.21 - Porcentagem de exemplos onde foi atingida solução factível (\%FAC) pelas heurísticas considerando custo baixo de preparação e capacidade folgada.

\begin{tabular}{||c|c|c|c|c|c||}
\hline \multirow{2}{*}{ ESTRUTURA } & H0 & HR1 & HR2 & HR3 & HR4 \\
\cline { 2 - 6 } & \%FAC & \%FAC & \%FAC & \%FAC & \%FAC \\
\hline Serial & 93,3 & 93,3 & 93,3 & 93,3 & 93,3 \\
\hline Geral & 83,3 & 86,7 & 90,0 & 86,7 & 90,0 \\
\hline Média & $\mathbf{8 8 , 3}$ & $\mathbf{9 0 , 0}$ & $\mathbf{9 1 , 7}$ & $\mathbf{9 0 , 0}$ & $\mathbf{9 1 , 7}$ \\
\hline
\end{tabular}


Tabela 4.22 - Porcentagem de exemplos onde foi atingida solução factível (\%FAC) pelas heurísticas considerando custo alto de preparação e capacidade normal.

\begin{tabular}{||c|c|c|c|c|c||}
\hline \hline \multirow{2}{*}{ ESTRUTURA } & H0 & HR1 & HR2 & HR3 & HR4 \\
\cline { 2 - 6 } & \%FAC & \%FAC & \%FAC & \%FAC & $\% \mathrm{FAC}$ \\
\hline Serial & 50,0 & 50,0 & 50,0 & 50,0 & 50,0 \\
\hline Geral & 46,7 & 50,0 & 53,3 & 50,0 & 50,0 \\
\hline Média & $\mathbf{4 8 , 4}$ & $\mathbf{5 0 , 0}$ & $\mathbf{5 1 , 7}$ & $\mathbf{5 0 , 0}$ & $\mathbf{5 0 , 0}$ \\
\hline
\end{tabular}

Tabela 4.23 - Porcentagem de exemplos onde foi atingida solução factível (\%FAC) pelas heurísticas considerando custo alto de preparação e capacidade folgada.

\begin{tabular}{||c|c|c|c|c|c||}
\hline \multirow{2}{*}{ ESTRUTURA } & H0 & HR1 & HR2 & HR3 & HR4 \\
\cline { 2 - 6 } & \%FAC & \%FAC & \%FAC & \%FAC & \%FAC \\
\hline Serial & 93,3 & 93,3 & 93,3 & 93,3 & 93,3 \\
\hline Geral & 83,3 & 86,7 & 90,0 & 86,7 & 90,0 \\
\hline Média & $\mathbf{8 8 , 3}$ & $\mathbf{9 0 , 0}$ & $\mathbf{9 1 , 7}$ & $\mathbf{9 0 , 0}$ & $\mathbf{9 1 , 7}$ \\
\hline
\end{tabular}

Pelas tabelas acima (4.20 a 4.23) pode-se concluir que a estrutura serial conseguiu obter uma porcentagem maior de soluções factíveis em relação à estrutura geral para custo alto de preparação tanto para capacidade normal quanto para folgada $\mathrm{O}$ mesmo acontece para custo baixo de preparação e capacidade folgada. Como dito anteriormente, para capacidade folgada, como esperado, a porcentagem de soluções factíveis para ambas estruturas foram maior do que para capacidade normal.

Ressalta-se que entre todas as heurísticas estudadas neste trabalho, a heurística HR2 conseguiu obter um número maior de soluções factíveis, principalmente para estrutura geral com custo alto e baixo de preparação.

\subsubsection{Qualidade das Soluções Obtidas}

Nesta seção, é mostrada a qualidade do custo das soluções das heurísticas. Os gráficos $4.13,4.14,4.15$ e 4.16 mostram, respectivamente, o valor médio dos gaps obtidos agrupados por quantidade de itens e estrutura de produto. 


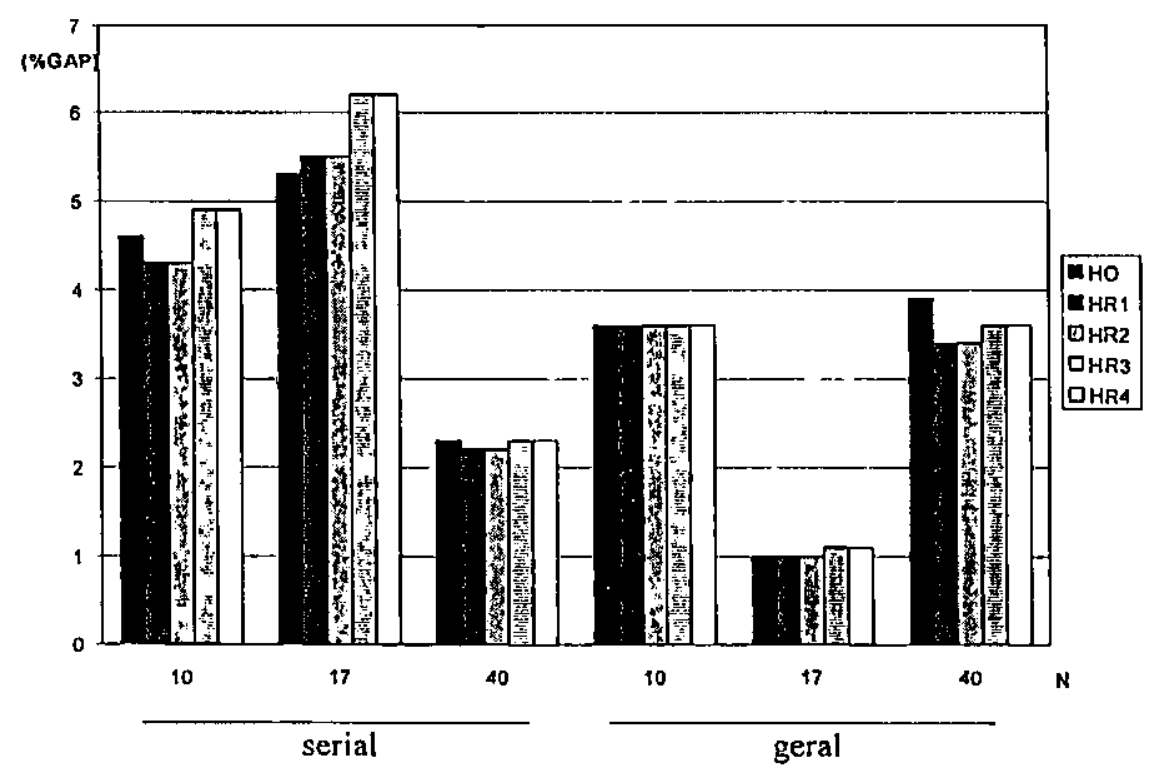

Gráfico 4.13 - Qualidade das soluções obtidas (\%GAP) pelas diferentes heurísticas considerando custo baixo de preparação e capacidade normal.

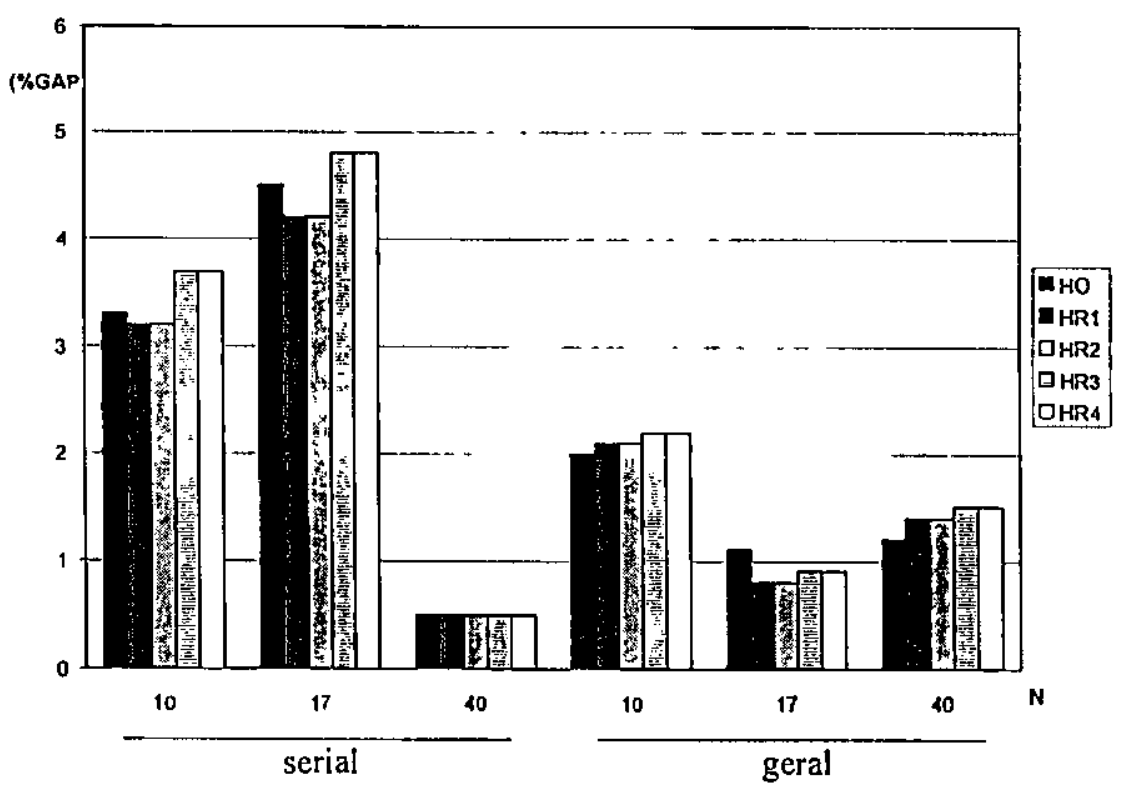

Gráfico 4.14 - Qualidade das soluções obtidas (\%GAP) pelas diferentes heurísticas considerando custo baixo de preparaçăo e capacidade folgada. 


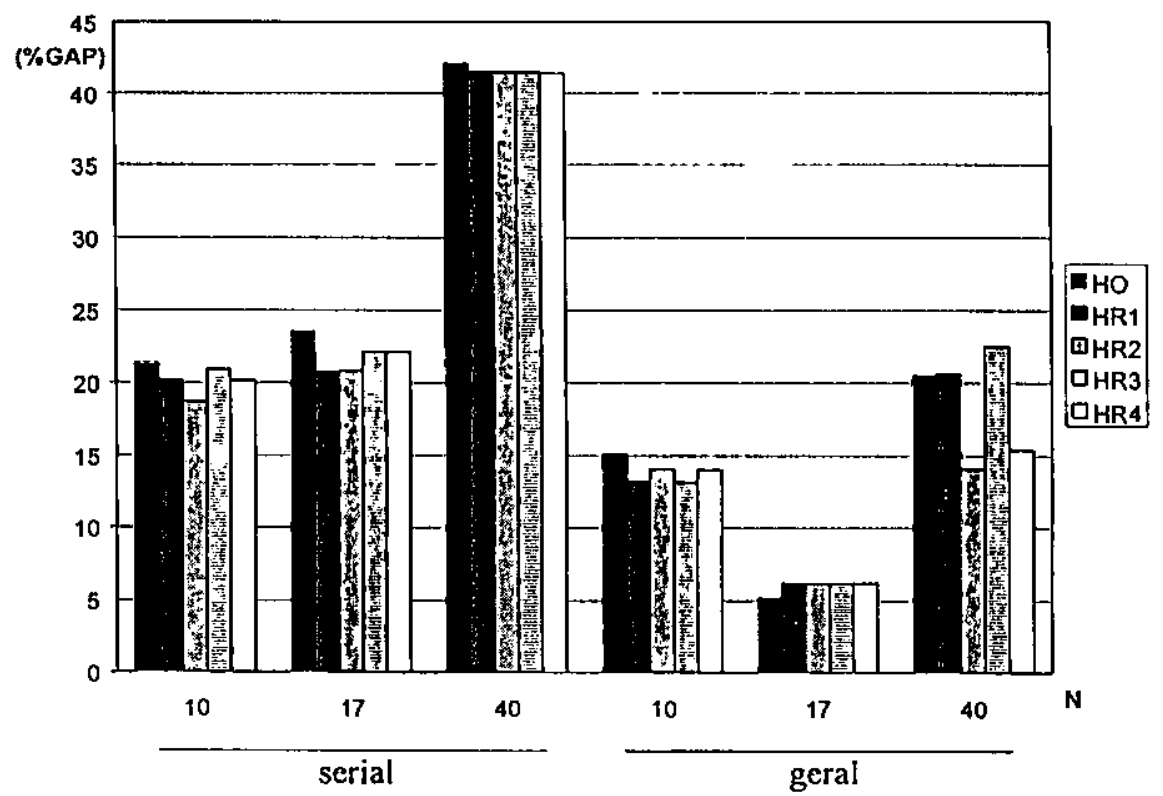

Gráfico 4.15 - Qualidade das soluções obtidas (\%GAP) pelas diferentes heurísticas considerando custo alto de preparação e capacidade normal.

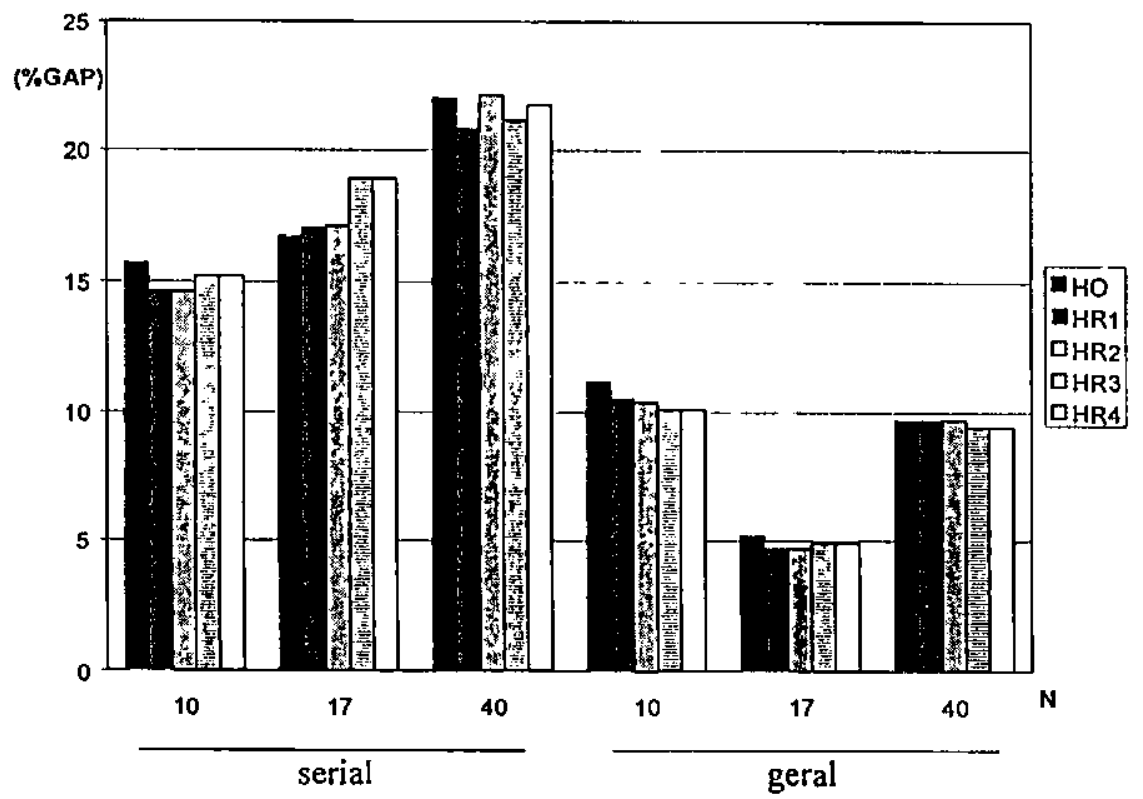

Gráfico 4.16 - Qualidade das soluçðes obtidas (\%GAP) pelas diferentes heuristicas considerando custo alto de preparação e capacidade folgada. 
Pelo gráfico 4.13, observe que para estrutura serial, as heurísticas HR1 e HR2 apresentaram qualidade de soluções melhores que a H0. Ainda, considerando 40 itens essas mesmas heurísticas apresentaram uma pequena melhora nos valores dos gaps em relação a Ho.

Considerando capacidade folgada e custo baixo de preparação (gráfico 4.14), tanto para estrutura serial quanto geral e 17 itens, as heurísticas HR1 e HR2 foram melhores do que a H0.

Note pelo gráfico 4.15 que para estrutura serial todas as heurísticas obterão soluções melhores do que $\mathrm{H} 0$ e, para estrutura geral e 40 itens, a heurística HR2 apresentou significativa melhora na qualidade de sua solução em relação a H0.

Pelo gráfico 4.16 observe que para ambas estruturas e 10 itens, as heurísticas HR1, HR2, HR3 e HR4 apresentaram uma melhora nos valores dos gaps em relação a H0.

As tabelas 4.24 a 4.27 mostram respectivamente, a média por estrutura de \%GAP.

Tabela 4.24 - Qualidade das soluções obtidas (\%GAP) pelas diferentes heurísticas considerando custo baixo de preparação e capacidade normal.

\begin{tabular}{||c|c|c|c|c|c|c||}
\hline \multirow{2}{*}{ ESTRUTURA } & \multirow{2}{*}{ \%FAC } & H0 & HR1 & HR2 & HR3 & HR4 \\
\cline { 3 - 7 } & & \%GAP & \%GAP & \%GAP & \%GAP & \%GAP \\
\hline Serial & 46,7 & 4,8 & 4,9 & 4,9 & 5,4 & 5,4 \\
\hline Geral & 46,7 & 2,1 & 2,1 & 2,1 & 2,2 & 2,2 \\
\hline Média & $\mathbf{4 6 , 7}$ & $\mathbf{3 , 5}$ & $\mathbf{3 , 5}$ & $\mathbf{3 , 5}$ & $\mathbf{3 , 8}$ & $\mathbf{3 , 8}$ \\
\hline
\end{tabular}

Tabela 4.25- Qualidade das soluções obtidas (\%GAP) pelas diferentes heurísticas considerando custo baixo de preparação e capacidade folgada.

\begin{tabular}{||c|c|c|c|c|c|c||}
\hline \multirow{2}{*}{ ESTRUTURA } & \multirow{2}{*}{$\% \mathrm{FAC}$} & $\mathrm{H} 0$ & $\mathrm{HR} 1$ & HR2 & HR3 & HR4 \\
\cline { 3 - 7 } & & \%GAP & \%GAP & \%GAP & \%GAP & \%GAP \\
\hline Serial & 93,3 & 2,7 & 2,5 & 2,5 & 2,9 & 2,9 \\
\hline Geral & 83,3 & 1,4 & 1,4 & 1,3 & 1,5 & 1,5 \\
\hline Média & $\mathbf{8 8 , 3}$ & $\mathbf{1 , 9}$ & $\mathbf{2 , 0}$ & $\mathbf{1 , 9}$ & $\mathbf{2 , 2}$ & $\mathbf{2 , 2}$ \\
\hline
\end{tabular}


Tabela 4.26 - Qualidade das soluções obtidas (\%GAP) pelas diferentes heurísticas considerando custo alto de preparação e capacidade normal.

\begin{tabular}{||c|c|c|c|c|c|c||}
\hline \multirow{2}{*}{ ESTRUTURA } & \multirow{2}{*}{ \%FAC } & H0 & HR1 & HR2 & HR3 & HR4 \\
\cline { 3 - 7 } & & \%GAP & \%GAP & \%GAP & \%GAP & \%GAP \\
\hline Serial & 50,0 & 23,8 & 21,9 & 21,3 & 22,9 & 22,6 \\
\hline Geral & 46,7 & 9,8 & 9,0 & 8,9 & 9,2 & 9,0 \\
\hline Média & $\mathbf{4 8 , 4}$ & $\mathbf{1 6 , 8}$ & $\mathbf{1 5 , 5}$ & $\mathbf{1 5 , 1}$ & $\mathbf{1 6 , 1}$ & $\mathbf{1 5 , 8}$ \\
\hline
\end{tabular}

Tabela 4.27 - Qualidade das soluçð̃es obtidas (\%GAP) pelas diferentes heurísticas considerando custo alto de preparação e capacidade folgada.

\begin{tabular}{||c|c|c|c|c|c|c||}
\hline \multirow{2}{*}{ ESTRUTURA } & \multirow{2}{*}{ \%FAC } & H0 & HR1 & HR2 & HR3 & HR4 \\
\cline { 3 - 7 } & & \%GAP & \%GAP & \%GAP & \%GAP & \%GAP \\
\hline Serial & 93,3 & 18,2 & 17,6 & 18,1 & 18,5 & 18,7 \\
\hline Geral & 83,3 & 8,4 & 7,9 & 7,9 & 7,8 & 7,8 \\
\hline Média & $\mathbf{8 8 , 3}$ & $\mathbf{1 3 , 3}$ & $\mathbf{1 2 , 8}$ & $\mathbf{1 3 , 0}$ & $\mathbf{1 3 , 2}$ & $\mathbf{1 3 , 3}$ \\
\hline
\end{tabular}

Pelas tabelas 4.24 a 4.27 observa-se que os valores dos gaps apresentaram melhora em relação aos valores obtidos pela $\mathrm{H} 0$ para custo alto de preparação tanto para capacidade normal quanto para capacidade folgada. Em média, pode-se dizer que a qualidade da solução da heurística HR2 foi $1 \%$ melhor do que a da H0.

Como dito anteriormente, os valores dos gaps calculados são comparados com o limitante inferior e assim, os resultados apresentados podem ser melhores do que os números indicam pois o valor do limitante inferior pode incorporar um gap de dualidade do problema.

$\mathrm{Na}$ seção anterior, observou-se que a heurística HR2 conseguiu obter uma porcentagem maior de soluções factíveis comparado as outras heurísticas. Foi observado, nesta seção, que no geral, a heurística HR2 conseguiu também obter soluções de melhor qualidade. Pode ser que a heurística HR2 tenha obtido uma porcentagem maior de soluções factíveis pelo fato do procedimento P4 presente nas heurísticas HR1 e HR3 não ajudar a melhorar sua qualidade e a presença dos custos relaxados na heurística HR2 faça com que a mesma consiga obter soluções de melhor qualidade. 
Desta forma, a seguir pelos gráficos 4.17 e 4.18 , é mostrada a qualidade do custo das soluções (\%GAP) da heurística HR2 de forma mais detalhada, agrupados por quantidade de itens e períodos.

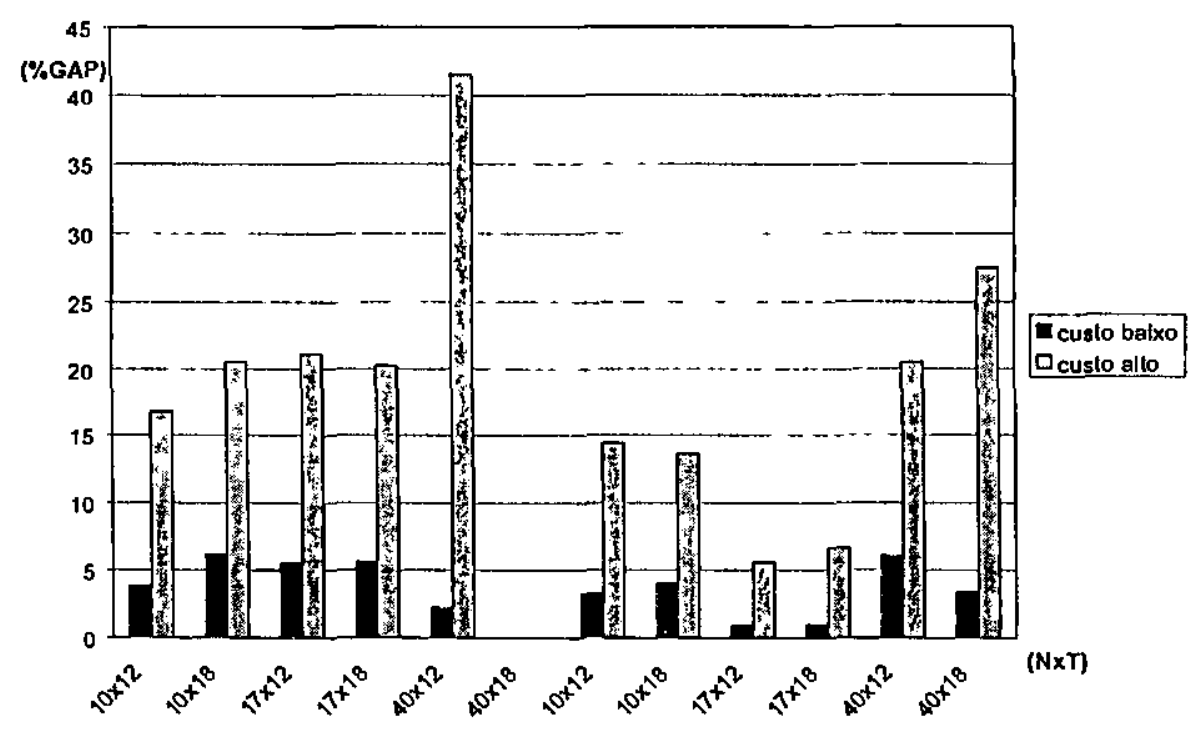

Gráfico 4.17 - Qualidade das soluçð̋es obtidas (\%GAP) pela heuristica HR2 considerando capacidade normal.

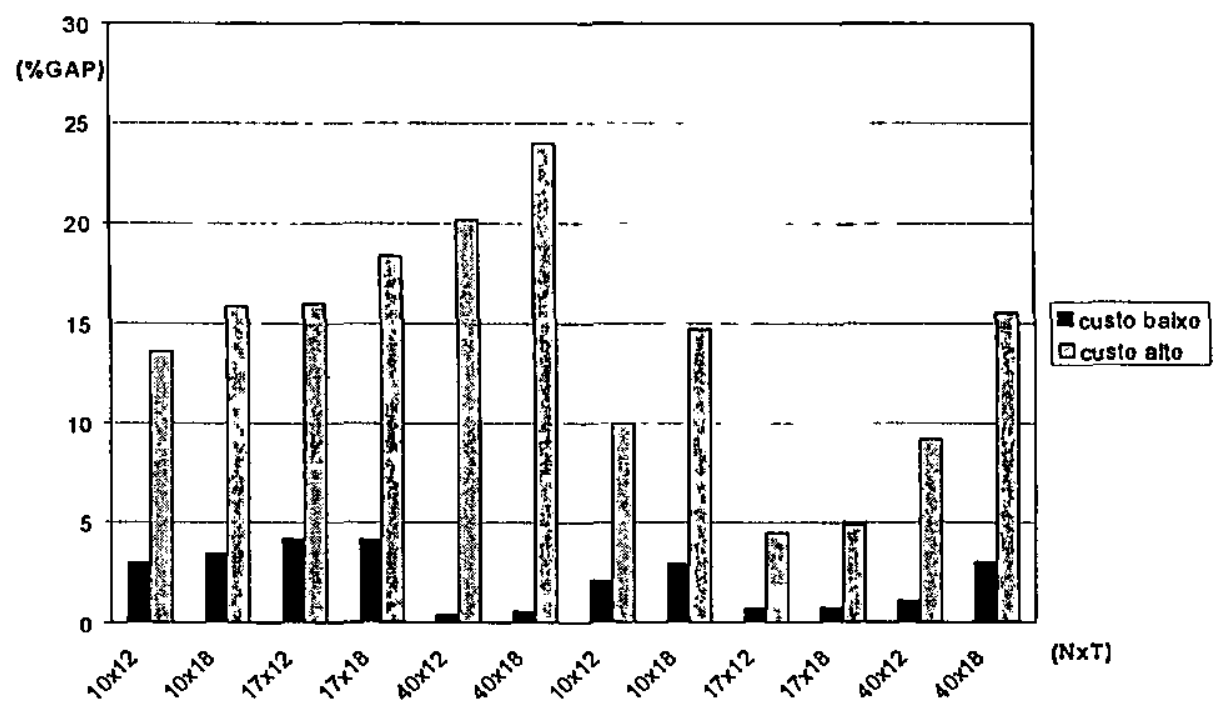

Gráfico 4.18 - Qualidade das soluçðes obtidas (\%GAP) pela heurística HR2 considerando capacidade folgada. 
A tabela 4.28, mostra na média, os resultados apresentados pela heurística HR2.

Tabela 4.28 - Resumo dos resultados da heurística HR2.

\begin{tabular}{|c|c|c|c|c|}
\hline ESTRUTURA & CAPACIDADE & $\begin{array}{c}\text { CUSTO DE } \\
\text { PREPARAÇÃO }\end{array}$ & $\% \mathrm{FAC}$ & $\%$ GAP \\
\hline \multirow{2}{*}{ Serial } & $\mathrm{cl}$ & $\begin{array}{l}\text { baixo } \\
\text { alto }\end{array}$ & $\begin{array}{l}50,0 \\
50,0\end{array}$ & $\begin{array}{r}5,1 \\
21,3\end{array}$ \\
\hline & c2 & $\begin{array}{c}\text { baixo } \\
\text { alto }\end{array}$ & $\begin{array}{l}93,3 \\
93,3\end{array}$ & $\begin{array}{r}2,5 \\
18,1\end{array}$ \\
\hline \multirow{2}{*}{ Geral } & $\mathrm{cl}$ & $\begin{array}{l}\text { baixo } \\
\text { alto }\end{array}$ & $\begin{array}{l}53,3 \\
53,3\end{array}$ & $\begin{array}{r}2,6 \\
11,7\end{array}$ \\
\hline & c2 & $\begin{array}{l}\text { baixo } \\
\text { alto }\end{array}$ & $\begin{array}{l}90,0 \\
90,0\end{array}$ & $\begin{array}{l}1,7 \\
9,4\end{array}$ \\
\hline \multicolumn{3}{|c|}{ Média } & 71,7 & 9,1 \\
\hline
\end{tabular}

\subsubsection{Análise de Alguns Resultados Utilizando a Heurística HR2}

Nesta seção será apresentada a análise de resultados utilizando a heurística HR2. Será apresentada a análise dos excessos de todas as soluções finais (soluções factíveis e infactíveis) e dos exemplos onde não foi possível encontrar solução factível. Também será apresentada a evolução da solução incumbente no decorrer da execução da heurística e, finalmente, o ganho obtido nos valores dos custos das heurísticas H0 e HR2.

\subsubsection{Análise dos Excessos}

Como feito na seção 4.4.3.1., será apresentado aqui a análise dos excessos apresentados pela heurística HR2.

Como dito anteriormente, ao terminar o programa com uma solução infactível, o mesmo informa qual a melhor solução infactível encontrada, onde "melhor" pode significar a solução com menor excesso médio ou a solução como menor excesso máximo encontrado em um período. Assim, temos a informação da melhor solução em relação ao excesso médio e em relação ao excesso máximo. 
A seguir, são apresentados os resultados da heurística HR2 de acordo com a estrutura de produto e custo de preparação. Na tabela 4.29 são analisadas todas as soluções finais, ou seja, as soluções factíveis e infactíveis. Nas tabelas 4.30 a análise é feita apenas com os exemplos onde não foi possível encontrar solução factível.

Como na seção 4.4.3.1., a notação utilizada nas tabelas foi a seguinte:

Exc - excesso médio por período.

Exc_max - o maior excesso encontrado em um período.

Exc_T - porcentagem de períodos com excesso.

Tabela 4.29 - Média dos excessos da heurística nas soluçðes factĺveis e infactíveis.

\begin{tabular}{|c|c|c|c|c|c|c|c|c|c|c|c|c|}
\hline \multirow[t]{2}{*}{ Estrutura } & \multirow{2}{*}{$\begin{array}{c}\text { Custo de } \\
\text { Preparação }\end{array}$} & \multirow[t]{2}{*}{ CAP } & \multirow[t]{2}{*}{$\% \mathrm{FAC}$} & \multicolumn{3}{|c|}{ Antes } & \multicolumn{3}{|c|}{$\begin{array}{c}\text { Melhor Excesso } \\
\text { Médio }\end{array}$} & \multicolumn{3}{|c|}{$\begin{array}{l}\text { Melhor Excesso } \\
\text { Máximo }\end{array}$} \\
\hline & & & & Exc & Exc_max & Exc_T & Exc & Exc_max & Exc_I & Exc & Exc_max & Exc_T \\
\hline \multirow{4}{*}{ serial } & \multirow{2}{*}{ baixo } & cl & 50,0 & 26,7 & 231,9 & 0,4 & 1,0 & 16,7 & 0,1 & 1,8 & 10,7 & 0,1 \\
\hline & & c2 & 93,3 & 6,6 & 42,7 & 0,3 & 0,1 & 1,9 & 0,0 & 0,2 & 1,7 & 0,0 \\
\hline & \multirow{2}{*}{ alto } & $\mathrm{cl}$ & 50,0 & 33,2 & 258,8 & 0,3 & 1,3 & 18,9 & 0,1 & 2,2 & 11,7 & 0,1 \\
\hline & & c2 & 93,3 & 19,8 & 142,1 & 0,3 & 0,1 & 2,0 & 0,0 & 0,2 & 1,9 & 0,0 \\
\hline \multirow{4}{*}{ geral } & \multirow{2}{*}{ baixo } & c1 & 53,3 & 26,6 & 228,4 & 0,3 & 1,4 & 21,1 & 0,1 & 2,0 & 13,8 & 0,1 \\
\hline & & c2 & 90,0 & 12,0 & 131,4 & 0,3 & 0,2 & 3,7 & 0,0 & 0,3 & 2,8 & 0,0 \\
\hline & \multirow{2}{*}{ alto } & cl & 53,3 & 33,3 & 307,5 & 0,2 & 1,5 & 23,2 & 0,1 & 2,1 & 12,6 & 0,1 \\
\hline & & c2 & 90,0 & 22,8 & 198,9 & 0,3 & 0,2 & 3,2 & 0,0 & 0,3 & 2,4 & 0,0 \\
\hline
\end{tabular}


Tabela 4.30 - Média dos excessos da heurística nas soluções infactíveis.

\begin{tabular}{|c|c|c|c|c|c|c|c|c|c|c|c|c|}
\hline \multirow[t]{2}{*}{ Estrutura } & \multirow[t]{2}{*}{$\begin{array}{c}\text { Custo de } \\
\text { Preparação }\end{array}$} & \multirow[t]{2}{*}{ CAP } & \multirow[t]{2}{*}{$\%$ FAC } & \multicolumn{3}{|c|}{ Antes } & \multicolumn{3}{|c|}{$\begin{array}{c}\text { Melhor Excesso } \\
\text { Médio }\end{array}$} & \multicolumn{3}{|c|}{ Melhor Excesso Máximo } \\
\hline & & & & Exc & Exc_max & Exc_t & Exc & Exc_ma & Exc_T & Exc & Exc_max & Exc $T$ \\
\hline \multirow{4}{*}{ serial } & \multirow{2}{*}{ ixo } & c1 & 50,0 & 29,6 & 284,1 & 0,2 & 1,7 & 28,3 & 0,1 & 3,1 & 18,9 & 0,2 \\
\hline & & c2 & 93,3 & 9,1 & 96,3 & 0,1 & 0,5 & 9,3 & 0,0 & 1,0 & 8,4 & 0,1 \\
\hline & \multirow{2}{*}{ alto } & $\mathrm{cl}$ & 50,0 & 32,3 & 298,4 & 0,2 & 2,4 & 36,3 & 0,1 & 4,4 & 22,1 & 0,2 \\
\hline & & c2 & 93,3 & 9,7 & 104,7 & 0,1 & 0,6 & 10,1 & 0,0 & 1,0 & 9,2 & 0,1 \\
\hline \multirow{4}{*}{ geral } & \multirow{2}{*}{ Xo } & c1 & 53,3 & 29,0 & 246 & 0,3 & 2,5 & 36 & 0,1 & 3,5 & 24,3 & 0,2 \\
\hline & & c2 & 90,0 & 18,7 & 222,9 & 0,1 & 1,0 & 16,0 & 0,1 & 1,5 & 11,8 & 0,1 \\
\hline & \multirow{2}{*}{ du } & c1 & 53,3 & 33,3 & 272,2 & 0,3 & 2,6 & 39 , & 0,1 & 3,4 & 21,6 & 0,2 \\
\hline & & c2 & 90,0 & 19,2 & 211,5 & 0,1 & 1,0 & 15,9 & 0,1 & 1,5 & 11,8 & 0,1 \\
\hline
\end{tabular}

Como dito anteriormente, pode -se fazer a análise da heurística quanto ao melhor excesso médio e menor excesso máximo.

Na tabela 4.29 considerando estrutura serial, custo baixo de preparação e capacidade cl e analisando o melhor excesso médio temos inicialmente $26,7 \%$ de excesso médio com $0,4 \%$ de períodos infactíveis ( $231,9 \%$ de excesso máximo) e terminamos com $1 \%$ de excesso médio em $0,1 \%$ dos períodos infactíveis ( $16,7 \%$ de excesso máximo). Se analisarmos apenas os exemplos infactíveis na tabela $4.30 \mathrm{com}$ capacidade $\mathrm{cl}$, temos $29,6 \%$ de excesso médio com $0,2 \%$ de períodos infactíveis $(284,1 \%$ de excesso máximo) inicialmente e terminamos com $1,7 \%$ de excesso médio e $0,1 \%$ de períodos infactíveis ( $28,3 \%$ de excesso máximo). Note que o excesso máximo foi consideravelmente reduzido (de $284,1 \%$ para $28,3 \%$ ).

No entanto, se analisarmos a solução infactível com o menor excesso máximo encontrado, temos na tabela 4.29 considerando estrutura serial, custo baixo de preparação e capacidade c2, um excesso médio final um pouco maior $(1,8 \%)$, mas um excesso máximo final um pouco menor $(10,7 \%)$. Observe que o excesso máximo foi reduzido de $16,7 \%$ para 10,7\%. Nos exemplos onde não foi encontrada solução factível (tabela 4.29), o excesso máximo final encontrado foi de $18,9 \%$ com $0,2 \%$ de períodos infactíveis e na solução com melhor excesso temos $28,3 \%$ de excesso máximo com $0,1 \%$ de períodos infactíveis. 


\subsubsection{Evolução da Solução Incumbente}

Os gráficos a seguir (gráficos 4.19, 4.20, 4.21 e 4.22) mostram a evolução da solução incumbente durante a execução da heurística H0 e HR2. Para avaliar a solução incumbente, foram executadas 5000 iterações de ambas heurísticas, considerando capacidade normal para um exemplo com 10 itens e 12 períodos.

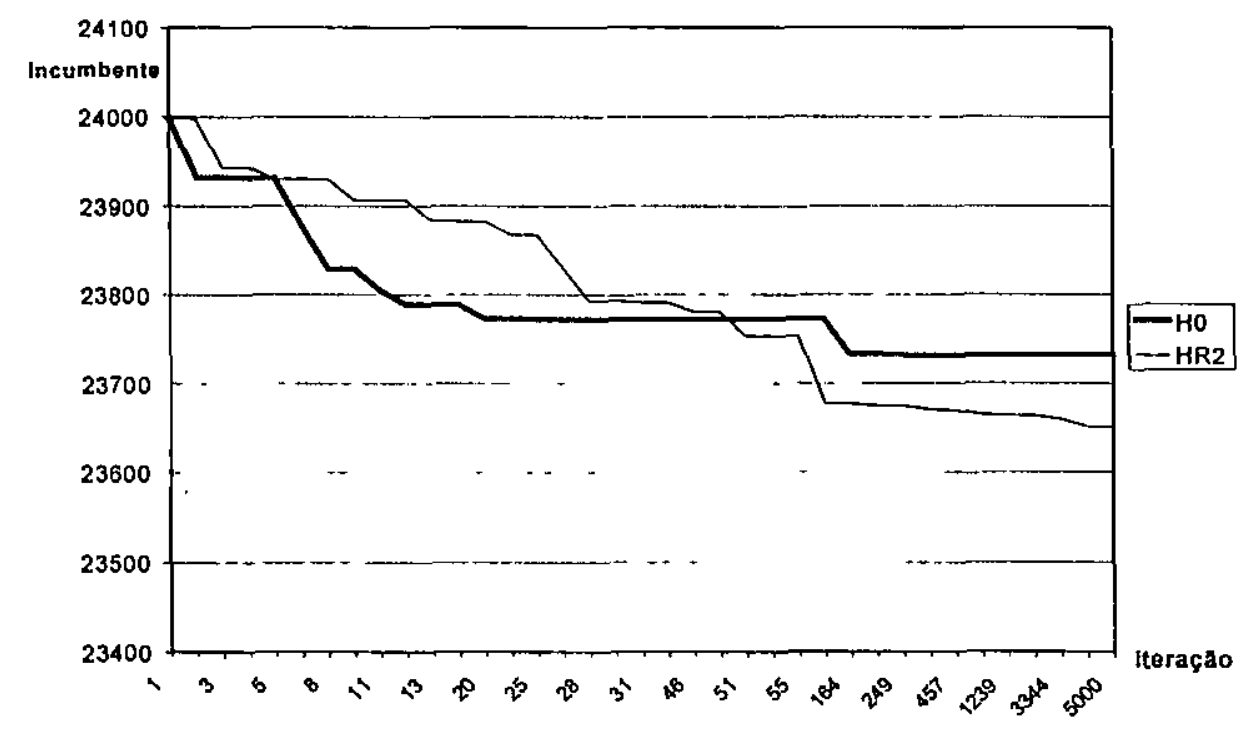

Gráfico 4.19 - Evolução da solução incumbente considerando estrutura serial e custo baixo de preparação.

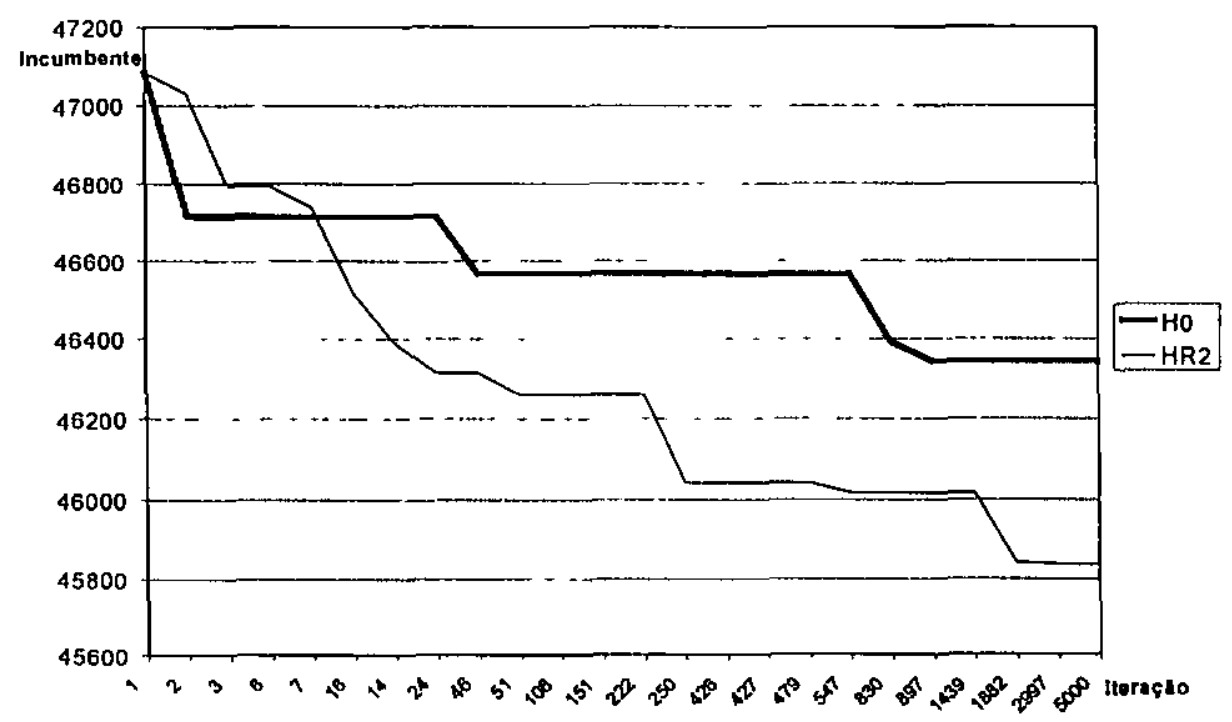

Gráfico 4.20 - Evolução da solução incumbente considerando estrutura serial e custo alto de preparação. 


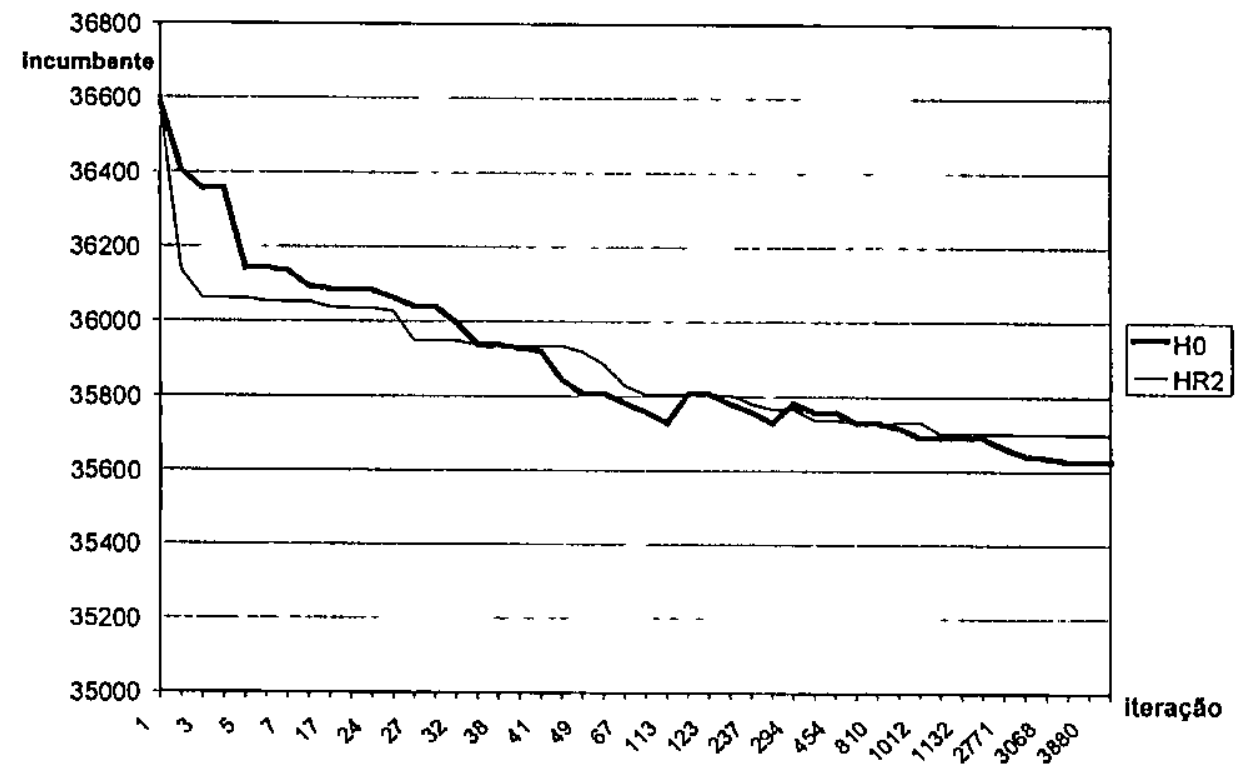

Gráfico 4.21 - Evolução da solução incumbente considerando estrutura geral e custo baixo de preparação.

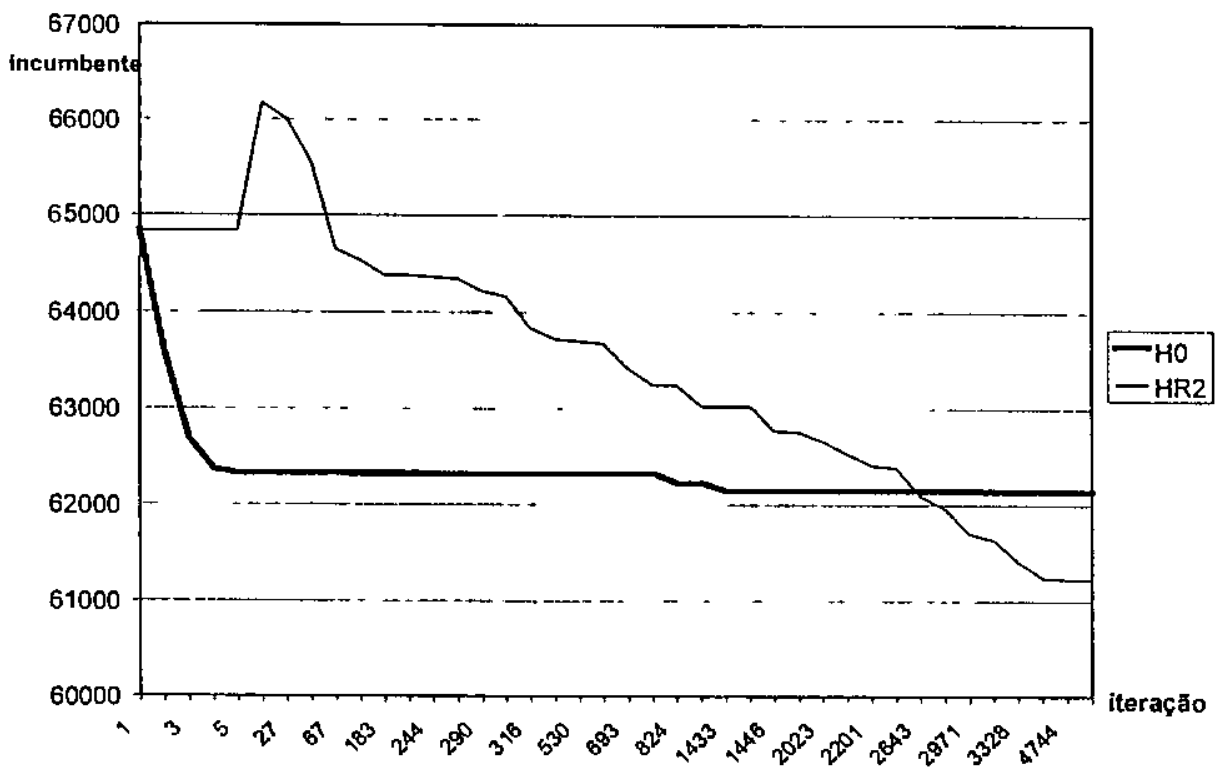

Gráfico 4.22 - Evolução da solução incumbente considerando estrutura geral e custo alto de preparação. 
Os gráficos acima mostram que a heurística que utiliza as informações dos custos Lagrangianos (HR2) encontra soluções de melhor qualidade durante quase toda a sua execução. Pode-se dizer também que, no geral, o número de atualizações na solução incumbente é maior em HR2.

\subsubsection{Análise do Ganho Obtido nos Valores dos Custos das Heurísticas H0 e HR2.}

Os gráficos abaixo (gráficos 4.23 e 4.24) mostram o ganho em pontos percentuais nos valores do custo da heurística HR2 em relação à $\mathrm{H} 0$ para os exemplos agrupados de acordo com o número de itens e custo alto e baixo de preparação.

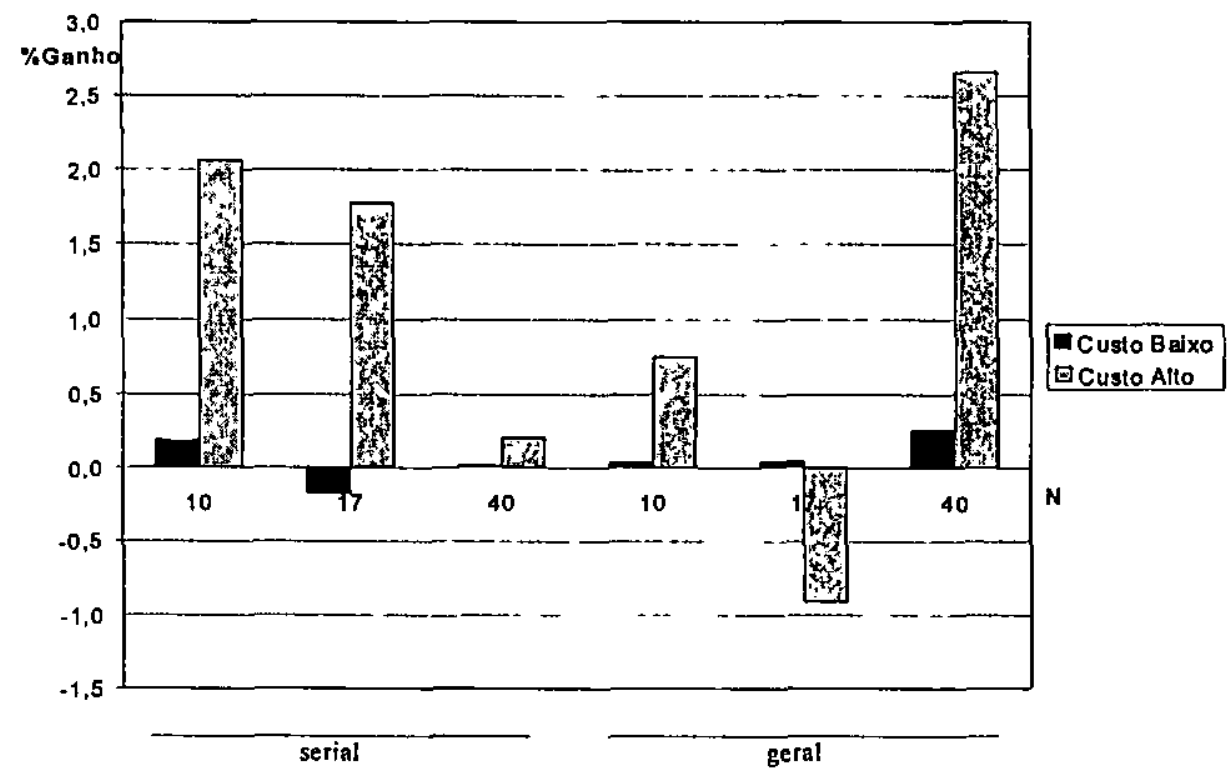

Gráfico 4.23 - Ganho em pontos percentuais da heuristica HR2 em relação à HO considerando capacidade normal. 


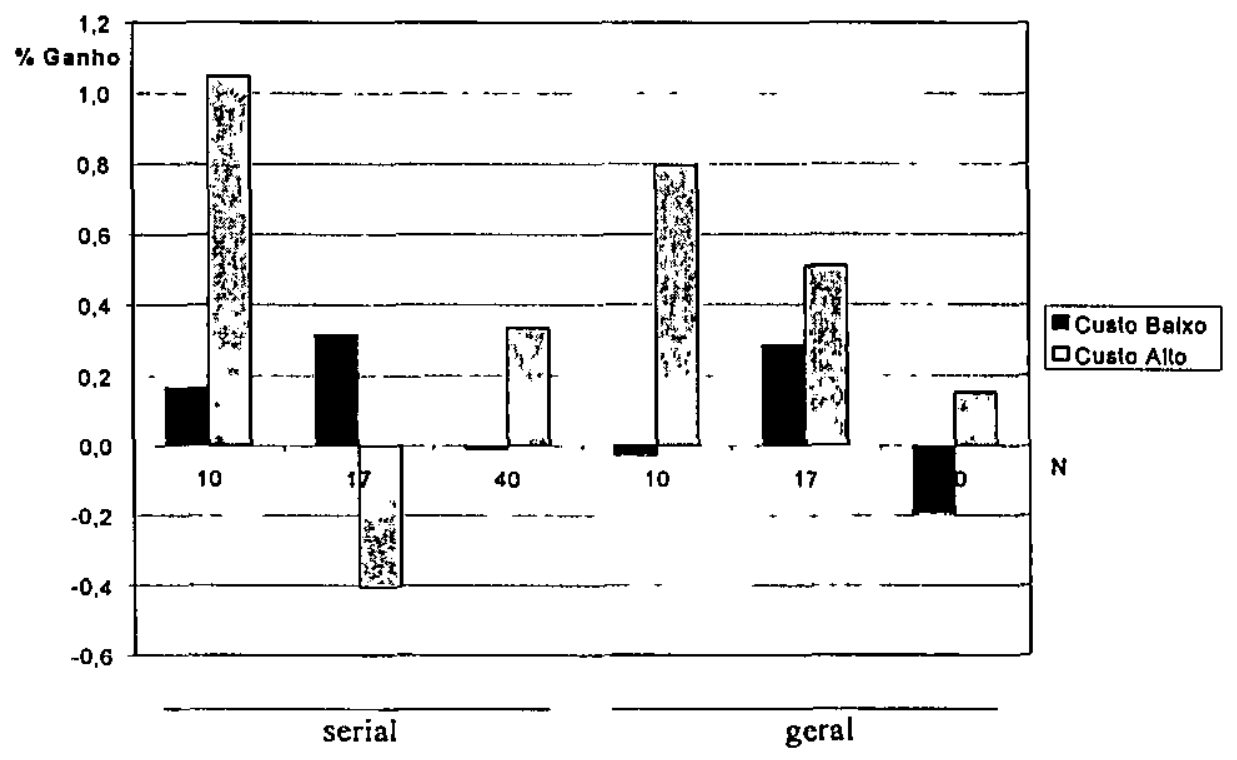

Gráfico 4.24 - Ganho em pontos percentuais da heuristica HR2 em relação à H0 considerando capacidade rolgada.

Pelo gráfico 4.23, note que a heuristica HR2 obteve custos piores apenas para estrutura serial, 17 itens e custo baixo de preparação e para estrutura geral, 17 itens e custo alto de preparação. O mesmo pode ser observado pelo gráfico 4.28 para estrutura serial, 17 itens e custo alto de preparação e para estrutura geral, 40 itens e custo baixo de preparação.

Pelos gráficos acima, pode-se concluir que a incorporação da informação do problema Lagrangiano ajudou a melhorar o valor dos custos na maioria dos casos. No caso de custo alto de preparação, observa-se que a melhora dos custos foi bem maior do que considerando custo baixo de preparação. 


\section{Capítulo 5}

\section{Conclusões e Propostas Futuras}

Esse trabalho abordou a resolução do problema de dimensionamento de lotes em sistemas multiestágios com limitações de capacidade. Mais especificamente, em determinar um plano de produção de forma a atender a demanda em um determinado período. Nesse planejamento é utilizado o sistema MRP que em sua forma básica assume que não há restrição de capacidade, podendo gerar planos infactíveis.

Essas limitações de um sistema MRP compõem a essência do problema de dimensionamento de lotes multiestágio capacitado, o qual é o problema abordado neste trabalho. Tal problema consiste em realizar o dimensionamento do tamanho dos lotes de produção de forma que os custos envolvidos sejam minimizados, considerando recursos limitados de produção.

O objetivo principal deste trabalho foi o desenvolvimento de heurísticas baseadas em relaxação Lagrangiana com o propósito de fornecer um plano de produção, ou seja, determinar quanto, quando e o que produzir de maneira a minimizar o custo do problema de dimensionamento de lotes capacitado, sendo que os custos considerados foram os de produção, preparação e estoque.

A heurística utilizada neste trabalho foi baseada no trabalho de França et al. (1997), o qual não incorpora as informações do problema Lagrangiano na sua resolução e pode possuir os seguintes procedimentos:

P1 - Procedimento para a Obtenção da Solução Inicial.

P2 - Procedimento de Factibilização. 
P3 - Procedimento de Melhoria.

P4 - Procedimento de Alteração.

P5 - Procedimento para a Atualização dos Multiplicadores de Lagrange.

O procedimento inicial (P1), é um algoritmo de construção que gera uma solução de partida pela aplicação seqüencial do algoritmo de Wagner e Whitin (1958), mas não garante que a solução encontrada seja factível. A seguir, caso a solução encontrada em PI seja infactível, o procedimento de factibilização (P2) é aplicado na tentativa de obter uma solução factível.

Caso tenha sido encontrada uma solução factível (em Pl ou em P2), o procedimento de melhoria (P3) tenta encontrar melhores soluções a partir da obtida anteriormente. Se encontrarmos uma solução infactível em P2, o procedimento de alteração (P4) é aplicado para a obtenção de novas soluções, mesmo infactíveis ou de pior custo, com o objetivo de obter um novo ponto de partida para o procedimento P2. Em seguida, para a atualização dos multiplicadores de Lagrange, o procedimento P5 utiliza a otimização do subgradiente, fornecendo novos custos de produção, preparação e estoque. Estes custos serão utilizados para encontrar uma nova solução inicial usando o algoritmo de Wagner e Whitin (1958).

Após realizar as implementações necessárias das heurísticas, iniciaram-se os testes computacionais utilizando os grupos de exemplos indicados no Capítulo 4. Em um conjunto de 240 exemplos considerando estrutura serial e geral, as heurísticas estudadas neste trabalho apresentaram bons resultados (tabela 5.1). A porcentagem de soluções factíveis aumentou em relação a $\mathrm{HO}$ e, em especial, a heurística $\mathrm{HR} 2$ obteve uma porcentagem maior de soluções factiveis para ambas estruturas em relação a todas as outras heurísticas. Os valores dos gaps foram reduzidos, melhorando dessa forma a qualidade das soluções obtidas pelas heurísticas Lagrangianas. Uma justificativa do porque a heuristica HR2 obteve uma porcentagem maior de soluções factíveis pode ter sido o fato do procedimento P4, presente nas heurísticas HRl e HR3, não ajudasse a melhorar sua qualidade e a presença dos custos relaxados na heurística HR2 fizesse com que a mesma conseguisse obter soluções de melhor qualidade.

Os valores dos excessos encontrados pela heurística também foram "pequenos". Foi feita a análise em relação ao melhor excesso médio e em relação ao menor excesso máximo, onde "melhor" pode significar a solução com menor excesso médio ou a solução como menor excesso máximo encontrado em um período. O que observou-se foi que, em geral, tanto o excesso médio quanto o excesso máximo foram consideravelmente reduzidos, resultando em valores pequenos. 
Tabela 5.1 - Resultados com as heurísticas para a obtenção de solução factível e qualidade das soluções.

\begin{tabular}{|c|cc|cc|}
\hline \multirow{2}{*}{ Estrutura } & \multicolumn{2}{|c|}{ H0 } & \multicolumn{2}{c|}{ HR2 } \\
\cline { 2 - 5 } & \%FAC & \%GAP & \%FAC & \%GAP \\
\hline serial & 70,8 & 12,4 & 71,7 & 11,8 \\
\hline geral & 65,0 & 5,4 & 71,7 & 5,1 \\
\hline
\end{tabular}

Para uma melhor análise dos resultados atingidos pela heurística, considerou-se a solução ótima de 136 exemplos utilizando o pacote de otimização CPLEX. Estes resultados indicaram que a heurística que incorpora as informações do problema Lagrangiano nestes exemplos estava a $1,2 \%$ do ótimo e $10,5 \%$ distante do limitante inferior. Portanto, pode-se dizer que os números mostrados na tabela 5.1 são bem melhores do que os indicados e seriam ainda melhores se tivéssemos acesso aos valores da solução ótima, pois os limitantes inferiores obtidos são de pouca qualidade.

Pelos resultados obtidos, pode-se dizer que este trabalho contribuiu com uma heurística para a resolução do problema de dimensionamento de lotes multiestágio capacitado. Dessa forma, foram desenvolvidas heurísticas que obtiveram uma porcentagem maior de soluções factíveis e também estas soluções foram de melhor qualidade que a heuristica original, no caso a de França et al. (1997).

No entanto, os sistemas MRP, na prática, são de maior tamanho aos testados neste trabalho. Assim, é preciso investir mais nessa área de pesquisa com a elaboração de métodos heurísticos que possam ser aplicados de forma mais eficaz em problemas mais próximos à realidade.

Como propostas para trabalhos futuros podem ser consideradas:

- considerar a permissão de estoques negativos ao problema;

- aplicar o algoritmo de Wagner e Whitin (1958) de modo não seqüencial e em seguida aplicar a heurística para tomá-la factível em termos de inter-escalão;

- Na heurística deste trabalho (HR2), os custos Lagrangianos foram utilizados para obtenção de uma nova solução e a heurística H0 é uma heurística baseada em transferências. Uma questão que poderia ser avaliada é se o uso de alguma técnica que não use essa informação, como por exemplo, o uso de uma meta-heurística poderia substituir a informação dos custos Lagrangianos e apresentar melhores resultados. 


\section{Referências Bibliográficas}

AFENTAKIS, P.; GAVISH, B. e KARMAKAR, U. (1984), Computationally Efficient Optimal Solutions to the Lot-Sizing Problem in Multistage Assembly System, Management Science, vol 30, no. 2, pp 222-239.

AFENTAKIS, P. e GAVISH, B. (1986), Optimal Lot-Sizing Algorithms for Complex Product Structures, Operations Research, vol 34, no. 2, pp 237-249.

BAHL, H. C.; RITZMAN, L. P. e GUPTA, J. N. D. (1987), Determining Lot Sizes and Resource Requirements: a Review, Operations Research, vol. 35, no. 3, pp 329-345.

BERRETTA, R. E. (1997), Heurísticas para o Planejamento da Produção em Sistemas MRP, tese de doutorado, FEEC-UNICAMP.

BILLINGTON, P. J.; BLACKBURN, J. D.; MAES, J.; MILLEN, R. A. e VAN WASSENHOVE, L. N. (1994), Multi-Item LotSizing in Capacitated Multi-Stage Serial System. IIE Transactions, vol. 26, no.2, pp 12-18.

BILLINGTON, P. J.; McCLAIN, J. O. e THOMAS, L. J. (1983), Mathematical Programming Approaches to Capacity MRP Systems: Review, Formulation and Problem Reduction, Management Science, vol. 29, no. 10, pp 1126-1141. 
BILLINGTON, P. J.; McCLAIN, J. O. e THOMAS, L. J. (1986), Heuristics for Multi-Level Lot-Sizing with a Bbottleneck, Management Science, vol. 32, no. 8, pp 989-1006.

BILLINGTON, P. J.; BLACKBURN, J. D.; MAES J.; MILLEN, R. A. e VAN WASSENHOVE, L. N. (1994), Multi-Item LotSizing in Capacitated Multi-Stage Serial Systems, IIE Transactions, vol. 26, no. 2, pp 12-18.

BLACKBURN, J. D. e MILLEN, R. A. (1984), Simultaneous Lot-Sizing and Capacity Planning in Multi-Stage Assembly Processes, European Journal of Operations Research, vol. 16, pp 84-93.

CAMERINI, P. M.; FRATTA, L. e MAFFIOLI, F. (1975), On Improving Relaxation Methods by Modified Gradient Techniques, Mathematical Programming Study, no. 3, pp 26-34.

CHIU, H. M. e LIN, T. M. (1988), An Optimal Lot-Sizing Model for Multi-Stage Series/Assembly Systems, Computers and Operations Research, vol. 15, no. 5, pp 403415.

CLARK, A. J e SCARF, H. (1960), Optimal Policies for a Multi-Echelon Inventory Problem, Management Science, vol. 6, pp 475-490.

CLARK, A. R. e ARMENTANO, V. A. (1993), Echelon Stock Formulation for Multi-Stage Lot-Sizing with Component Lead Time, International Journal of Research Society, vol. 24 , no. 9 , pp 1759-1775.

CLARK, A. R. e ARMENTANO, V. A. (1995), A Heuristic for a Resource-Capacitated Multi-Stage Lot-Sizing Problem with Lead Time, Journal of the Operational Research Society, vol. 46, pp 1208-1222.

FRANÇA, P. M.; ARMENTANO, V. A.; BERRETTA, R. E. e CLARK, A. R. (1997), $A$ Heuristic for Lot-Sizing in Multi-Stage Systems, Computers and Operations Research, vol. 24 , no. 9 , pp $861-874$. 
FLORIAN, M.; LENSTRA, J. K. e RINNOY KAN, A. H. G. (1980), Deterministic Production Planning Algorithms and Complexity, Management Science, vol. 26 no. 7, pp 669-679.

GABBAY, H. (1979), Multi-Stage Production Planning. Management Science, vol. 25, no. 11, pp 1138-1148.

GAREY, M. e JOHNSON, D. (1978), Computers, Complexity and Intractibility: $A$ Guide to Theory of NP-Completeness, W. H. Freeman, San Francisco.

HARRYSON, T. P. e LEWIS, H. S. (1996), Lot Sizing in Serial Assembly Systems with Multiple Constrained Resources, Management Science, vol. 42, no. 1, pp 19-36.

KATOK, E.; LEWIS, S. H. e HARRISON, T. P. (1998), Lot Sizing in General Assembly Systems with Setup Costs, Setup Times and Multiple Constrained Resources, Management Science, vol. 44, no. 6, pp 859-877.

KIMMS A. (1999), A Genetic Algorithm for Multi-level, Multi-machine Lot Sizing and Scheduling, Computers Operations Research, vol. 26, pp 829-848.

KUIK, R. e SALOMON, M. (1994), Batching Decisions: Structure and Models, European Journal of Operational Research, vol. 75, pp 243-263.

KUIK, R.; SALOMON, M.; VAN WASSENHOVE, L. N..e MAES, J. (1993), Linear Programming, Simulated Annealing and Tabu Search Heuristics for LotSizing in Bottleneck Assembly Systems, IIE Transactions, vol. 25, no. 1, pp 62-72.

LAMBRECHT, M. e VANDEREECHEN, L. (1978), A Facilities in Series Capacity Constrained Dynamic Lot-Size Model, European Journal of Operational Research, vol. $2, \mathrm{pp} 42-49$.

MAES, J.; McCLAIN, J. O. e VAN WASSENHOVE, L. N. (1991), Multilevel Capacitated LotSizing Complexity and LP Heuristics, European Journal of Operational Research, vol. 53, pp 131-148. 
MAES, J. e VAN WASSENHOVE, L. N. (1991), Capacity Dynamic LotSizing Heuristics for Serial Systems, International Journal of Production Research, vol. 29, no. 6, pp 12351249.

REEVES, C. R., (1993), Modern Heuristic Techniques for Combinatorial Problem, Departament of Statistics and Operacional Research, School of Mathematical and Information Sciences, Coventry University.

ROLL, Y. e KARNI, R. (1991), Multi-Item, Multi-Level Lot Sizing with an Aggregate Capacity Constraint, European Journal of Operational Research, vol. 51, pp 73-87.

STEINBERG, E. e NAPIER, H. A. (1980), Optimal Multi-Level Lot Sizing for Requirements Planning Systems, Management Science, vol. 26, no. 12, pp 1258-1271.

TEMPELMEIER H. (1997), Resource-Constrained Materials Requirements Planning - MRP $r c$, Production Planning \& Control, vol. 8, no. 5, pp 451-461.

TEMPELMEIER, H. e DERSTROFF, M. (1996), A Lagrangean-Based Heuristic for Dynamic Multilevel Multitem Constrained LotSizing with Setup Times, Management Science, vol. 42, no. 5, pp 738-757.

TOKLU, B. e WILSON, J. M. (1992), An Analysis of Multi-Level Lot-Sizing Problems with a Bottleneck Under a Rolling Schedule Environment, International Journal of Production Research, vol. 33, no.7, pp 1835-1847.

TRIGEIRO, W. W.; THOMAS, L. J. e McCLAIN, J. O. (1989), Capacitated Lot Sizing with Setup Times, Management Science, vol. 35, no. 3, pp 353-366.

ZANGWILL, W. I. (1969), A Backlogging Model and Multi-Echelon Model of Dynamic Economic Lot-Size Production System - a Network Approach, Management Science, vol. 15 , no. 9 , pp 506-527.

WAGNER, H. M. e WHITIN, T. M. (1958), Dynamic Version of the Economic Lot Size Model, Management Science, vol. 5, no. 3, pp 336-352. 


\section{ERRATA}

- página 86, gráfico 4.21 e 4.22.

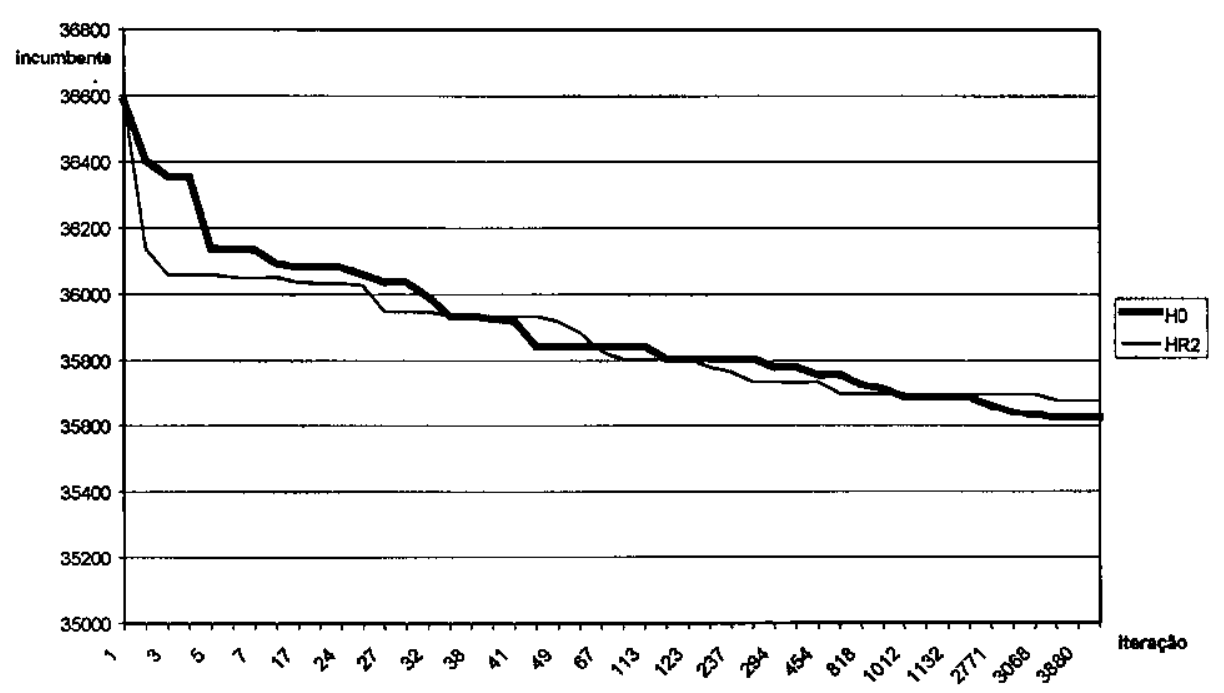

Gráfico 4.21 - Evolução da solução incumbente considerando estrutura geral e custo baixo de preparação.

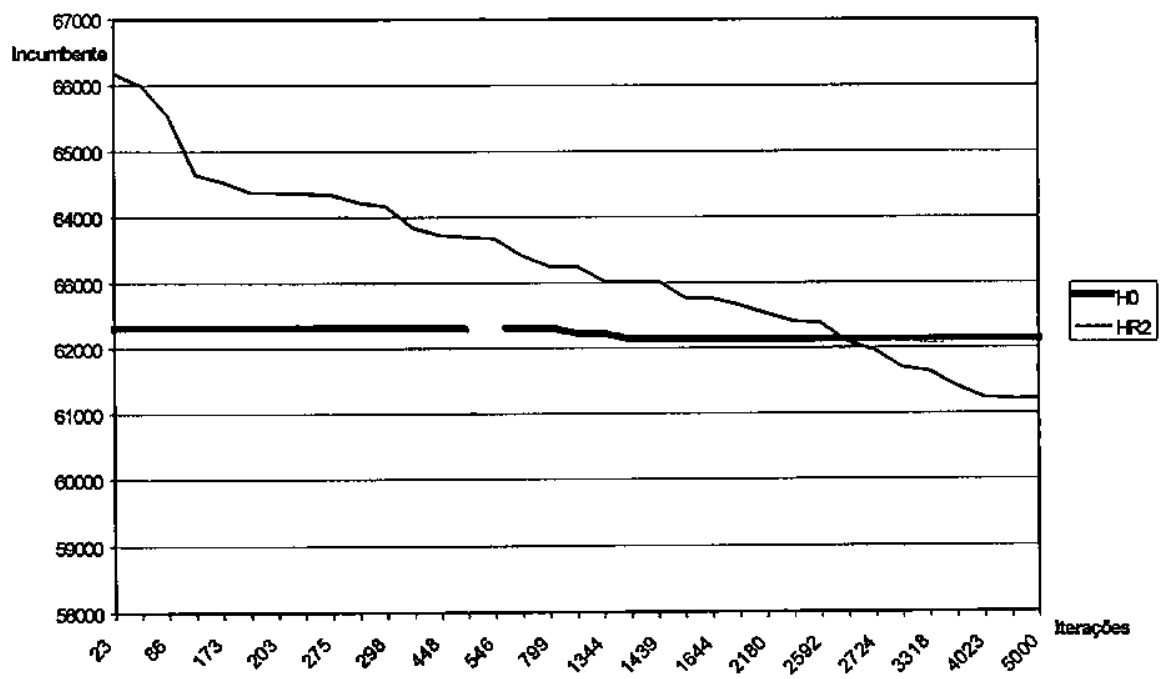

Gráfico 4.22 - Evolução da solução incumbente considerando estrutura geral e custo alto de preparação. 